University of Louisville

ThinkIR: The University of Louisville's Institutional Repository

\title{
Interaction style of mothers of young children with Williams syndrome and relations with child expressive vocabulary.
}

Danielle R. Henderson

University of Louisville

Follow this and additional works at: https://ir.library.louisville.edu/etd

Part of the Developmental Psychology Commons

\section{Recommended Citation}

Henderson, Danielle R., "Interaction style of mothers of young children with Williams syndrome and relations with child expressive vocabulary." (2017). Electronic Theses and Dissertations. Paper 2774. https://doi.org/10.18297/etd/2774

This Doctoral Dissertation is brought to you for free and open access by ThinkIR: The University of Louisville's Institutional Repository. It has been accepted for inclusion in Electronic Theses and Dissertations by an authorized administrator of ThinkIR: The University of Louisville's Institutional Repository. This title appears here courtesy of the author, who has retained all other copyrights. For more information, please contact thinkir@louisville.edu. 


\title{
INTERACTION STYLE OF MOTHERS OF YOUNG CHILDREN WITH WILLIAMS SYNDROME AND RELATIONS WITH CHILD EXPRESSIVE VOCABULARY
}

\author{
By
}

Danielle R. Henderson

B.A., Indiana State University, 2004

B.S., University of Louisville, 2007

M.A., University of Louisville, 2012

\begin{abstract}
A Dissertation
Submitted to the Faculty of the

College of Arts and Sciences of the University of Louisville In Partial Fulfillment of the Requirements

For the Degree of
\end{abstract}

Doctor of Philosophy in Clinical Psychology

Department of Psychological and Brain Sciences

University of Louisville

Louisville, KY

August 2017 
Copyright 2017 by Danielle R. Henderson

All rights reserved 



\section{INTERACTION STYLE OF MOTHERS OF YOUNG CHILDREN WITH WILLIAMS SYNDROME AND RELATIONS WITH CHILD EXPRESSIVE VOCABULARY}

By

Danielle R. Henderson

B.A., Indiana State University, 2004

B.S., University of Louisville, 2007

M.A., University of Louisville, 2012

A Dissertation Approved on

May 24, 2017

by the following Dissertation Committee:

Carolyn B. Mervis, Ph.D.

Dissertation Director

Janet Woodruff-Borden, Ph.D.

Cara H. Cashon, Ph.D.

Paul Salmon, Ph.D.

Deborah W. Davis, Ph.D. 


\section{ACKNOWLEDGEMENTS}

I would like to express my gratitude to my family and friends who have supported me during this journey. I would also like to express my gratitude for Dr. Carolyn B. Mervis's NICHD grant (R37 HD29957), which helped make my research possible. 


\begin{abstract}
INTERACTION STYLE OF MOTHERS OF YOUNG CHILDREN WITH WILLIAMS SYNDROME AND RELATIONS WITH CHILD EXPRESSIVE VOCABULARY

Danielle R. Henderson
\end{abstract}

August पा2017

Children of a given age vary widely in their expressive vocabulary abilities. One factor that is related to child expressive vocabulary ability is the style in which the mother interacts with her child. Studies that have considered this relation for either typically-developing (TD) children or children with developmental or intellectual disability (DD/ID) (e.g., autism spectrum disorder, fragile $\mathrm{X}$ syndrome) have shown that children whose mothers have a more sensitive/responsive interaction style have significantly larger expressive vocabularies than do children whose parents have a less sensitive/responsive style (e.g., Baker et al., 2010; Belsky et al., 2007; Brady et al., 2014; NICHD Early Child Care Research Network, 2003). In this dissertation, I provide the first examination of relations between child expressive vocabulary, child chronological age (CA), child nonverbal reasoning IQ, estimated annual family income, and maternal interaction style for young children with Williams syndrome (WS). The hypothesis of the study was that child expressive vocabulary ability relative to TD peers would be predicted by maternal interaction style beyond the effect of child nonverbal reasoning ability relative to TD peers. 
Participants were 75 children (35 girls, 40 boys) with classic WS deletions aged $4.01-8.39$ years. Median estimated family income was \$120,000 (IQR: \$70,000 \$200,000). Children completed the Differential Ability Scales-II (DAS-II; mean Nonverbal Reasoning Cluster standard score (SS): 79.4, SD: 14.8) and the Expressive Vocabulary Test-2 (EVT-2; mean SS: 81.6, SD: 16.5). In addition, each mother-child dyad participated in a 30-minute play session with developmentally appropriate toys. Play sessions were videotaped.

The mothers' behavior during the play sessions was coded from the videorecordings using three scales from the NICHD Early Child Care Research Network: Supportive Presence, Respect for Child Autonomy, and Hostility (reversed). A 7-point Likert scale was used for each scale, with higher scores indicating more responsive maternal interaction. As in previous studies (e.g., Belsky et al., 2007; Downer \& Pianta, 2006; NICHD Early Child Care Research Network, 2003), a composite of these ratings was used to evaluate maternal interaction style. The median maternal interaction style composite score was 16.0 (range: $10.5-21.0$ ).

To examine relations between child expressive vocabulary, child CA, child nonverbal reasoning SS, estimated annual family income, and maternal interaction style composite bivariate nonparametric correlations were computed. The maternal interaction style composite was moderately positively correlated with EVT-2 SS $\left(r_{s}=.42, p<.001\right)$ and DAS-II Nonverbal Reasoning Cluster SS $\left(r_{s}=.42, p<.001\right)$. EVT-2 SS was strongly positively correlated with DAS-II Nonverbal Reasoning Cluster SS $\left(r_{s}=.62, p<.001\right)$. Estimated annual family income and child CA were not significantly correlated with any of the study variables ( $M d n$ p-values $=.849$ and .382 , respectively). 
To test the study hypothesis, sequential-model multiple regression analysis was performed. Model 1 was comprised of child CA, estimated annual family income, and DAS-II Nonverbal Reasoning Cluster SS. Maternal interaction style composite was added in Model 2. Model 2 provided a significantly better fit to the data than did Model 1, accounting for $43.4 \%$ of the variance in EVT-2 SS. Child CA and estimated family income were not significant predictors of child EVT-2 SS ( $p s>.5)$. Maternal interaction style composite and DAS-II Nonverbal Reasoning Cluster SS were significant predictors of child EVT-2 SS ( $p=.02$ and $p<.001$, respectively).

These results support the hypothesis that maternal interaction style significantly predicts child expressive vocabulary SS in children with Williams syndrome aged 4-8 years even after taking into account the effects of nonverbal reasoning SS, estimated annual family income, and child CA. Implications for clinical interventions to facilitate more positive parent-child interactions are discussed. 


\section{TABLE OF CONTENTS}

Page

ACKNOWLEDGEMENTS

iii

ABSTRACT

iv

LIST OF TABLES

LIST OF FIGURES

CHAPTER

I. INTRODUCTION

Williams Syndrome Behavioral Phenotype

Expressive Language in Williams Syndrome

3

Intellectual Abilities in Williams Syndrome 16

Parental Sensitivity

Parental Sensitivity - Parents of Typically Developing Children

Parental Sensitivity - Parents of Children with Intellectual

52

Disability

Relations between Sensitivity and Family Income and/or

53

Maternal Education

Dissertation Project 
II. METHODS AND RESULTS 57

$\begin{array}{ll}\text { Participants } & 57\end{array}$

$\begin{array}{lr}\text { Measures } & 58\end{array}$

$\begin{array}{ll}\text { Procedure } & 60\end{array}$

$\begin{array}{ll}\text { Results: Descriptive Statistics } & 61\end{array}$

$\begin{array}{ll}\text { Results: Correlations } & 62\end{array}$

$\begin{array}{ll}\text { Results: Regressions } & 65\end{array}$

$\begin{array}{ll}\text { Additional Analyses } & 67\end{array}$

III. GENERAL DISCUSSION 80

Relations between Maternal Interaction Style and Child Expressive $\quad 80$ Vocabulary

$\begin{array}{ll}\text { Relations with Nonverbal Reasoning Ability } & 83\end{array}$

Relations between Maternal Interaction Style Subscales and 84 Expressive Vocabulary

Relations with Estimated Family Income and Age $\quad 86$

$\begin{array}{ll}\text { Clinical Implications } & 87\end{array}$

$\begin{array}{ll}\text { Future Directions } & 91\end{array}$

$\begin{array}{ll}\text { Conclusion } & 92\end{array}$

$\begin{array}{ll}\text { REFERENCES } & 93\end{array}$

$\begin{array}{ll}\text { CURRICULUM VITAE } & 113\end{array}$ 


\section{LIST OF TABLES}

TABLE

1. Key Findings Regarding Expressive Vocabulary in Young Children with

Williams Syndrome

2. Studies Using an Examiner-Administered Standardized Assessment to Measure Expressive Vocabulary in Children with Williams Syndrome

3. Key Findings Regarding Intellectual Abilities in Individuals with Williams Syndrome

4. Key Findings Regarding Sensitivity in Parents of TD Children

5. Key Findings Regarding Sensitivity in Parents of Children with ID/DD

6. Descriptive Statistics for Independent and Dependent Variables

7. Parametric Correlations between Independent and Dependent Variables

8. Sequential Multiple Regression Analysis Predicting EVT-2 SS

9. Descriptive Statistics for Supportive Presences, Respect for Child

Autonomy, and Hostility (reversed)

10. Parametric Correlations between Independent and Dependent Variables

11. Descriptive Statistics for Respect-Hostility Composite

12. Parametric Correlations between Independent Variables and the Respect-

Hostility Composite

13. Sequential Multiple Regression Analysis Predicting EVT-2 SS 


\section{LIST OF FIGURES}

$\begin{array}{ll}\text { FIGURE } & \text { PAGE }\end{array}$

1. Scatterplot of Correlations between Estimated Annual Family Income 63 and Maternal Education

2. Scatterplot of Correlations between Maternal Interaction Style Composite $\quad 64$ and DAS-II Nonverbal Reasoning Cluster SS

3. Scatterplot of Correlations between DAS-II Nonverbal Reasoning Cluster SS 64 andSS

4. Scatterplot of Correlations between Maternal Interaction Style Composite $\quad 65$ and EVT-2 SS

5. Scatterplot of Correlations between Respect for Child Autonomy and

DAS-II Nonverbal Reasoning Cluster SS

6. Scatterplot of Correlations between Hostility (reversed) and DAS-II

Nonverbal Reasoning Cluster SS

7. Scatterplot of Correlations between Respect for Child Autonomy and EVT-2 SS

8. Scatterplot of Correlations between Hostility (reversed) and EVT-2 SS

9. Scatterplot of Correlations between Supportive Presence and

Respect for Child Autonomy

10. Scatterplot of Correlations between Supportive Presence and EVT-2 SS 
11. Scatterplot of Correlations between Supportive Presence and

Respect for Child Autonomy

12. Scatterplot of Correlations between Supportive Presence and

Hostility (reversed)

13. Scatterplot of Correlations between Respect for Child Autonomy and

Hostility (reversed)

14. Scatterplot of Correlations between Respect-Hostility Composite and DAS-II Nonverbal Reasoning Cluster SS

15. Scatterplot of Correlations between Respect-Hostility Composite and EVT-2 SS

16. Scatterplot of Correlations between Respect-Hostility Composite and 76 Supportive Presence 


\section{CHAPTER I}

\section{INTRODUCTION}

There is evidence that parental behaviors significantly impact child development (e.g., Steelman, Assel, Swank, Smith, \& Landry, 2002). Typicallydeveloping (TD) children whose mothers exhibit responsive behaviors during the first few years of life achieve language milestones earlier and more proficiently (e.g., Leigh, Nievar, \& Nathans, 2011; Tamis-LeMonda, Bornstein, \& Baumwell, 2001) and score higher on cognitive tests (e.g., Bornstein, 1989; Bornstein \& Tamis-LeMonda, 1997; Landry, Garner, Swank, \& Baldwin, 1996; Landry, Smith, Miller-Loncar, \& Swank, 1997; Landry \& Smith, 2000) than children whose mothers did not exhibit these behaviors. Similar effects have been found in studies of children with intellectual disability (ID) (e.g., Brady, Warren, Fleming, Keller, \& Sterling, 2014; McDuffie \& Yoder, 2010; Yoder \& Warren, 1999); children with ID whose mothers exhibit responsive behaviors achieve better outcomes in expressive vocabulary.

In this dissertation, I examine the relations between maternal sensitivity and child expressive vocabulary ability for children with Williams syndrome (WS) ages 4 to 8 years old. The introduction is divided into three parts. First, I describe the WS behavioral phenotype with a focus on findings for expressive vocabulary and cognitive abilities. I focus on studies that include children in the age range that is used in the dissertation project and/or the Expressive Vocabulary Test - 2 (EVT-2; Williams, 2007), the measure of expressive vocabulary used in 
the dissertation project. Then I review the literature addressing the relation between parental sensitivity and child language development both for TD children and for children with ID. Finally, I briefly introduce my dissertation study.

\section{Williams Syndrome Phenotype}

WS is a neurodevelopmental disorder resulting from a hemideletion of 25 genes on chromosome 7q11.23 (Ewart et al., 1993; Morris, 2006). It is estimated that the prevalence of WS is 1 in 7500 live births (Strømme, Bjørnstad, \& Ramstad, 2002), with boys and girls equally likely to be affected (American Academy of Pediatrics Committee on Genetics, 2001). Approximately 95\% of individuals with WS have the same set of genes deleted ("classic deletion"). WS is characterized by dysmorphic facial features, heart disease [especially supravalvar aortic stenosis], connective tissue abnormalities, and failure to thrive or growth deficiency (Morris, 2006).

Individuals with WS are often described as showing an excessive interest in others and disinhibition with regard to approaching others in social contexts (e.g., Jones et al., 2000). Children with WS are also described as highly sociable (Dilts, Morris, \& Leonard, 1990), gregarious and overly friendly (Gosch \& Pankau, 1997), and charming (Fryns, Borghgraef, Volcke, \& van den Berge, 1991). Despite these seemingly positive attributes, children with WS experience marked difficulty in peer relationships (Davies, Udwin, \& Howlin, 1998; Sullivan, Winner, \& Tager-Flusberg, 2003) and elevated levels of sensitivity 
(Klein-Tasman \& Mervis, 2003). As adults, most individuals with WS are highly anxious and experience social isolation and difficulties with social interactions, including establishing and maintaining relationships (Davies et al., 1998; Dykens

\& Rosner, 1999; Udwin \& Yule, 1991). Deficits in social pragmatic skills could explain the problems individuals with WS experience in social interactions.

\section{Expressive Language in Williams Syndrome}

The first articles on language acquisition in WS were written approximately 30 years ago when Meyerson and Frank (1987) reported that individuals with WS were delayed in language compared to TD peers and had cognitive abilities ranging from moderate to mild intellectual disability. Independently, Bellugi et al. (1988) argued that individuals with WS had excellent language abilities despite having severe intellectual disability. Bellugi et al. (1988) argued that despite these cognitive deficits, individuals with WS demonstrated remarkable lexical semantic abilities, complexity in expressive syntax and morphology, as well as strong metalinguistic abilities. Language abilities are delayed compared to TD peers, but scores on assessments of language are higher than scores on assessments of nonverbal abilities (Bellugi et al., 1988). More recent research of language development in children with WS is more nuanced.

In order to better understand language abilities in individuals with WS, studies of expressive vocabulary in children with WS were reviewed and are listed in Tables 1 and 2. Studies that include very young children are listed in 
Table 1. Studies that use an examiner-administered standardized assessment to measure child expressive vocabulary are listed in Table 2 . In both tables, studies are listed in alphabetical order by author. Sample characteristics, assessment measures, and key findings are described. In Table 1, mode of assessment includes caregiver-report questionnaire. The majority of studies report that children with WS develop relatively good language abilities, but onset of language is almost always significantly delayed compared to TD peers. Most studies have a small age range. 
Table 1

Key Findings Regarding Expressive Vocabulary in Young Children with Williams Syndrome

\begin{tabular}{|c|c|c|c|c|}
\hline$\underline{\text { Author(s) }}$ & $\underline{n}$ & Age Range & $\underline{\text { Measures }}$ & Major Findings for WS Participants \\
\hline $\begin{array}{l}\text { Laing et al., } \\
(2002)\end{array}$ & $\begin{array}{l}\text { Expt 1: } 13 \\
\text { Expt 2: } 11\end{array}$ & $1-4 y r s$ & CDI & $\begin{array}{l}\text { Expt. 1: Language production raw score: } M: 56, \\
S D: 83.3 \text { (TD - } M: 31.5, S D: 53.2 \text { ), WS grp } \\
\sim 17 \text { mos older than TD grp } \\
\text { Expt. 2: Language production raw score: } M: \\
55.6, S D: 89.5 \text { (TD - } M: 34.5, S D: 57.7 \text { ), WS grp } \\
\sim 16 \text { mos older than TD grp }\end{array}$ \\
\hline $\begin{array}{l}\text { Levy \& Eilam } \\
\text { (2013) }\end{array}$ & 9 & $\begin{array}{l}M: 46.8 \\
\text { mos }\end{array}$ & $\begin{array}{l}\text { DAS, } \\
\text { Vocabulary } \\
\text { size - mean } \\
\text { number of } \\
\text { words } \\
\text { (counted by } \\
\text { authors) }\end{array}$ & $\begin{array}{l}\text { (1) Sig. higher mean GCA }(63.6, S D=6.1) \text { than } \\
\text { DS grp }(52.7, S D=4.9) \\
\text { (2) GCA did not acct for language status } \\
\text { (3) Significant delay in language compared to TD } \\
\text { grp (mean age (in mos) at Stage } 1 \text { for TD grp - } \\
22.8, S D=2.6 \text {; mean age for WS grp at Stage } 1- \\
46.8, S D=8.8 \text { ); DS grp most delayed (mean age } \\
\text { at Stage } 1-54.7, S D=10.5 \text { ) } \\
\text { (4) Sig delay in language growth compared to } \\
\text { TD grp (Mean age at Stage } 5 \text { for TD grp }-40.1 \text {, } \\
S D=3.4 ; 74, S D=13 \text { for WS grp); DS grp most } \\
\text { delayed (mean age at Stage } 5-89.7, S D=8.03 \text { ) }\end{array}$ \\
\hline $\begin{array}{l}\text { Mervis \& } \\
\text { Robinson } \\
(2000)\end{array}$ & 24 & $2 \mathrm{yrs}$ & CDI & $\begin{array}{l}\text { (1) Significantly larger expressive vocabs than } \\
\text { children w/ DS (WS- } M=132.50, S D=122.29 \text {; } \\
\mathrm{DS}-M=66.35, S D=79.24 \text { ) }\end{array}$ \\
\hline
\end{tabular}




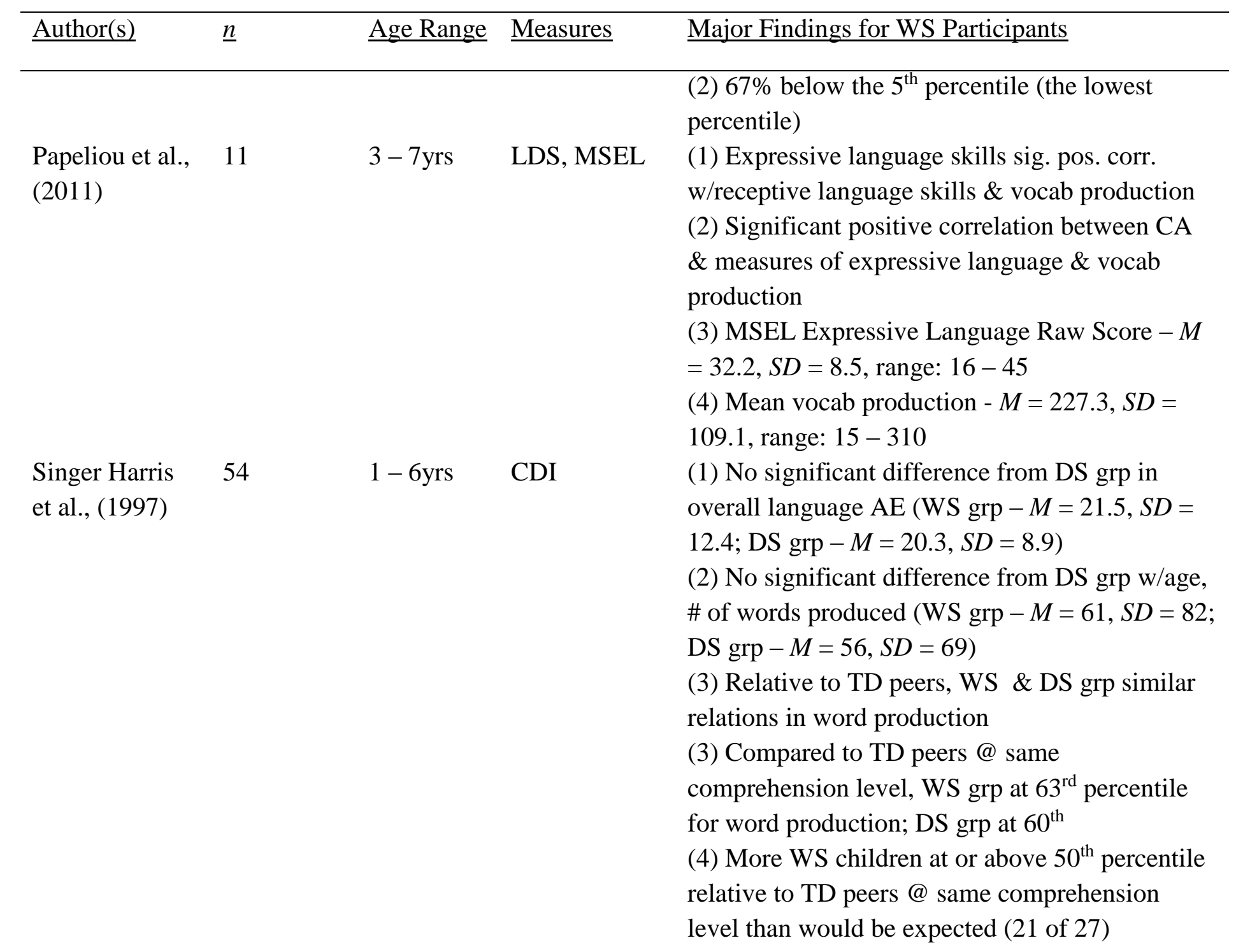




\begin{tabular}{|c|c|c|c|c|}
\hline Author(s) & $\underline{n}$ & Age Range & $\underline{\text { Measures }}$ & Major Findings for WS Participants \\
\hline $\begin{array}{l}\text { Thal et al., } \\
\text { (1989) }\end{array}$ & 2 & $\begin{array}{l}\text { Child 1: } \\
\text { 23mos; } \\
\text { Child 2: } 5 \\
\text { yrs, 6mos }\end{array}$ & LDS & $\begin{array}{l}\text { (1) \# of words }- \text { Child } 1: 34 \text {, Child } 2: 142 ; \text { young } \\
\text { TD grp: } M=30.0, S D=38.5 \text {; late talkers grp: } M \\
=39.7, S D=71.4 \text {; older TD grp: } M=277.1, S D= \\
195.0\end{array}$ \\
\hline $\begin{array}{l}\text { Vicari et al., } \\
(2002)\end{array}$ & 12 & $\begin{array}{l}M= \\
58.2 \mathrm{mos} \\
S D=22.4\end{array}$ & $\begin{array}{l}\text { Italian } \\
\text { version of } \\
\text { CDI }\end{array}$ & $\begin{array}{l}\text { (1) Language delayed compared to TD grp, but } \\
\text { no significant difference in words produced } \\
\text { between the } 3 \text { grps (WS grp - } M=452, S D= \\
157.3 \text {; DS grp - } M=457, S D=125.4 \text {; TD grp - } \\
M=488, S D=116.4 \text { ) }\end{array}$ \\
\hline $\begin{array}{l}\text { Volterra et al., } \\
(2003)\end{array}$ & 6 & 3-6yrs & $\begin{array}{l}\text { Italian } \\
\text { version of } \\
\text { CDI }\end{array}$ & $\begin{array}{l}\text { (1) Language delayed compared to TD grp, but } \\
\text { vocab size not significantly different (WS grp - } \\
M=430, S D=137.7 \text {; DS grp }-M=428, S D= \\
80.8 ; \text { TD grp }-M=484, S D=104.1)\end{array}$ \\
\hline
\end{tabular}

Abbreviations: $\mathrm{AE}=$ age equivalent, $\mathrm{CA}=$ chronological age, $\mathrm{CDI}=$ MacArthur-Bates Communicative Development Inventory (Fenson, et al., 1993, 2007), LDS = Language Development Survey (Bates et al., 1995), M = mean, MLU = mean length utterance, MSEL: Mullen Scales of Early Learning (Mullen, 1995), SD = standard deviation, TD = typically-developing, WS = Williams syndrome 
The MacArthur-Bates Communicative Development Inventory (CDI; Fenson et al., 1993, 2007) is a parental report measure of language acquisition that has been widely used to measure the expressive vocabulary development of children with WS and to compare their development to TD peers. Seven studies used a version of the CDI to examine expressive vocabulary development in children with WS (Levy, 2004; Laing et al., 2002; Mervis \& Becerra, 2007; Mervis \& Robinson, 2000; Singer et al., 1997; Vicari et al., 2002; Volterra et al., 2003). All studies found that expressive vocabulary development in children with WS is delayed compared to TD peers.

In a longitudinal study of 13 children with WS assessed monthly from the time of their first words (Mervis et al., 2003), the age of acquisition of a 10-word expressive vocabulary was below the $5^{\text {th }}$ percentile (the lowest percentile provided) for the CDI norms for all 13 children. Twelve children had scores below the $5^{\text {th }}$ percentile for age of acquisition of 50 -word and 100-word expressive vocabularies. Participants in the study by Laing et al. (2002) had larger expressive vocabularies than the TD children; however, the WS group was approximately 17 months older than the TD group.

The expressive vocabulary of children with WS has frequently been compared to the expressive vocabulary of children with Down syndrome (DS). Five studies (Mervis \& Becerra, 2007; Mervis \& Robinson, 2000; Singer et al., 1997; Vicari et al., 2002; Volterra et al., 2003) made this comparison; the trend in 
all studies was the expressive vocabulary of children with WS was larger than the expressive vocabulary of children with DS. In a study of 24 children with WS aged 2 years, the children with WS had a mean expressive vocabulary of 132 words, compared to a mean expressive vocabulary of 66 for the CA-matched children with DS (Mervis \& Robinson, 2000; Mervis \& Becerra, 2007). Studies by Singer et al. (1997), Vicari et al. (2002), and Volterra et al. (2003) found that though the children with WS produced more words than children with DS, the difference was not significant.

There is evidence that vocabulary size is strongly related to grammatical development (Vicari et al., 2002). In the longitudinal study by Mervis et al. (2003), parents completed the CDI Early Sentence Checklist, a checklist that consists of 37 pairs of phrases or sentences, monthly, once their child began to combine words. Findings indicate that the onset of grammatical development for most children with WS is delayed; however, when compared to the general population, the relation between productive vocabulary size and grammatical ability was the same for children with WS. Mervis et al. (2003) also found that vocabulary development was related to nonverbal reasoning abilities. Children whose vocabulary development followed a logistic growth pattern performed significantly higher on a measure of nonverbal reasoning than children whose vocabulary development followed a linear growth pattern. These results suggest 
that vocabulary development is closely linked to grammatical and nonverbal reasoning skills.

Studies of expressive vocabulary development that use the CDI illustrate that the expressive vocabulary development of children with WS is significantly delayed compared to TD peers. The CDI is helpful in understanding how expressive vocabulary develops in children with WS, and it allows for comparison to the language development of TD peers and peers with DS. The CDI has been shown to be an excellent measure of expressive vocabulary (see validity studies reported by Fenson et al., 2007); however, it is important to note that it is a caregiver report. The validity of the information relies on how well the caregiver can remember each word the child acquires and/or keeps an accurate account. Examiner-administered standardized assessments of expressive vocabulary can provide additional insight into the development of vocabulary in children with WS. 
Table 2

Studies Using an Examiner-Administered Standardized Assessment to Measure Expressive Vocabulary in Children with Williams Syndrome 


\begin{tabular}{|c|c|c|c|c|}
\hline Author(s) & $\underline{n}$ & Age Range & Measures & Major Findings for WS Participants \\
\hline $\begin{array}{l}\text { Arnold, Yule, \& } \\
\text { Martin (1985) }\end{array}$ & 23 & $7-12 \mathrm{yrs}$ & $\begin{array}{l}\text { RDLS - } \\
\text { Revised }\end{array}$ & $\begin{array}{l}\text { (1) Scores for } 3 \text { children exceeded ceiling of the } \\
\text { test }(7 \mathrm{yrs}) \\
\text { (2) Scores for the other children ranged from } 3 \text { - } \\
7 \text { yrs } \\
\text { (3) Mean score on expressive language = } 5 \text { yrs, } 9 \\
\text { mos }\end{array}$ \\
\hline $\begin{array}{l}\text { Levy \& Eilam } \\
\text { (2013) }\end{array}$ & 9 & $\begin{array}{l}M: \\
46.8 \operatorname{mos}\end{array}$ & $\begin{array}{l}\text { DAS - II, } \\
\text { Vocabulary } \\
\text { size - mean } \\
\text { number of } \\
\text { words } \\
\text { (counted by } \\
\text { authors) }\end{array}$ & $\begin{array}{l}\text { (1) Significantly higher mean GCA (63.6, } S D= \\
\text { 6.1) than DS grp (52.7, } S D=4.9 \text { ) } \\
\text { (2) GCA did not acct for language status } \\
\text { (3) Mean vocab. size for each MLU Stage: } 1- \\
61.8(11.4) \text {; Stage } 2-71.4(18.4) \text {; Stage } 3-81.8 \\
\text { (25.1); Stage } 4-105.1(10.2) \text {; Stage } 5-150.2 \\
\text { (36.6) } \\
\text { (4) Significantly higher mean \# of words than DS } \\
\text { grp in Stages } 2 \& 3 \\
\text { (5) Significant delay in language compared to } \\
\text { TD grp (mean age (in mos) at Stage } 1 \text { for TD grp } \\
\text { - 22.8, } S D=2.6 \text {; mean age for WS grp at Stage } 1 \\
\text { - 46.8, } S D=8.8 \text { ); DS grp most delayed (mean } \\
\text { age at Stage } 1-54.7, S D=10.5 \text { ) } \\
\text { (6) Significant delay in language growth } \\
\text { compared to TD grp (Mean age at Stage } 5 \text { for TD } \\
\text { grp - } 40.1, S D=3.4 ; 74, S D=13 \text { for WS grp); } \\
\text { DS grp most delayed (mean age at Stage } 5- \\
\text { 89.7, } S D=8.03 \text { ) }\end{array}$ \\
\hline
\end{tabular}




\begin{tabular}{|c|c|c|c|c|}
\hline Author(s) & $\underline{n}$ & Age Range & Measures & Major Findings for WS Participants \\
\hline $\begin{array}{l}\text { Mervis, Robinson, } \\
\text { Rowe, Becerra, \& } \\
\text { Klein-Tasman } \\
\text { (2003) }\end{array}$ & $\begin{array}{l}\text { Mullen: } 34 \\
\text { EVT: } 119\end{array}$ & & MSEL, EVT & $\begin{array}{l}\text { (1) Mullen Expressive Language T: } M: 33.21 \\
\text { (9.59), 20-48 } \\
\text { (2) EVT SS: } 64.14 \text { (19.18), 40-106 }\end{array}$ \\
\hline $\begin{array}{l}\text { Mervis \& John } \\
\text { (2010, 2012), } \\
\text { review }\end{array}$ & $\begin{array}{l}144- \\
\text { MSEL } \\
129- \\
\text { EVT-2 }\end{array}$ & $\begin{array}{l}\text { MSEL: } 2- \\
\text { 4yrs; } \\
\text { EVT-2: } 4 \\
-17 y r s\end{array}$ & $\begin{array}{l}\text { EVT-2, } \\
\text { MSEL }\end{array}$ & $\begin{array}{l}\text { (1) Expressive vocab is relative strength }-83 \% \\
\text { earned EVT-2 SS } \geq 70 ; 6 \% \mathrm{SS} \geq 100 \\
\text { (2) MSEL Expressive Language T }-M: 32.60 \text {; } \\
S D: 11.31 \text {, range: } 20-56 \\
\text { (3) EVT-2 SS - M: } 79.43 ; S D: 14.83 \text {, range: } 20- \\
120\end{array}$ \\
\hline $\begin{array}{l}\text { Mervis \& Pitts } \\
\text { (2015) }\end{array}$ & 76 & $4-15 \mathrm{yrs}$ & EVT-2 & $\begin{array}{l}\text { (1) Overall EVT-2 SS mean: } 83.83 \\
\text { (2) EVT-2 SS: about two-thirds had SSs decrease } \\
\text { from T1 to T2 (but decrease was not sig. for the } \\
\text { group as a whole); for participants who did } \\
\text { experience sig. change, } ~ 50 \% \text { had increase, } \\
550 \% \text { had decrease } \\
\text { (3) No sig relation between CA at T1 \& change } \\
\text { in SS from T1 to T2 for EVT-2 SS } \\
\text { (4) No sig difference between younger and older } \\
\text { cohorts in magnitude of change for EVT-2 SS }\end{array}$ \\
\hline
\end{tabular}




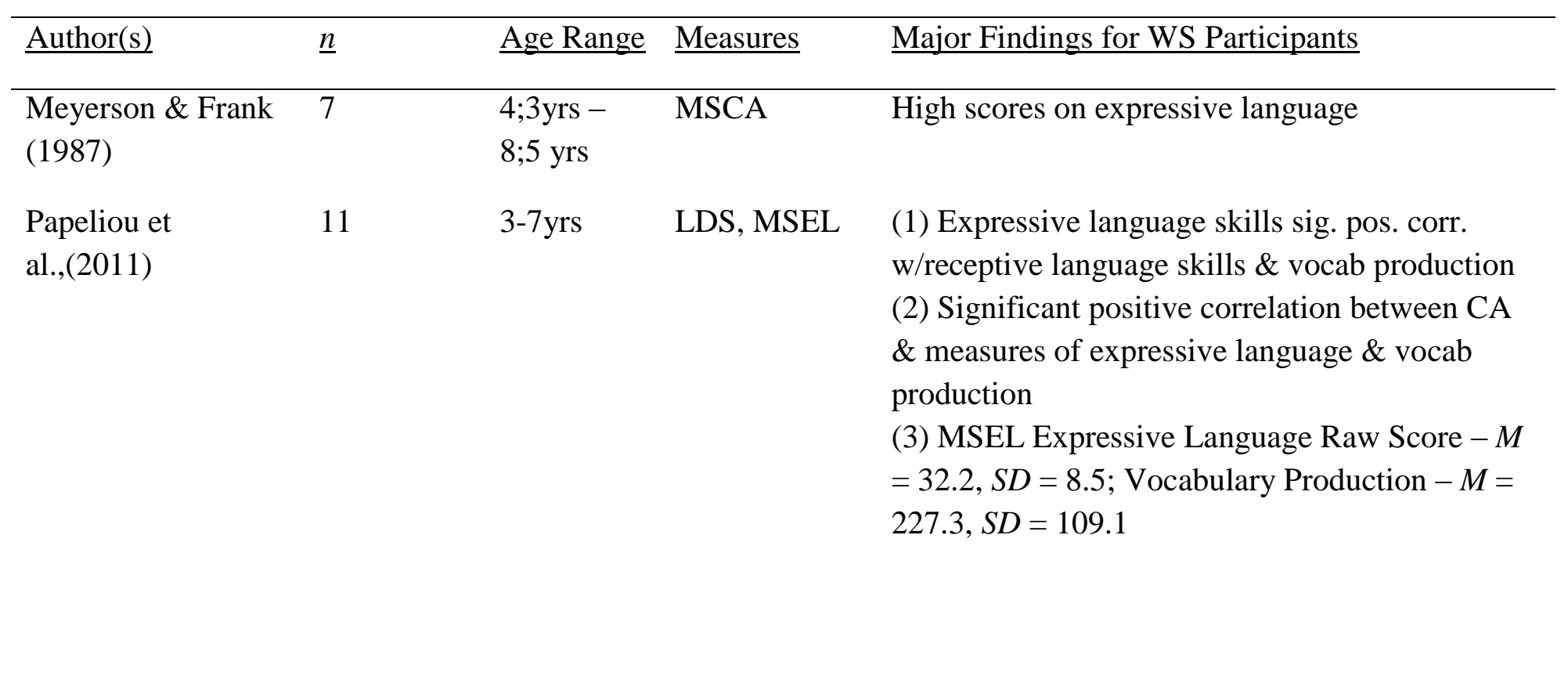


Abbreviations: CA = chronological age, DAS - II = Differential Ability Scales, Second edition (Elliot, 2007), DQ = developmental quotient, DS = Down syndrome, EVT - 2 = Expressive Vocabulary Test (Williams, 2007), GCA = General Conceptual Ability, LDS = Language Development Survey (Bates et al., 1995), M = mean, MSCA = McCarthy Scales of Children's Abilities (McCarthy, 1972), MSEL = Mullen Scales of Early Learning (Mullen, 1995), Mdn = median, MLU = mean length utterance, RDLS = Reynell Developmental Language Scales (Reynell, 1977), $\mathrm{SD}=$ standard deviation, $\mathrm{SS}=$ standard score, $\mathrm{TD}=$ typically-developing, $\mathrm{WS}=\mathrm{Williams}$ syndrome 
Godbee and Porter (2013) assessed expressive vocabulary using the Woodcock-Johnson (Revised) Tests of Cognitive Ability (WJ-R Cog; Woodcock \& Johnson, 1989, 1990). The mean age-equivalent for expressive vocabulary was 6;10 and ranged from 3;3 to 10;4, which was significantly lower than CAmatched controls. There was no significant difference in expressive vocabulary AE between individuals with WS and MA-matched controls.

Four studies used the Mullen Scales of Early Learning (MSEL; Mullen, 1995) to measure expressive vocabulary in young children with WS (Mervis et al., 2003; Mervis \& John, 2010, 2012; Papeliou et al., 2011). Standard scores ranged from severe intellectual disability to average ability. Mean SSs fell within the borderline range. The MSEL scales are normed only 3 standard deviations below the mean. Though it is not the best measure of expressive language abilities in young children with WS, it is one of the few standardized measures available for toddlers.

A version of the Expressive Vocabulary Test (EVT; Williams, 1997, 2004) was used in four studies (Mervis et al., 2003; Mervis \& John, 2010, 2012; Mervis \& Pitts, 2015). Standard scores ranged from severe intellectual disability to average ability. In a study of 76 individuals with WS, Mervis and Pitts (2015) reported a mean EVT-2 SS that fell within the low average range. The mean EVT SS in the Mervis et al. (2003) study was lower and fell within the mild intellectual disability range. Mervis and John (2010) reported $83 \%$ of individuals with WS 
earned standard scores of at least 70 on the EVT-2, and six percent $(6 \%)$ earned standard scores of at least 100. The EVT-2 has been normed to 5.33 standard deviations below the general population mean and is able to capture the full range of expressive vocabulary abilities in children with WS.

One study examined the change in expressive vocabulary SSs over time (Mervis \& Pitts, 2015). Over the course of three years, the standard score of approximately two-thirds of the participants decreased, but most of the decreases were not significant. For those whose scores did change significantly, approximately $50 \%$ had scores that increased and approximately $50 \%$ had scores that decreased. There was no significant relation between CA and change in standard score across the study.

Though expressive vocabulary is a relative strength in children with WS, the development of language is delayed compared to TD peers. Studies of language development in children with WS demonstrate that there is a large range in expressive vocabulary abilities with standard scores ranging from severe intellectual disability to low average ability; average standard scores fall within the borderline range. To date, no studies have addressed why there is this range. It is likely that variation in maternal sensitivity would account for some of the variability in language and/or cognitive abilities. Caregiver reports using standardized measures have commonly been used to assess expressive vocabulary abilities in young children with WS; however, an examiner-administered 
standardized measure is more appropriate for older children with WS.

Additionally, the standardized measure should be normed at least 4 standard deviations below the mean to fully measure the expressive vocabulary abilities.

\section{Intellectual Abilities in Williams Syndrome}

Researchers have sought to better understand the cognitive profiles of individuals with WS. As a whole, individuals with WS have relative strengths in (concrete) language, nonverbal reasoning, and verbal short-term memory. Visuospatial construction is a severe weakness (Mervis \& John, 2010). The intellectual abilities of most individuals with WS fall within the borderline to moderate intellectual disability range (Mervis \& John, 2010). There is considerable variability in verbal and nonverbal reasoning. Studies have found that nonverbal reasoning abilities range from severe intellectual disability to average ability.

A variety of standardized assessments has been used to measure intellectual abilities in individuals with WS. The publications that have examined intellectual abilities in samples of individuals with WS are listed in Table 1.

Sample characteristics, assessment measures, and key findings are described. The table is organized by type of measure used and study authors are listed

alphabetically. Studies that used a single measure of intellectual abilities are listed first, followed by studies with multiple measures. Studies that used multiple 
measures are grouped together by measure type. All but one study used a standardized assessment to measure intellectual abilities. 


\section{Table 3}

Key Findings Regarding Intellectual Abilities in Individuals with Williams Syndrome

\begin{tabular}{llll}
\hline$\underline{\text { Author(s) }}$ & $\underline{n}$ & $\underline{\text { Mge Range }}$ & $\underline{\text { Major Findings for WS }}$ \\
& & $\underline{\text { Participants }}$
\end{tabular}

\begin{tabular}{|c|c|c|c|c|}
\hline $\begin{array}{l}\text { Jones \& Smith } \\
\text { (1975) }\end{array}$ & 14 & 3 mos-23yrs & not specified & IQ range: $41-80, M=56$ \\
\hline $\begin{array}{l}\text { Gosch \& Pankau } \\
\text { (1996) }\end{array}$ & 18 & $\begin{array}{l}4-10 \mathrm{yrs} \\
M: 6.6 \mathrm{yrs}\end{array}$ & CMMS & $\begin{array}{l}\text { (1) T1 - Avg. IQ: } 77, S D=10.7 \text {; } \\
\text { T2 - Avg. IQ: } 68, S D=13.1 \\
\text { (2) Over } 2 y r s, 22 \% \text { to } 50 \% \text { of } \\
\text { participants classified as having } \\
\text { IQ in ID range }\end{array}$ \\
\hline $\begin{array}{l}\text { Mervis et al. } \\
(2001)\end{array}$ & 41 & $4-8 y r s$ & DAS & $\begin{array}{l}\text { Mean } \mathrm{GCA}=59.32, S D=11.84 \text {, } \\
\text { range: } 26 \text { to } 78 \text { ) }\end{array}$ \\
\hline $\begin{array}{l}\text { Mervis et al. } \\
(2000)\end{array}$ & 84 & $\begin{array}{l}3-46 y r s, \\
(M=12 y r s ; 9, S D= \\
10 ; 2)\end{array}$ & DAS & $\begin{array}{l}\text { (1) Mean GCA }=59.22(S D= \\
11.05) \\
\text { (2) Weakness in visuospatial- } \\
\text { constructive ability, relative } \\
\text { strength in language abilities and } \\
\text { verbal short-term memory }\end{array}$ \\
\hline $\begin{array}{l}\text { Mervis \& Pitts } \\
(2015)\end{array}$ & 76 & $\begin{array}{l}4-15 \mathrm{yrs} \\
(M=8.25 \mathrm{yrs}, S D= \\
3.47)\end{array}$ & DAS - II & $\begin{array}{l}\text { (1) T1: GCA: } M=66.88, S D= \\
\text { 11.01; Verbal SS: } M=79.97, S D \\
=14.99 \text {; Nonverbal Reasoning SS: }\end{array}$ \\
\hline
\end{tabular}




\begin{tabular}{|c|c|c|c|c|}
\hline Author(s) & $\underline{n}$ & Age Range & Measures & $\begin{array}{l}\text { Major Findings for WS } \\
\underline{\text { Participants }}\end{array}$ \\
\hline & & & & $\begin{array}{l}M=84.38, S D=11.90 ; \text { Spatial } \\
\text { SS: } M=56.26, S D=11.78 \\
\text { (2) T2: GCA: } M=68.03, S D= \\
\text { 12.22; Verbal SS: } M=76.86, S D \\
=15.83 \text {; Nonverbal Reasoning SS: } \\
M=79.93, S D=12.77 \text {; Spatial } \\
\text { SS: } M=58.68, S D=13.20 \\
\text { (3) GCA stable over time. } \\
\text { (4) Nonverbal Reasoning SS sig } \\
\text { higher than Verbal \& Spatial SS; } \\
\text { Verbal SS sig higher than Spatial } \\
\text { SS }\end{array}$ \\
\hline $\begin{array}{l}\text { Hoffmann et al., } \\
\text { (2013) }\end{array}$ & 20 & $\begin{array}{l}6-16 \mathrm{yrs} \\
(M=11.7 \mathrm{yrs}, S D= \\
3.7)\end{array}$ & KBIT -2 & $\begin{array}{l}\text { (1) IQ Composite: } M=74, S D= \\
16 \\
\text { (2) Verbal IQ: } M=74, S D=12 \\
\text { (3) Nonverbal IQ: } M=80, S D= \\
18\end{array}$ \\
\hline $\begin{array}{l}\text { Klein-Tasman et } \\
\text { al., (2011) }\end{array}$ & 84 & $\begin{array}{l}4-16 \mathrm{yrs}(M= \\
9.44 \mathrm{yrs}, S D=3.89)\end{array}$ & KBIT -2 & $\begin{array}{l}\text { IQ Composite: } M=70.63, S D= \\
13.86\end{array}$ \\
\hline $\begin{array}{l}\text { Lense \& Dykens } \\
\text { (2013) }\end{array}$ & 46 & $\begin{array}{l}7-49 y r s \\
(M=23.13 y r s, S D= \\
9.55)\end{array}$ & KBIT -2 & $\begin{array}{l}\text { (1) IQ Composite: } M=69.84, S D \\
=14.31\end{array}$ \\
\hline
\end{tabular}




\begin{tabular}{|c|c|c|c|c|}
\hline Author(s) & $\underline{n}$ & Age Range & $\underline{\text { Measures }}$ & $\begin{array}{l}\text { Major Findings for WS } \\
\underline{\text { Participants }}\end{array}$ \\
\hline & & & & $\begin{array}{l}\text { (2) Verbal IQ: } M=74.81, S D= \\
11.68 \\
\text { (3) Nonverbal IQ: } M=71.93, S D \\
=17.07\end{array}$ \\
\hline $\begin{array}{l}\text { Leyfer et al., } \\
(2012)\end{array}$ & 192 & $\begin{array}{l}5-10 \mathrm{yrs} \\
(M=7.28 \mathrm{yrs}, S D= \\
1.75)\end{array}$ & KBIT & $\begin{array}{l}\text { IQ Composite: } M=75.59, S D= \\
15.32\end{array}$ \\
\hline $\begin{array}{l}\text { Martens et al., } \\
(2012)\end{array}$ & 30 & $\begin{array}{l}8-41 \mathrm{yrs} \\
(M=20.8 \mathrm{yrs}, S D= \\
10.1)\end{array}$ & KBIT-2 & $\begin{array}{l}\text { IQ Composite: } M=73.9, S D= \\
14.2\end{array}$ \\
\hline $\begin{array}{l}\text { Martens et al., } \\
(2011)\end{array}$ & 37 & $\begin{array}{l}6-59 \mathrm{yrs}(M= \\
20.42 \mathrm{yrs})\end{array}$ & KBIT-2 & $\begin{array}{l}\text { (1) IQ Composite: } M=68.62, S D \\
=13.01\end{array}$ \\
\hline & & & & $\begin{array}{l}\text { (2) Verbal IQ: } M=76.11, S D= \\
11.85 \\
\text { (3) Nonverbal IQ: } M=67.97, S D \\
=14.97\end{array}$ \\
\hline $\begin{array}{l}\text { Mervis et al., } \\
(2012)\end{array}$ & 40 & $\begin{array}{l}4-13 \mathrm{yrs} \\
(M=7.44 \mathrm{yrs})\end{array}$ & KBIT-2 & $\begin{array}{l}\text { (1) Verbal SS: Variability; } \\
\text { children w/higher SSs showed } \\
\text { greater pos. change while children } \\
\text { with lower SSs showed greater } \\
\text { decline; children of moms with 4- } \\
\text { year degrees had Verbal SS higher } \\
\text { than those whose moms didn't } \\
\text { have 4-year degree }\end{array}$ \\
\hline
\end{tabular}




\begin{tabular}{|c|c|c|c|c|}
\hline Author(s) & $\underline{n}$ & Age Range & Measures & $\begin{array}{l}\text { Major Findings for WS } \\
\underline{\text { Participants }}\end{array}$ \\
\hline & & & & $\begin{array}{l}\text { (2) Nonverbal SS: sig. lower than } \\
\text { gen. pop. }\end{array}$ \\
\hline $\begin{array}{l}\text { Opfer \& } \\
\text { Martens (2012) }\end{array}$ & 15 & $\begin{array}{l}6-17 \mathrm{yrs} \\
(M=11.8 \mathrm{yrs})\end{array}$ & KBIT-2 & $\begin{array}{l}\text { (1) IQ Composite: } M=67.28 \\
\text { (2) Verbal IQ: } M=75.31 \\
\text { (3) Nonverbal IQ: } M=66.25\end{array}$ \\
\hline $\begin{array}{l}\text { Palomares \& } \\
\text { Shannon (2013) }\end{array}$ & 17 & $8-35 y r s$ & KBIT-2 & $\begin{array}{l}\text { (1) IQ Composite: } M=73 \text {, range: } \\
49-90\end{array}$ \\
\hline $\begin{array}{l}\text { Pitts \& Mervis } \\
(2016)\end{array}$ & 292 & $\begin{array}{l}4-17 \mathrm{yrs} \\
(M=9.59 \mathrm{yrs}, M d n= \\
8.72, S D=4.07)\end{array}$ & KBIT-2 & $\begin{array}{l}\text { (1) IQ: } M=73.50, S D=15.44 \text {; } \\
\text { Verbal SS: } M=76.57, S D= \\
\text { 14.81; Nonverbal SS: } M=76.78 \text {, } \\
S D=15.82 \\
\text { (5) Sig higher Verbal SSs for } \\
\text { children whose moms had } \\
\text { bachelor degrees } \\
\text { (6) Nonverbal SS did not differ } \\
\text { based on mom's education }\end{array}$ \\
\hline $\begin{array}{l}\text { Plesa Skwerer et } \\
\text { al. (2013) }\end{array}$ & 21 & $\begin{array}{l}5-12 \mathrm{yrs} \\
(M=8 \mathrm{yrs}, 6 \mathrm{mos}, S D \\
=2 ; 4)\end{array}$ & KBIT-2 & $\begin{array}{l}\text { (1) IQ Composite: } M=75, S D= \\
14.1\end{array}$ \\
\hline $\begin{array}{l}\text { van der Fluit et } \\
\text { al., (2012) }\end{array}$ & 24 & $\begin{array}{l}8-15 \mathrm{yrs} \\
(M=12 \mathrm{yrs}, 5 \mathrm{mos} \\
S D=2 ; 8)\end{array}$ & KBIT-2 & $\begin{array}{l}\text { (1) IQ Composite: } M=65.21, S D \\
=11.99 \\
\text { (2) Verbal IQ: } M=73.08, S D= \\
11.96\end{array}$ \\
\hline
\end{tabular}




\begin{tabular}{|c|c|c|c|c|}
\hline Author(s) & $\underline{n}$ & Age Range & $\underline{\text { Measures }}$ & $\begin{array}{l}\text { Major Findings for WS } \\
\underline{\text { Participants }}\end{array}$ \\
\hline & & & & $\begin{array}{l}\text { (3) Nonverbal IQ: } M=66.29, S D \\
=13.56\end{array}$ \\
\hline $\begin{array}{l}\text { Yoshioka et al., } \\
\text { (2013) }\end{array}$ & 23 & $\begin{array}{l}7-32 \mathrm{yrs} \\
(M=17 \mathrm{yr}, 5 \mathrm{mos})\end{array}$ & KBIT-2 & Mean IQ Composite: 82 \\
\hline $\begin{array}{l}\text { Teixeira et al., } \\
(2010)\end{array}$ & 10 & $5-16 y r s$ & Leiter-Revised & Mean Fluid IQ of 67.8 \\
\hline $\begin{array}{l}\text { Bennett et al., } \\
\text { (1978) }\end{array}$ & 7 & $4-8 y r s$ & MSCA & $\begin{array}{l}\text { (1) Mean GCI: } 53.9 \\
\text { (2) Highest scores on items } \\
\text { w/expressive language component } \\
\text { (verbal, memory, or quantitative) }\end{array}$ \\
\hline $\begin{array}{l}\text { Crisco et al., } \\
(1988)\end{array}$ & 22 & $4-10 y r s$ & Stanford-Binet: L-M & Mean global IQ $=67.6, S D=16.3$ \\
\hline $\begin{array}{l}\text { Vicari et al, } \\
(2004)\end{array}$ & $\begin{array}{l}\text { Expt. 1: } 69 \\
\text { Expt. 2: } 16\end{array}$ & $\begin{array}{l}\text { Expt. 1: 4-29yrs } \\
\text { Expt. 2: } 5-8 y r s\end{array}$ & Stanford-Binet: L-M & $\begin{array}{l}\text { Expt. 1: IQ: } M=52.7, S D=14.2 \\
\text { Expt. 2: IQ: } M=66.7, S D=15.0\end{array}$ \\
\hline $\begin{array}{l}\text { Fisch et al., } \\
(2010)\end{array}$ & 65 & $\begin{array}{l}4-15 \mathrm{yrs} \\
M: 8.85 \mathrm{yrs}\end{array}$ & $\begin{array}{l}\text { Stanford-Binet, Fourth } \\
\text { Edition }\end{array}$ & $\begin{array}{l}\text { (1) Initial IQs: mean IQ = 51.65, } \\
S D=11.55\end{array}$ \\
\hline $\begin{array}{l}\text { Greer et al., } \\
\text { (1997) }\end{array}$ & 15 & $4-18 y r s$ & $\begin{array}{l}\text { Stanford-Binet, Fourth } \\
\text { Edition }\end{array}$ & $\begin{array}{l}\text { (1) Test Composite ranged from } \\
\text { Moderate to Low Avg. }(M= \\
62.33, S D=11.82 \text {, } \\
\text { (2) Verbal Reasoning SS }-M= \\
66.33, S D=12\end{array}$ \\
\hline
\end{tabular}




\begin{tabular}{|c|c|c|c|c|}
\hline Author(s) & $\underline{n}$ & Age Range & $\underline{\text { Measures }}$ & $\begin{array}{l}\text { Major Findings for WS } \\
\text { Participants }\end{array}$ \\
\hline & & & & $\begin{array}{l}\text { (3) Abstract/Visual Reasoning SS } \\
-M=70.13, S D=13.89 \\
\text { (4) Quantitative Reasoning SS: } M \\
=70.15, S D=8.14 \\
\text { (6) No sig. diff between verbal \& } \\
\text { nonverbal skills }\end{array}$ \\
\hline $\begin{array}{l}\text { Arnold et al., } \\
(1985)\end{array}$ & 23 & $7-12 \mathrm{yrs}$ & WISC - R & $\begin{array}{l}\text { (1) } 6 \text { children had scores below } \\
\text { basal ( } 40 \text { ) } \\
\text { (2) Range of IQ for remaining } 16 \\
\text { was } 40-72 ; M d n=42 \\
\text { (3) Verbal IQ }-M d n=49 \text { ( } 4 \\
\text { scored below floor) }\end{array}$ \\
\hline & & & & $\begin{array}{l}\text { (4) Performance IQ }-M d n=47 \\
(10 \text { did not score above floor) } \\
\text { (5) No significant difference } \\
\text { between Verbal IQ \& } \\
\text { Performance IQ }\end{array}$ \\
\hline $\begin{array}{l}\text { Udwin et al., } \\
\text { (1987) }\end{array}$ & 44 & $6-16 y r s$ & WISC - R & $\begin{array}{l}\text { (1) Full Scale IQ fell below basal } \\
\text { level (40) for } 10 \text { participants } \\
\text { (2) Full Scale IQs for remaining } \\
\text { participants; } M=54.5 \text {, } \\
\text { (3) Verbal IQ: } 8 \text { participants } \\
\text { below floor; } M=62.4\end{array}$ \\
\hline
\end{tabular}




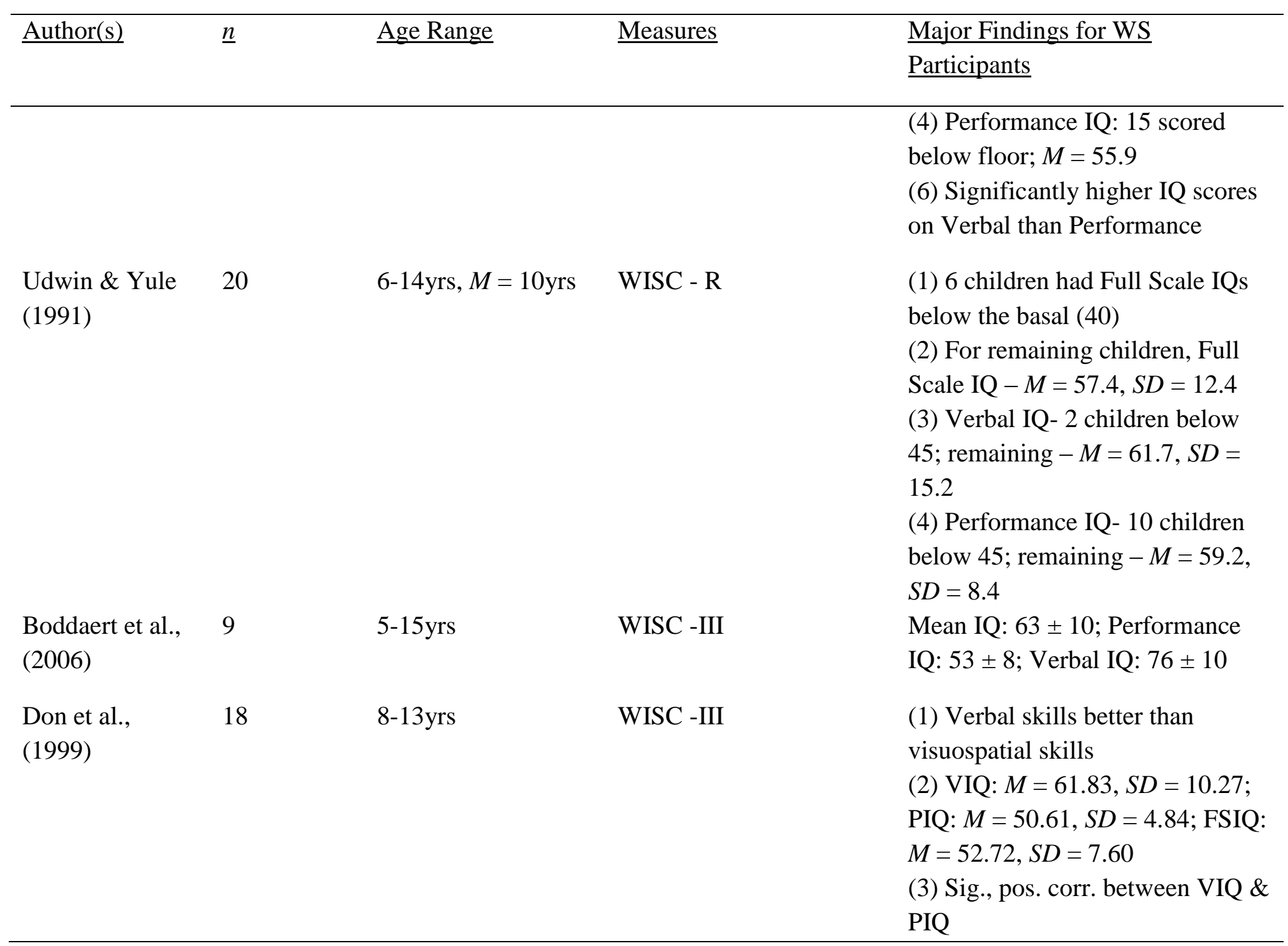




\begin{tabular}{|c|c|c|c|c|}
\hline Author(s) & $\underline{n}$ & Age Range & $\underline{\text { Measures }}$ & $\begin{array}{l}\text { Major Findings for WS } \\
\underline{\text { Participants }}\end{array}$ \\
\hline $\begin{array}{l}\text { Porter \& } \\
\text { Coltheart (2005) }\end{array}$ & 31 & $5-43 y r s$ & $\begin{array}{l}\text { W - J Tests of Cognitive } \\
\text { Ability-Revised }\end{array}$ & $\begin{array}{l}\text { (1) Strengths in verbal abilities } \\
\text { (4) Variability in cognitive } \\
\text { function }\end{array}$ \\
\hline $\begin{array}{l}\text { Porter \& Dodd } \\
\text { (2011) }\end{array}$ & 27 & $\begin{array}{l}\text { T1: } 5-44 y r s ; ~ T 2: \\
10-50 y r s\end{array}$ & $\begin{array}{l}\text { W - J Tests of Cognitive } \\
\text { Ability-Revised }\end{array}$ & $\begin{array}{l}\text { (1) IQ: T1- } M=44, S D=18, \text { T2- } \\
M=47, S D=17 \\
\text { (2) No sig change in IQ from T1 } \\
\text { to T2 }\end{array}$ \\
\hline $\begin{array}{l}\text { Karmiloff-Smith } \\
\text { et al., (1997) }\end{array}$ & 20 & $\begin{array}{l}8-34 \mathrm{yrs}(M= \\
18.7 \mathrm{yrs}, S D=7.8)\end{array}$ & $\begin{array}{l}\text { WAIS -R, } \\
\text { WISC -R }\end{array}$ & $\begin{array}{l}\text { Mean Verbal IQ: 66; Mean } \\
\text { Performance IQ: } 54\end{array}$ \\
\hline $\begin{array}{l}\text { Rae et al., } \\
(1998)\end{array}$ & 11 & $8-37 \mathrm{yrs}$ & $\begin{array}{l}\text { WAIS -R, } \\
\text { WISC -III }\end{array}$ & $\begin{array}{l}\text { (1) VIQ mean: } 71.2 \\
\text { (2) PIQ mean: } 60.3\end{array}$ \\
\hline $\begin{array}{l}\text { Stevens \& } \\
\text { Karmiloff-Smith } \\
\text { (1997) }\end{array}$ & 11 & $8-31$ yrs & $\begin{array}{l}\text { WAIS -R, } \\
\text { WISC -III }\end{array}$ & IQ mean $=58.9$ \\
\hline $\begin{array}{l}\text { Deruelle et al., } \\
\text { (1999) }\end{array}$ & 12 & $7-23 y r s$ & $\begin{array}{l}\text { WISC - III, } \\
\text { WPPSI-R }\end{array}$ & $\begin{array}{l}\text { Verbal IQ }(M=58.3, S D=11.5) \\
\text { sig. higher than Performance IQ } \\
(M=48, S D=7.6)\end{array}$ \\
\hline $\begin{array}{l}\text { Levy \& Bechar } \\
\text { (2003) }\end{array}$ & 9 & $\begin{array}{l}6-17 \mathrm{yrs} \\
(M=12 \mathrm{yrs} 11 \mathrm{mos})\end{array}$ & WISC -R, WPPSI & (1) Mean general IQ was 60.8 \\
\hline
\end{tabular}




\begin{tabular}{|c|c|c|c|c|}
\hline Author(s) & $\underline{n}$ & Age Range & $\underline{\text { Measures }}$ & $\begin{array}{l}\text { Major Findings for WS } \\
\underline{\text { Participants }}\end{array}$ \\
\hline $\begin{array}{l}\text { Carlier et al., } \\
\text { (2006) }\end{array}$ & 34 & $8-26 y r s$ & $\begin{array}{l}\text { WISC-IV, } \\
\text { Stanford-Binet:L-M }\end{array}$ & (1) Mean FSIQ: $52.70 \pm 2.28$ \\
\hline $\begin{array}{l}\text { Kataria et al., } \\
\text { (1984) }\end{array}$ & 7 & $1-5 y r s$ & Bayley, Stanford-Binet & $M=50.6$ \\
\hline $\begin{array}{l}\text { Mervis \& John } \\
\text { (2010), review }\end{array}$ & $\begin{array}{l}\text { 120-DAS- } \\
\text { II; 144- } \\
\text { MSEL }\end{array}$ & $\begin{array}{l}\text { DAS-II: 4-17yrs; } \\
\text { MSEL: 2-4yrs }\end{array}$ & DAS-II; MSEL & $\begin{array}{l}\text { (1) Relative strengths in concrete } \\
\text { language \& concrete nonverbal } \\
\text { reasoning } \\
\text { (2) Severe weakness in } \\
\text { visuospatial construction } \\
\text { (3) DAS-II: GCA - M: } 64.56, S D \text { : } \\
\text { 12.33; Verbal Cluster SS - M: } \\
74.06, S D: 16.41 \text {; Nonverbal } \\
\text { Reasoning Cluster SS - } M \text { : } 78.89 \text {, } \\
S D: 15.44 \text {; Spatial Cluster SS - M: } \\
54.82, S D: 11.27 \text {; Recall of Digits } \\
\text { - Forward - M: } 72.06, S D: 15.71 \text {, } \\
\text { (9) MSEL ELC - M: } 61.45, S D \text { : } \\
\text { 11.31 }\end{array}$ \\
\hline $\begin{array}{l}\text { Mervis \& } \\
\text { Morris (2007), } \\
\text { review }\end{array}$ & $\begin{array}{l}\text { 306-KBIT; } \\
211-\mathrm{DAS} \\
\text { Preschool \& } \\
\text { School Age; } \\
\text { 119-DAS }\end{array}$ & $\begin{array}{l}\text { KBIT: 4-17yrs; } \\
\text { DAS Preschool \& } \\
\text { School Age: 4-17; }\end{array}$ & K-BIT, DAS, MSEL & $\begin{array}{l}\text { (1) KBIT - IQ: } M=69.32, S D= \\
\text { 15.35; Vocab: } M=71.35, S D= \\
\text { 16.15; Matrices: } M=72.47, S D= \\
16.94\end{array}$ \\
\hline
\end{tabular}




\begin{tabular}{|c|c|c|c|}
\hline Author(s) & $\underline{n}$ & $\underline{\text { Measures }}$ & $\begin{array}{l}\text { Major Findings for WS } \\
\text { Participants }\end{array}$ \\
\hline & $\begin{array}{l}\text { School Age; } \\
\text { 79-MSEL }\end{array}$ & $\begin{array}{l}\text { DAS School Age: } 8- \\
\text { 17; MSEL: } 2-4\end{array}$ & $\begin{array}{l}\text { (2) DAS Preschool: GCA: } M= \\
58.57, S D=12.31 \\
\text { (3) DAS School Age: GCA: } M= \\
58.29, S D=12.77 \text {; Verbal Cluster } \\
\text { SS: } M=70.18, S D=14.16 \text {; } \\
\text { Nonverbal Reasoning Cluster SS: } \\
M=67.43, S D=11.44 \text {; Spatial } \\
\text { Cluster SS: } M=55.54, S D=6.86 \\
\text { (4) MSEL - ELC: } M=63.44, S D \\
=11.97\end{array}$ \\
\hline
\end{tabular}

(6) Abbreviations: Bayley = Bayley Scales of Infant Development (Bayley, 1969), CMMS = Columbia Mental Maturity Scale (Bondy et al., 1969), DAS = Differential Ability Scales (Elliot, 1990, 2007), ELC = Early Learning Composite, GCA = General Conceptual Ability, GCI = General Cognitive Index, KBIT = Kaufman Brief Intelligence Test (Kaufman \& Kaufman, 1990, 2004), Leiter = Leiter International Performance Scale (Roid \& Miller, 1997), IQ = intelligence quotient, $M=$ mean, MSCA = McCarthy Scales of Children's Abilities (McCarthy, 1972), Mdn = median, MR = mental retardation, mo = months, MSEL = Mullen Scales of Early Learning (Mullen, 1995), SD = standard deviation, SS = standard score, Stanford-Binet = Stanford-Binet Intelligence Test (Terman \& Merrill, 1973), T1 = time 1, T2 = time 2, WAIS = Wechsler Adult Intelligence Scale (Wechsler, 1981), WISC = Wechsler Intelligence Scale for Children (Wechsler, 1974, 1992, W - J = WoodcockJohnson, WPPSI = Wechsler Preschool and Primary Scale of Intelligence (Wechsler, 1967, 1995) 
Eleven studies used a Wechsler test [e.g., Wechsler Intelligence Scale for Children-Revised (WISC-R), Wechsler Intelligence Scale for Children-III (WISC-III), Wechsler Preschool and Primary Scale of Intelligence-Revised (WPPSI-R), Wechsler Adult Intelligence Scale-Revised (WAIS-R)] to assess intellectual abilities in individuals with WS (Arnold, Yule, \& Martin, 1985; Boddaert et al., 2006; Carlier et al., 2006; Deruelle et al., 1999; Don, Schellenberg, \& Rourke, 1999; Karmiloff-Smith et al., 1997; Levy \& Bechar, 2003; Rae et al., 1998; Stevens \& Karmiloff-Smith, 1997; Udwin \& Yule, 1991; Udwin, Yule, \& Martin, 1987). As measured by these assessments, overall intellectual abilities of participants with WS ranged from severe intellectual disability to low average ability. Udwin, Yule, and Martin (1987) reported that approximately 55\% of participants earned Full Scale IQs below 50, approximately $41 \%$ earned SSs that fell within the moderate learning difficulties range (51-70), and only about $5 \%$ of participants earned SSs above 71.Verbal intellectual abilities also ranged from severe intellectual disability to low average ability. Verbal IQ SSs fell below 50 for approximately $34 \%$ of participants. Approximately $48 \%$ of participants earned SSs that fell within the moderate learning difficulties range, and approximately $16 \%$ earned SSs that fell within the borderline to low average range. Visuospatial and processing speed abilities ranged from severe to borderline intellectual disability. More than half $(\sim 57 \%)$ of participants earned Performance IQs below 50. Over 30\% earned SSS that fell 
within the moderate learning difficulties range. No participants earned scores above 85 (Udwin, Yule, \& Martin, 1987). Three studies reported significant differences between types of intellectual abilities (Don, Schellenberg, \& Rourke, 1999; Deruelle et al., 1999; Udwin, Yule, \& Martin, 1987). In all three studies, verbal abilities were significantly higher than visuospatial and processing speed abilities.

Though Wechsler tests have been commonly used to measure intellectual abilities in individuals with WS, they are only normed to three standard deviations below the mean, which is not low enough to fully capture the cognitive profiles of individuals with WS (Mervis \& John, 2010). Arnold, Yule, and Martin, 1985 used the WISC-R (Wechsler, 1976) in a study of 23 children with WS. IQs could not be computed for one child due to the child not earning an points on at least three Performance subtests; Of the remaining 22 children, the computed IQs for six were not above floor. The WISC-R (Wechsler, 1976) was also used in a study of 44 children with WS. Ten children had Full Scale IQs that fell below floor. Eight participants were below floor on Verbal IQ and 15 on Performance IQ (Udwin, Yule, \& Martin, 1987). Similar findings were also obtained by Udwin and Yule (1991).

The Wechsler tests measure nonverbal reasoning and spatial abilities together; they do not fully capture the WS cognitive profile (Mervis \& John, 2010). Visuospatial abilities are an area of weakness for individuals with WS; an 
intellectual assessment that does not measure this ability separate from others is unable to measure the distinct intellectual characteristics of individuals with WS.

Two studies (Leyfer et al., 2012; Mervis \& Morris, 2007) used the Kaufman Brief Intelligence Test (KBIT), First Edition to measure IQ. In 12 studies (Hoffman et al., 2013; Klein-Tasman, Li-Barber, \& Magargee, 2011; Lense \& Dykens, 2013; Martens et al., 2012; Martens, Jungers, \& Steele, 2011; Mervis et al., 2012; Pitts \& Mervis, 2016; Opfer\& Martens, 2012; Palomares \& Shannon, 2013; Plesa Skwerer, Ammerman, \& Tager-Flusberg, 2013; van der Fluit, Gaffrey, \& Klein-Tasman, 2012; and Yoshioka et al., 2013), IQ was measured using the second edition of the KBIT (KBIT-2). Both the KBIT and KBIT-2 measure verbal and nonverbal abilities and yield an IQ composite. Neither the KBIT nor the KBIT-2 measures visuospatial abilities; their relations to other areas of intellectual abilities cannot be measured. IQ Composite SSs ranged from severe intellectual disability to high average ability. Verbal SSs and Nonverbal SSs ranged from severe intellectual disability to high average. In a study of 292 individuals with WS, Pitts and Mervis (2016) reported mean IQ Composite, mean Verbal, and mean Nonverbal SSs that fell within the borderline range. The K-BIT and KBIT-2 are normed to four standard deviations below the mean.

The Stanford-Binet (Terman \& Merrill, 1973) was used in six studies (Carlier et al., 1973; Crisco, Dobbs, \& Mulhern, 1988; Fisch et al., 2010; Greer et 
al., 1997; Kataria, Goldstein, \& Kushnick, 1984; Vicari et al., 2004). Global IQs ranged from severe intellectual disability to average ability. Greer et al. (1997) reported that $53 \%$ of participants had Global IQs within the mild disability range; $20 \%$ were within the moderate rang,; $20 \%$ within the borderline range, and $7 \%$ were within the low average range. Greer et al. (1997) also reported Verbal Reasoning and Quantitative Reasoning SSs that ranged from severe intellectual disability to low average ability and Abstract/Visual Reasoning SSs from severe intellectual ability to average ability..

Two studies (Porter \& Coltheart, 2005; Porter \& Dodd, 2011) used the Woodcock-Johnson Tests of Cognitive Ability - Revised (Woodcock \& Johnson, 1989, 1990). Overall IQ ranged from severe disability to borderline intellectual ability. Porter and Coltheart (2005) reported relative strengths in auditory processing and verbal abilities. Other measures used to assess intellectual abilities include the Bayley Scales of Infant Development (Bayley, 1969), Columbia Mental Maturity Scale (Bondy et al., 1969), McCarthy Scales of Children's Abilities (McCarthy, 1972), and Mullen Scales of Early Learning (Mullen, 1995). IQs ranged from severe intellectual disability to average ability.

Intellectual abilities were measured using a version of the Differential Ability Scale (DAS; Elliott, 1990, 2007) in six studies (Mervis et al., 2000; Mervis, Klein-Tasman, \& Mastin, 2001; Mervis \& John, 2010; Mervis \& Morris, 2007; Mervis \& Pitts, 2015; and Mervis \& Velleman, 2011). Two studies (Mervis 
et al., 2001; Mervis et al., 2000) used the DAS, and the DAS-II was used in the other studies. General Conceptual Ability (GCA), which is similar to IQ, ranged from severe intellectual disability to low average ability. The top of the range for Verbal SS and Nonverbal Reasoning SS is in the average range ( 100$)$.

The DAS also measures spatial abilities in addition to verbal and nonverbal reasoning abilities. The range of Spatial SSs was severe intellectual ability to low average ability. At the group level, nonverbal reasoning abilities were significantly higher than both verbal and spatial abilities, and verbal abilities were significantly higher than spatial abilities (Mervis \& Pitts, 2015; Mervis et al., 2000).

The DAS-II subtests have been normed to four standard deviations below the mean. This aspect further allows for the distinct cognitive profiles of individuals with WS to be measured making it an ideal assessment to use with the population.

A measure of nonverbal IQ was used in one study (Teixeira et al., 2010). In the study, the Leiter International Performance Scale - Revised (Roid \& Miller, 1997) was used. Teixeira et al. (2010) reported an average IQ that fell within the mild intellectual disability range.

Three studies have examined the change in IQ over time. Gosch and Pankau (1996) found mean IQ decreased by nine points over the two year period of the study; by the end of the study, the number of participants who were 
classified as having intellectual disability increased from $22 \%$ to $50 \%$. Overall IQ, as measured by the WJ-R Cog, did not change significantly over time, although $10 \%$ of adults had a reliable decrease in language ability and $33 \%$ evidenced a reliable increase (Porter \& Dodd, 2011). Mervis and Pitts (2015) found GCA, Verbal SS, Nonverbal Reasoning SS, and Special Nonverbal Composite, as measured by the DAS-II, were stable over a 3-year period.

Two studies examined the relations between maternal education and child intellectual ability. In a longitudinal study of 40 children with WS, Mervis et al. (2012) reported that children whose mothers had a four-year college degree had significantly higher Verbal SSs on the KBIT-2 than children whose mothers did not have a four-year degree. Similar findings were obtained in a larger, crosssectional study by Pitts and Mervis (2016). The median Verbal SS and IQ Composites differed by eight points between children whose mothers had a fouryear college degree and children whose mothers did not have a college degree. However, the authors did not find a significant difference in Nonverbal SSs based on maternal education. These two studies illustrate the important relation between child verbal ability and maternal education. Maternal education strongly influences child verbal ability; however, to date, no studies have examined the underlying mechanisms behind this relation.

Several of the studies include participants with large age ranges, with the age difference between the youngest and oldest participant ranging from 14 to 43 
years (e.g., Carlier et al., 2006; Deruelle et al., 1999; Greer et al., 1997; Jones \& Smith, 1975; Karmiloff-Smith et al., 1997; Lense \& Dykens, 2013; Martens et al., 2012; Martens, Jungers, \& Steele, 2011; Mervis et al., 2000; Palomares \& Shannon, 2012; Porter \& Coltheart, 2005; Porter \& Dodd, 2011; Rae et al., 1998; Stevens \& Karmiloff-Smith, 1997; Vicari et al., 2004; Yoshioka et al., 2013). These studies included both children and adults, making it difficult to ascertain the unique strengths and weaknesses each age group might possess.

Due to this unique profile, it is important that a measure of intellectual abilities be used that will fully capture the range of abilities in individuals with WS. A measure, such as the DAS-II, that has been normed to at least four standard deviations below the mean and measures spatial abilities separately from other intellectual abilities is ideal. None of the studies examined the relations between intellectual abilities and expressive vocabulary abilities. Additional studies are needed to better understand the variability observed in nonverbal reasoning abilities and to examine possible relations with expressive vocabulary. 


\section{Parental Sensitivity}

Parental sensitivity refers to how a parent provides for his or her child and responds to him/her. The current understanding of parental sensitivity is rooted in the work of Baumrind and Ainsworth (Tamis-LeMonda \& Baumwell, 2011). Baumrind $(1967,1991)$ rated parents of preschool and school-aged children for responsiveness and demandingness and used the ratings to classify parents as authoritative, authoritarian, or permissive. The ideal parents were those who were authoritative - high in responsiveness and demandingness - and sensitive to their child's autonomy while providing structure and support (Tamis-LeMonda \& Baumwell, 2011). Ainsworth's work (1978) focused on parental sensitivity in infancy. Mothers who responded promptly and appropriately to their infant's signals were rated as highly sensitive, and their infants were securely attached. These mothers were more accessible, accepting, and cooperative than mothers whose infants were insecurely attached (Tamis-LeMonda \& Baumwell, 2011).

Parental sensitivity can be conceptualized in a variety of ways. Parental sensitivity can include the qualities of warmth, nurturance, stability, and predictability (Warren \& Brady, 2007). Contingent responsiveness, a parent's appropriate and prompt responses to exploratory and communicative initiatives by his/her child, also may be included in parental sensitivity. Including contingent responsiveness emphasizes that the process of parental sensitivity is reciprocal and bidirectional (Tamis-LeMonda \& Baumwell, 2011). 
Vygotsky's zone of proximal development can provide a link between parental sensitivity and child outcome. The zone of proximal development is the distance between a child's "actual developmental level as determined by independent problem solving" (Wertsch, 2008, p. 66) and the "potential development as determined through problem solving under adult guidance..." (Wertsch, 2008, p. 66). The guidance an adult provides in the zone of proximal development can have a significant impact on a child's independent performance in the future (Kermani \& Brenner, 2000). A highly sensitive parent is attuned to the needs of his/her child and can therefore provide the appropriate supports his/her child needs in order to progress developmentally.

There is evidence to suggest that for optimal learning to occur it is important for adults to modify their means of support based upon their child's level of competence. Optimal scaffolding occurs when an adult varies his/her support based on the child's skill level, provides minimal directiveness, and responds appropriately to the child's expression of emotions (Salonen, Lepola, \& Vauras, 2007). In a study of children ranging in age from 55 months to 76 months, Kermani and Brenner (2000) found that when children displayed difficulty completing a task, mothers modified their level of support appropriately, providing hints, directive instruction, and correcting errors. 
The purpose of this section is to briefly review prior studies of parental sensitivity in parents of TD children and in parents of children with ID. The publications that have examined parental sensitivity and its relations to child language and/or cognitive abilities are listed in Tables 4 and 5. Studies were included if participants included children in the age range included in the dissertation study ( $4-8$ years). Studies that include TD children are listed first, in alphabetical order by author, followed by studies that include children with ID/DD. Sample characteristics, assessment measures, and key findings are described. Mode of assessment of cognitive abilities includes standardized assessment; mode of assessment of language includes standardized assessment, caregiver report, and analysis of words spoken. All studies report that the children of mothers who are rated as high in maternal sensitivity perform significantly better on measures of language and cognition than children of mothers who are not rated high in maternal sensitivity. Most studies have a small age range. 
Table 4

Key Findings Regarding Sensitivity in Parents of TD Children

$\begin{array}{llll}\underline{\text { Author (s) }} \quad \underline{\text { Age Range }} \quad \underline{\text { Outcome Measures }} & \underline{\text { Primary Findings of Relevance }} \\ \text { to Dissertation Topic }\end{array}$

\begin{tabular}{|c|c|c|c|c|}
\hline $\begin{array}{l}\text { Belsky et al., } \\
(2007)\end{array}$ & $\begin{array}{l}1364 \\
\text { mothers \& } \\
\text { TD children }\end{array}$ & $\begin{array}{l}6 \mathrm{mos}, 15 \mathrm{mos}, \\
24 \mathrm{mos}, \\
36 \mathrm{mos}, \\
54 \mathrm{mos}, 1^{\text {st }}-6^{\text {th }} \\
\text { grade }\end{array}$ & $\begin{array}{l}\text { Achievement: } 4 \text { subtests } \\
\text { from WJ-R; Parental } \\
\text { quality: Composite of } \\
\text { NICHD ECCRN codes } \\
\text { \& HOME }\end{array}$ & $\begin{array}{l}\text { Parenting strong \& more } \\
\text { consistent predictor of child } \\
\text { development than early child- } \\
\text { care; higher quality care } \\
\text { predicted higher vocab scores }\end{array}$ \\
\hline $\begin{array}{l}\text { Campbell et al., } \\
\text { (2007) }\end{array}$ & $\begin{array}{l}1261 \\
\text { mothers \& } \\
\text { TD children }\end{array}$ & $\begin{array}{l}6 \mathrm{mos}, 15 \mathrm{mos}, \\
24 \mathrm{mos}, \\
36 \mathrm{mos}, \\
54 \mathrm{mos}, 1^{\text {st }} \\
\text { grade }\end{array}$ & $\begin{array}{l}\text { Achievement: } 4 \text { subtests } \\
\text { from WJ-R; Parental } \\
\text { sensitivity: NICHD } \\
\text { ECCRN codes }\end{array}$ & $\begin{array}{l}\text { Sensitivity contributed unique } \\
\text { variance to WJ-R scores }\end{array}$ \\
\hline $\begin{array}{l}\text { Downer \& Pianta } \\
\text { (2006) }\end{array}$ & $\begin{array}{l}832 \mathrm{TD} \\
\text { children }\end{array}$ & $\begin{array}{l}\text { Birth to } \\
54 \mathrm{mos}\end{array}$ & $\begin{array}{l}\text { Parental sensitivity: } \\
\text { NICHD ECCRN codes; } \\
\text { Achievement: WJ-R } \\
\text { Cognitive: Expressive \& } \\
\text { Auditory Comprehension } \\
\text { subtests on PLS }\end{array}$ & $\begin{array}{l}\text { (1) Maternal sensitivity sig } \\
\text { predictor of child phoneme } \\
\text { knowledge at } 54 \text { mos or } \\
\text { kindergarten, but not } 1^{\text {st }} \text { grade } \\
\text { (2) Higher on cognitive tests } \\
\text { when moms more sensitive } \\
\text { (3) Income-to-needs ratio, } \\
\text { maternal education, \& } \\
\text { maternal sensitivity accounted }\end{array}$ \\
\hline
\end{tabular}




\begin{tabular}{llll}
\hline Author (s) & $\underline{n} \quad \underline{\text { Age Range }} \quad \underline{\text { Outcome Measures }} \quad \underline{\text { Primary Findings of Relevance }}$ & $\underline{\text { to Dissertation Topic }}$
\end{tabular}

for sig increments in variance

in $1^{\text {st }}$ grade cognitive function

(even when academic \& social

competence controlled for)

Duncan \&

Brooks-Gunn

(2000), review
(1) Income influences home environment - differences in home learning environments of higher \& lower income accounts for about $1 / 2$ of the effect of income on cognitive development of preschool kids $\& 1 / 4$ to $1 / 3$ effect of income on achievement scores in elementary school

(2) Family economic stress leads to conflict between kids \& parents

(3) Low income negatively affects parent mental health, which negatively affects parent-child interactions 


\begin{tabular}{|c|c|c|c|c|}
\hline Author (s) & $\underline{n}$ & Age Range & Outcome Measures & $\frac{\text { Primary Findings of Relevance }}{\text { to Dissertation Topic }}$ \\
\hline $\begin{array}{l}\text { Hart \& Risley } \\
\text { (1995) }\end{array}$ & $\begin{array}{l}42 \text { from } 3 \\
\text { SES grps } \\
(13- \\
\text { professional, } \\
23- \\
\text { working- } \\
\text { class, } 6- \\
\text { welfare) }\end{array}$ & $\begin{array}{l}\text { Child CA at } \\
1^{\text {st }} \\
\text { observation: } \\
\text { Professional } \\
\text { (higher SES)- } \\
\text { 9mos (7-11); } \\
\text { Working-class } \\
\text { (middle/lower } \\
\text { SES) - 9mos } \\
(7-12) ; \\
\text { Welfare - } \\
8 \text { mos (7-9) }\end{array}$ & Words per hour & $\begin{array}{l}\text { (1) Gap between } 3 \text { grps } \\
\text { beginning as early as } 24 \text { mos - } \\
\text { children from professional } \\
\text { families had sig more vocab } \\
\text { words than children from } \\
\text { working class/ welfare families } \\
\text { (2) Time \& talk associated } \\
\text { w/SES status - professional } \\
\text { families spent more time } \\
\text { w/their children \& said } 3 x \text { as } \\
\text { much as welfare parents did } \\
\text { (3) More affirmatives \& fewer } \\
\text { prohibitions by professional } \\
\text { families than welfare families } \\
\text { (4) Parent feedback tone } \\
\text { (affirmative feedback) higher } \\
\text { in professional families, mixed } \\
\text { in working-class \& little in } \\
\text { welfare families } \\
\text { (5) Guidance style - very little } \\
\text { in welfare families; higher in } \\
\text { working-class \& professional } \\
\text { families, but mixed }\end{array}$ \\
\hline
\end{tabular}




\begin{tabular}{|c|c|c|c|c|}
\hline Author (s) & $\underline{n}$ & Age Range & Outcome Measures & $\frac{\text { Primary Findings of Relevance }}{\text { to Dissertation Topic }}$ \\
\hline $\begin{array}{l}\text { Hirsh-Pasek \& } \\
\text { Burchinal (2006) }\end{array}$ & $\begin{array}{l}1097 \text { TD } \\
\text { children \& } \\
\text { their } \\
\text { mothers }\end{array}$ & Birth $-54 \mathrm{mos}$ & $\begin{array}{l}\text { Language: PLS-3; } \\
\text { Maternal sensitivity: } \\
\text { NICHD ECCRN codes; } \\
\text { Pre-academics: WJ-R } \\
\text { Cog }\end{array}$ & $\begin{array}{l}\text { (8) Responsiveness (parent } \\
\text { response not preceded by } \\
\text { parent initiation) - professional } \\
\text { families more responsive } \\
\text { overall; most working-class } \\
\text { families responsive; mixed in } \\
\text { welfare families; } \\
\text { responsiveness strongly } \\
\text { associated with } \\
\text { accomplishment at age 3yrs } \\
\text { (1) On avg., children } \\
\text { experience moderate } \\
\text { sensitivity \& stimulation from } \\
\text { mothers from birth to } \\
\text { preschool; moms slightly more } \\
\text { sensitive over time (dip at } 15 \text { - } \\
\text { 24 mos) } \\
\text { (2) Children from more } \\
\text { advantaged families had moms } \\
\text { who were more sensitive at } \\
\text { each time point \& overall } \\
\text { (3) Kids scored higher on } \\
\text { language tests when they had }\end{array}$ \\
\hline
\end{tabular}




\begin{tabular}{|c|c|c|c|c|}
\hline Author (s) & $\underline{n}$ & Age Range & Outcome Measures & $\frac{\text { Primary Findings of Relevance }}{\text { to Dissertation Topic }}$ \\
\hline $\begin{array}{l}\text { Mulvaney et al. } \\
\text { (2006) }\end{array}$ & $\begin{array}{l}53 \mathrm{TD} \\
\text { children \& } \\
\text { mothers }\end{array}$ & $\begin{array}{l}1 \mathrm{mo}, 6 \mathrm{mos}, \\
15 \mathrm{mos}, \\
24 \mathrm{mos}, \& 1^{\text {st }} \\
\text { grade }\end{array}$ & $\begin{array}{l}\text { Cognition: Bayley, } \\
\text { School Readiness } \\
\text { Composite of Bracken, } \\
\text { \& Selected subtests WJ- } \\
\text { R; Maternal Sensitivity: } \\
\text { NICHD ECCRN codes }\end{array}$ & $\begin{array}{l}\text { more sensitive caregiving from } \\
\text { moms on avg. over time } \\
\text { (4) Children scored higher on } \\
\text { language outcomes when } \\
\text { moms increased } \\
\text { responsiveness from } 6 \text { \& } \\
54 \text { mos } \\
\text { (1) Average sensitivity sig } \\
\text { predicted scaffolding } \\
\text { (2) Maternal vocabulary sig. } \\
\text { predict child cog abilities at } 1^{\text {st }} \\
\text { grade } \\
\text { (3) Avg. sensitivity sig. } \\
\text { correlated with } 1^{\text {st }} \text { grade cog } \\
\text { scores, Bayley score at } 24 \\
\text { months, and score on school } \\
\text { readiness } \\
\text { (4) Avg. sensitivity also sig. } \\
\text { correlated with maternal } \\
\text { vocabulary, avg. income, and } \\
\text { maternal education }\end{array}$ \\
\hline
\end{tabular}




\begin{tabular}{|c|c|c|c|c|}
\hline Author (s) & $\underline{n}$ & Age Range & Outcome Measures & $\begin{array}{c}\text { Primary Findings of Relevance } \\
\text { to Dissertation Topic }\end{array}$ \\
\hline $\begin{array}{l}\text { NICHD Early } \\
\text { Child Care } \\
\text { Research } \\
\text { Network (2001) }\end{array}$ & 1100 & $\begin{array}{l}\text { Birth }-1^{\text {st }} \\
\text { grade }\end{array}$ & $\begin{array}{l}\text { Cognition: Selected } \\
\text { subtests WJ-R; } \\
\text { Language: PLS \& ALI; } \\
\text { Sensitivity: NICHD } \\
\text { ECCRN codes }\end{array}$ & $\begin{array}{l}\text { (1) Income-to-needs ratio \& } \\
\text { maternal cog stimulation } \\
\text { predicted performance on cog } \\
\text { measures at } 24 \& 36 \mathrm{mos} \& \\
\text { language at } 36 \mathrm{mos}\end{array}$ \\
\hline $\begin{array}{l}\text { NICHD Early } \\
\text { Child Care } \\
\text { Research } \\
\text { Network (2003) }\end{array}$ & $\begin{array}{l}1002 \mathrm{TD} \\
\text { children }\end{array}$ & $\begin{array}{l}6 \mathrm{mos}, 15 \mathrm{mos}, \\
24 \mathrm{mos}, \\
36 \mathrm{mos}, \& \\
54 \mathrm{mos}\end{array}$ & $\begin{array}{l}\text { Mat. cog. stimulation \& } \\
\text { sensitivity: NICHD } \\
\text { ECCRN codes; DQ: } \\
\text { Bayley; School } \\
\text { Readiness: Bracken; } \\
\text { Language: Reynell; } \\
\text { Vocabulary: CDI }\end{array}$ & $\begin{array}{l}\text { (1) @ 54mos: greater maternal } \\
\text { sensitivity \& cog. stimulation } \\
\text { pos. associated with cognition } \\
\& \text { language }\end{array}$ \\
\hline $\begin{array}{l}\text { NICHD Early } \\
\text { Child Care } \\
\text { Research } \\
\text { Network (2006) }\end{array}$ & $\begin{array}{l}1261 \mathrm{TD} \\
\text { children and } \\
\text { mothers }\end{array}$ & $\begin{array}{l}15,24,36, \& \\
54 \operatorname{mos}\end{array}$ & $\begin{array}{l}\text { Cognitive skills: Bayley; } \\
\text { Language: Reynell \& } \\
\text { PLS; Maternal } \\
\text { sensitivity: Composite of } \\
\text { NICHD ECCRN codes + } \\
\text { HOME; School } \\
\text { Readiness: Bracken }\end{array}$ & $\begin{array}{l}\text { (1) Children who experienced } \\
\text { more responsive \& stimulating } \\
\text { parenting had higher scores on } \\
\text { cognitive \& language measures }\end{array}$ \\
\hline
\end{tabular}




\begin{tabular}{llll}
\hline Author (s) & $\underline{n} \quad \underline{\text { Outcome Range }} \quad \underline{\text { Primary Findings of Relevance }}$
\end{tabular}

\begin{tabular}{lllll}
\hline Steelman et al., & 282 families & Child CA: 12, & Language: SICD \& & (1) Mat warm responsiveness \\
(2002) & with TD & $24,40, \&$ & CELF-Pre; Sensitivity: & @ 12mos predicted child \\
& Children & $54 \mathrm{mos}$ & Warm acceptance \& & language at 24mos(2) Child \\
& & flexibility/responsiveness & language at 40mos predicted \\
& & Social skills: timeliness & mat warm responsiveness at \\
& & & of verbal response & $54 \mathrm{mos}$
\end{tabular}

Abbreviations: ALI = Adaptive Language Inventory, Bayley = Bayley Scales of Infant Development, Bracken = Bracken School Readiness Assessment; CA = chronological age, CDI = MacArthur Communicative Development Inventory, $\mathrm{CELF}=$ Clinical Evaluation of Language Fundamentals; $\mathrm{DQ}=$ developmental quotient, HOME $=\mathrm{Home}$ Observation for the Measurement of the Environment Inventory, MSEL = Mullen Scales of Early Learning, mo = months, NICHD ECCRN = NICHD Early Child Care Research Network, PLS = Preschool Language Scales, RDLS $=$ Reynell Developmental Language Scales, SCID = Sequenced Inventory of Communication Development, SD = के standard deviation, SES = socioeconomic status, SICD = Sequenced Inventory of Communicative Development, T1 $=$ time $1, \mathrm{~T} 2=$ time $2, \mathrm{~T} 3=$ time $3, \mathrm{TD}=$ typically-developing, $\mathrm{W}-\mathrm{J}=$ Woodcock-Johnson, yrs = years 


\section{Parental Sensitivity - Parents of Typically Developing Children}

An important study of child language development and the role of parent input was conducted by Hart and Risley (1995). The study was inspired by the authors' observations that there was a significant gap in vocabulary size between children from impoverished environments and children of college professors and that despite attempts at intervention with the children from impoverished environments the gap in vocabulary size remained.

The study examined language development in 42 families with different socioeconomic statuses (SES). Based on SES, the families were classified as professional, working-class, or welfare. The children were observed beginning at the age of eight or nine months through three years of age. All families engaged in similar manners - teaching their children self-care skills, disciplining their children, and talking to their children about similar topics. However, as early as 24 months, the children from professional families had produced significantly more vocabulary words than children from working-class or welfare families. Additionally, the children from professional families produced significantly more utterances than children from working-class or welfare families (Hart \& Risley, 1995).

The amount of time parents from each family type spent with their children and 
the amount they spoke to their children also differed significantly. Parents in professional families spent more time with their children and said three times as much as parents in welfare families. Not only did the parents in professional families spend more time with their children, interact with them more, and talk to them more than parents in welfare families, they also addressed more words to their child than parents from welfare families (Hart \& Risley, 1995). The professional parents also provided more responses to child utterances and more initiations than parents from welfare families. The professional parents provided more affirmations to their children and offered more affirmative feedback than parents of children from welfare families. Parents from professional families were also rated as being more responsive than parents from working-class or welfare families (Hart \& Risley, 1995).

Vocabulary development at age 3 years predicted later language abilities. When the children were in third grade, 29 of the 42 families participated in a follow-up study of the children's performance. For the children observed, the rate of vocabulary growth at age 3 years was strongly and positively associated with performance on measures of receptive vocabulary, language development, and reading comprehension at age 9-10 years. This study emphasizes how parental interactions have long-lasting effects on child language development and school performance (Hart \& Risley, 2003). 
A large-scale study of parental responsiveness was conducted by the NICHD Early Child Care Research Network. The study's purpose was to examine the variations in nonmaternal care and how they are related to the child's socialemotional, cognitive, linguistic, and physical development. During the course of the study, a wide variety of data was collected about the child, his/her parent(s), home and school environments, additional caregivers, and cognitive, language, and behavioral outcomes. Data collected that are of particular interest to the scope of this study are the data on parental sensitivity and child language outcomes. Four NICHD Early Child Care Research Network studies were reviewed for this dissertation project (NICHD Early Child Care Research Network, 2001, 2003, 2006, 2011). All of the studies are longitudinal, include large sample sizes, and analyze data from infancy to 54 months or first grade. All of the studies found that maternal sensitivity significantly impacted child outcome. Maternal sensitivity predicted secure attachment at 15 months and secure attachment predicted more positive mother-child interaction. Maternal vocabulary significantly predicted child cognitive and language development at 15, 24, and 36 months (NICHD Early Child Care Research Network, 2001). At 54 months, greater maternal sensitivity was positively associated with cognitive and language abilities (NICHD Early Child Care Research Network, 2003). Overall, children whose mothers were highly sensitive performed better on measures of cognitive and 
language abilities than children whose mothers were less sensitive (NICHD Early Child Care Research Network, 2006).

Six additional studies not part of the NICHD Early Child Care Research Network also examined relations between maternal sensitivity and child outcome (Belsky et al., 2007; Campbell et al., 2007; Downer \& Pianta, 2006; Hirsh-Pasek \& Burchinal, 2006; Mulvaney et al., 2006; Steelman et al., 2002). All but one study (Steelman et al., 2002) used the codes used in the NICHD Early Child Care Research Network. The findings of these studies were similar to the findings in the NICHD Early Child Care Research Network studies. Hirsh-Pasek and Burchinal (2006) reported that children scored higher on measures of language when they had mothers who were rated higher in maternal sensitivity. One study examined the change in maternal sensitivity over time (Hirsh-Pasek \& Burchinal, 2006). On average, maternal sensitivity did not change over time, though there was a slight decrease in maternal sensitivity between 15 to 24 months, which the authors related to the children entering the "terrible twos".

Four studies (Belsky et al., 2007; Downer \& Pianta, 2006; NICHD Early Child Care Research Network, 2001, 2003) used three 7-point Likert scales to measure maternal sensitivity. Supportive Presence, Respect for Child Autonomy, and Hostility (reversed) were used by Belsky et al. (2007) and in the NICHD Early Child Care Research Network $(2001,2003)$ studies. These three Likert scales were used to measure maternal sensitivity at age 36 months, 54 months, 
and first grade in the study by Campbell et al. (2007); different scales were used to measure sensitivity at ages 6-,15, and 24 months. Similarly, Mulvaney et al. (2006) used these three Likert scales at age 36 months and used different scales for 6-, 15-, and 24 months. Sensitivity, Respect for Child Autonomy, and Quality of Assistance were used in the NICHD Early Child Care Research Network (2001) study. A composite of maternal sensitivity was combined with composite scores on a measure of positive stimulation in the home environment in Belsky et al. (2007) and NICHD Early Child Care Research Network (2006). 
Table 5

Key Findings Regarding Sensitivity in Parents of Children with ID/DD

$\begin{array}{llll}\underline{\text { Author }(\mathrm{s})} & \underline{n} \quad \underline{\text { Outcome Range Measures }} & \underline{\text { Primary Findings of Relevance to }}\end{array}$

\begin{tabular}{|c|c|c|c|c|}
\hline $\begin{array}{l}\text { Baker et al., } \\
(2010)\end{array}$ & $\begin{array}{l}33 \text { children } \\
\text { with ASD } \\
\& \text { mothers }\end{array}$ & $\begin{array}{l}18 \mathrm{mos}, \\
24 \mathrm{mos}, \\
30 \mathrm{mos}, 36 \mathrm{mos}\end{array}$ & $\begin{array}{l}\text { Language: MSEL; } \\
\text { Sensitivity: NICHD } \\
\text { ECCRN codes }\end{array}$ & $\begin{array}{l}\text { Maternal sensitivity @ 18mos } \\
\text { predicted expressive language } \\
\text { growth from 2-3yrs }\end{array}$ \\
\hline $\begin{array}{l}\text { Brady et al., } \\
(2014)\end{array}$ & $\begin{array}{l}55 \text { mothers } \\
\text { of children } \\
\text { with FXS }\end{array}$ & $\begin{array}{l}\text { Child CA:2- } \\
10 y r s, M= \\
8.06 y r s\end{array}$ & $\begin{array}{l}\text { IQ: Leiter-R; } \\
\text { Language: PPVT-4, } \\
\text { EVT-2, \& \#of } \\
\text { different words in } \\
\text { play session; } \\
\text { Sensitivity: Specific } \\
\text { behaviors during } \\
\text { interactions }\end{array}$ & $\begin{array}{l}\text { (1) All } 3 \text { vocab measures } \\
\text { significantly correlated (pos.) with } \\
\text { early \& sustained responsivity } \\
\text { (2) Sustained maternal sensitivity } \\
\text { significantly added to regression } \\
\text { model for receptive \& expressive } \\
\text { vocab except for when } \\
\text { participants scored } 0\end{array}$ \\
\hline
\end{tabular}




\begin{tabular}{|c|c|c|c|c|}
\hline Author (s) & $\underline{n}$ & Age Range & Outcome Measures & $\begin{array}{c}\frac{\text { Primary Findings of Relevance to }}{\text { Dissertation Topic }} \\
\text { Pis }\end{array}$ \\
\hline $\begin{array}{l}\text { Dyches et al., } \\
\text { (2012) }\end{array}$ & $\begin{array}{l}576 \\
\text { participants }\end{array}$ & $\begin{array}{l}\text { Child CA: } \\
1.5 \mathrm{yrs}-6.4 \mathrm{yrs}\end{array}$ & $\begin{array}{l}\text { Sensitivity: } \\
\text { Observation of } \\
\text { parent-child } \\
\text { interactions } \\
\text { w/ratings/counts of } \\
\text { parent \& child behs }\end{array}$ & $\begin{array}{l}\text { Moderate association between } \\
\text { pos. parenting and child outcomes }\end{array}$ \\
\hline $\begin{array}{l}\text { Sterling et al., } \\
\text { (2013) }\end{array}$ & $\begin{array}{l}55 \text { mothers } \\
\text { of children } \\
\text { with FXS }\end{array}$ & $\begin{array}{l}\text { Child CA: } \\
\text { 10mos-40mos }\end{array}$ & $\begin{array}{l}\text { DQ: IQ; WISC-III; } \\
\text { MSEL; }\end{array}$ & $\begin{array}{l}\text { (1) Child developmental level \& } \\
\text { language ability strongly } \\
\text { influenced by behavior-by- } \\
\text { behavior responsivity }\end{array}$ \\
\hline
\end{tabular}




\begin{tabular}{|c|c|c|c|c|}
\hline Author (s) & $\underline{n}$ & Age Range & Outcome Measures & $\begin{array}{c}\frac{\text { Primary Findings of Relevance to }}{\text { Dissertation Topic }} \\
\end{array}$ \\
\hline $\begin{array}{l}\text { Warren \& } \\
\text { Brady (2007), } \\
\text { review }\end{array}$ & & & & $\begin{array}{l}\text { (1) Responsivity most effective } \\
\text { when it is sustained up to age 5yrs } \\
\text { - responsiveness early but not late } \\
\text { or late but not early associated } \\
\text { with significantly low language \& } \\
\text { cognition } \\
\text { (2) No critical period for } \\
\text { sensitivity, just cumulative effect } \\
\text { (3) No studies have shown } \\
\text { negative effects of high } \\
\text { responsivity }\end{array}$ \\
\hline $\begin{array}{l}\text { Warren et al., } \\
\text { (2010) }\end{array}$ & $\begin{array}{l}55 \text { mothers } \\
\text { of children } \\
\text { with FXS }\end{array}$ & $\begin{array}{l}\text { Child CA: T1: } \\
\text { 11-48 mos; } \\
\text { T2: 26-64mos; } \\
\text { T3: 40-76mos }\end{array}$ & $\begin{array}{l}\text { DQ: MSEL; Mat. } \\
\text { responsivity \& } \\
\text { responsiveness: } \\
\text { observation }\end{array}$ & $\begin{array}{l}\text { Early mat responsivity positively } \\
\text { predicts child language }\end{array}$ \\
\hline
\end{tabular}

\footnotetext{
Abbreviations: $\mathrm{CA}=$ chronological age, $\mathrm{DQ}=$ developmental quotient, $\mathrm{EVT}=$ Expressive Vocabulary Test (Williams, 2007), FXS = fragile x syndrome, Leiter = Leiter International Performance Scale, IQ = intelligence quotient, $\operatorname{mos}=$ months, MSEL $=$ Mullen Scales of Early Learning, PPVT $=$ Peabody Picture Vocabulary Test, WISC $=$ Wechsler Intelligence Scale for Children
} 


\section{Parental Sensitivity - Parents of Children with Intellectual Disability}

The data from studies of parental responsiveness in parents of TD children illustrate how important responsive parenting is to child cognitive and language development. Responsivity is most effective when it is sustained up to age 5 years. There is no critical period for sensitivity, rather the cumulative effect is most important (Warren $\&$ Brady, 2007). Young children with DD evidence low rates of initiation and responsiveness. They might be likely to receive less responsiveness from their parents; examining parental responsiveness in this population is critical (Warren \& Brady, 2007).

Parental sensitivity has been shown to predict cognitive and language outcomes for children with ID/DD. The more positive the parent-child interaction, the greater the gains in child language abilities (Warren \& Brady, 2007). Twelve studies reviewed for the dissertation project included children with ID/DD (Baker et al., 2010; Blacher, Baker, \& Kaladjian, 2013; Brady et al., 2014; Dyches et al., 2012; McDuffie \& Yoder, 2010; Siller \& Sigman 2002; Siller \& Sigman, 2008; Sterling et al., 2013; Warren et al., 2010; Weisman et al., 2015; Wheeler et al., 2007; Yoder \& Warren, 1999). One study used a large age range (Siller \& Sigman, 2002). All studies but one (Baker et al., 2010) used observation and counting of behaviors to assess maternal sensitivity.

One study (Dyches et al., 2012) conducted a meta-analysis of 14 studies, including 576 participants, and examined positive parenting in parents of children with developmental delays, such as autism, Cerebral Palsy, or Down syndrome, The study found a moderate association between positive parenting and child outcome.

All studies that examined child language outcomes found that maternal sensitivity was a significant predictor. In a study of 55 mothers of children with FXS, Brady et al. 
(2013), examined relations between maternal sensitivity and child expressive vocabulary as measured by the EVT-2. Child expressive vocabulary was significantly positively correlated with early and sustained sensitivity. When sustained sensitivity was added to the regression model, it significantly predicted expressive vocabulary except for participants who had scored at floor.

\section{Relations between Sensitivity and Income and/or Maternal Education}

The results of the Hart and Risley (1995) study evidence the important relations between parent-child interaction, family income, and parental education. Three studies examined the relations between maternal sensitivity, maternal education, and child outcome (Blacher, Baker, \& Kaladjian, 2013; Campbell et al., 2007; Warren \& Brady, 2007). Mothers with more education had lower negative parenting scores (Blacher, Baker, \& Kaladjian). Warren and Brady (2007) found that low maternal education was strongly correlated with low maternal responsivity, and high maternal education was strongly correlated with high maternal responsivity. Similarly, Campbell et al. (2007) found that mothers with more education and higher incomes were more sensitive.

Income influences a child's home environment and accounts for significant effects on cognitive development (Duncan \& Brooks-Gunn, 2000). It is hypothesized that family financial stress leads to conflict between parents and children. Low income can also affect parental mental health, which negatively affects parent-child interactions (Duncan \& Brooks-Gunn, 2000). Hungerford and Cox (2006) reported that disadvantage in family income has negative effects on child cognitive development and on the parents as well. Two studies examined the relations between maternal sensitivity, family income, and child outcome (Hirsh-Pasek \& Burchinal, 2006; NICHD Early Child Care Research Network, 2001). Children from more advantaged families had mothers who were more 
sensitive at each time point in the study and overall (Hirsh-Pasek \& Burchinal, 2006) and income in combination with mother's cognitive stimulation predicted a child's cognitive abilities on measures at 24 and 36 months and language abilities at 36 months. The 2011 study by the NICHD Early Child Care Research Network examined the relations between maternal education, family income, and maternal sensitivity. Income, maternal education, and maternal sensitivity accounted for significant variance in cognitive function in first grade.

\section{Dissertation Project}

As indicated in the literature review earlier in this chapter, the results of studies of maternal interaction style for both TD children and children with ID/DD and their mothers indicate that there are significant relations between maternal sensitivity and child language outcomes. Children whose mothers are rated as highly sensitive perform better on measures of language abilities than do children of mothers who are rated as less sensitive (e.g., Hirsh-Pasek \& Burchinal, 2006; NICHD Early Child Care Research Network, 2001, 2003, 2006; Warren \& Brady, 2007, 2010).

In these studies, maternal sensitivity was most commonly measured based on a composite formed from three scales on the Parent Rating Scales for the NICHD Early Child Care Research Network: Supportive Presence (demonstration of positive regard and emotional support), Respect for Child Autonomy (recognition and respect for the validity of the child's individuality, motives, and perspectives), and Hostility (adult expression of anger, discounting, or rejecting the child) (reversed).This composite was selected as the measure of maternal sensitivity for my dissertation project. 
As indicated in the prior literature review, there also is evidence that family income is related to both maternal sensitivity and child language and cognitive outcomes. Annual family income is significantly positively correlated with maternal interaction style composite, and both family income-to-needs ratio and maternal interaction style composite significantly predicted child language scores (e.g., Hirsh-Pasek \& Burchinal, 2006; NICHD Early Child Care Research Network, 2001). In addition, nonverbal reasoning abilities were found to be related to expressive language abilities for individuals with WS (e.g., Mervis, 1999). For this reason, measures of annual family income, child nonverbal reasoning abilities, and child CA also were included in the dissertation project.

To date, no studies have examined relations between maternal sensitivity and child expressive vocabulary ability in children with WS. WS is a genetic syndrome with a unique cognitive and language profile. There is significant variability in both nonverbal reasoning abilities and language abilities among individuals with WS. It is likely that variation in maternal sensitivity would account for some of the variability in language and/or cognitive abilities. The purpose of this dissertation is to test the hypothesis that maternal interaction style predicts child expressive vocabulary ability in children with WS relative to TD peers, beyond the effects of child nonverbal reasoning ability, child $\mathrm{CA}$, and annual family income. 


\section{CHAPTER II \\ METHOD AND RESULTS}

\section{Method}

\section{Participants}

The final sample included 75 children (40 boys and 35 girls) with WS and their mothers. All children had genetically-confirmed, classic-length WS deletions. The children's ages ranged from 4.01 through 8.39 years $(M=5.66, M d n=5.17, S D=1.52)$. This age range was selected so that participants would be assessed using the same version of the DAS-II (DAS-II Early Years), the measure of intellectual abilities used in the study. Participants were recruited through a study of language and cognitive development in individuals with WS conducted at the University of Louisville by Dr. Carolyn Mervis. Children were excluded if they also had an autism spectrum disorder $(n=1)$ or an additional syndrome expected to affect intellectual functioning or behavior $(n=1$; fetal alcohol syndrome). One additional child was excluded because her standardized residual was more than 3 SDs below the mean in the regression predicting EVT-2 SS.

The racial and ethnic distribution of the 75 participants was: $64(85.3 \%)$ White non-Hispanic; 4 (5.3\%) White Hispanic; 1 (1.3\%) Asian non-Hispanic; 1 (1.3\%) AfricanAmerican non-Hispanic; 3 (4.0\%) biracial non-Hispanic [1 American Indian and White; 1 Asian and White; 1 Hawaiian/Pacific Islander and White]; 1 (1.3\%) biracial Hispanic; and $1(1.3 \%)$ tri-racial Hispanic [American-Indian, African-American, and White]. Approximately $79 \%$ of mothers reported having attained a bachelor's degree or higher. 


\section{Measures: Independent Variables}

Nonverbal Reasoning: The Differential Ability Scales-II Early Years (DAS-II;

Elliott, 2007) is an individually administered assessment of intellectual abilities of individuals aged 2.5 through 8.99 years. The DAS-II Nonverbal Reasoning Cluster standard score (SS) was used to measure nonverbal reasoning. For the general population, the mean is 100 , the standard deviation $(S D)$ is 15 , and the range is 32 to 170 . Test-retest reliability for the DAS-II Nonverbal Reasoning Cluster SS is .73 to .77. Internal consistency for the DAS-II Nonverbal Reasoning Cluster SS ranges from .85 to .94 for children aged $4-8$ years. It demonstrates validity with other standardized measures of cognitive abilities (e.g., WPPSI-III, WISC-IV). During the process of standardizing the

DAS-II, special group studies were conducted to examine the clinical utility of the assessment. In a group study of children with ID, the mean Nonverbal Reasoning Cluster SS was 60.7 , which is significantly lower $(p<.01)$ than the mean Nonverbal Reasoning Cluster SS for the matched control group $(M=102.0)$.

Maternal Interaction Style: The National Institutes of Child and Human Development Study of Early Child Care and Youth Development Coding System (InterUniversity Consortium for Political and Social Research, 2007) was developed to measure the quality of parent-child interaction. The scales include measures of a variety of qualities on a 7-point Likert-type scale, ranging from not at all characteristic of the interaction (1) to highly characteristic of the interaction (7). For the present study, three scales were used: Supportive Presence (demonstration of positive regard and emotional support), Respect for Child Autonomy (recognition and respect for the validity of the child's individuality, motives, and perspectives), and Hostility (adult expression of anger, 
discounting, or rejecting the child). The score on the Hostility scale was reversed, so that higher scores corresponded to lower hostility. A composite was formed from the sum of the scores on these three scales. The possible range of scores is $3-21$.

A composite score formed from these three scales has been used in several studies of parent-child interaction (NICHD Early Child Care Research Network, 2001, 2003, 2006). One of these studies included children with epilepsy, autism, or ID (NICHD Early Child Care Research Network, 2003).

\section{Dependent Variable}

Expressive Vocabulary. The Expressive Vocabulary Test-2 (EVT-2; Williams, 2007) is an individually administered assessment used to assess single-word expressive vocabulary in individuals aged 2 years 6 months through 90 years. It is comprised of 190 items that are arranged in order of increasing difficulty. For the general population, the mean is 100 and the SD is 15 . Standard scores can range from 20 to 160 . Split-half reliability for ages $4-8$ years is $.90-.95$; test-retest reliability ranges from .94 to .97 . The EVT-2 demonstrates validity with standard measures of language abilities, including the Peabody Picture Vocabulary Test-4 (PPVT-4; Dunn \& Dunn, 2007) and the Core Language, Receptive Language, and Expressive Language Indices from the Clinical Evaluation of Language Fundamentals -4 (CELF-4; Semel, Wiig, \& Secord, 2003). The EVT-2 was not normed on children with ID/DD, but it has been used to assess expressive vocabulary in these populations (e.g., Finestack et al., 2013; Mervis \& John, 2010; Mervis \& Pitts, 2015; Unterstein, 2010). 


\section{Procedure}

Parental consent was obtained as part of a larger study of the development of children with WS. The DAS-II and EVT-2 were part of a larger battery of assessments that was administered to participants over two days. The DAS-II was administered on the first day of testing; most often, the EVT-2 was administered on the second day of testing. Both were administered according to the standardized procedures. Usually on the first day of testing, after testing had been completed the mother and child completed a 30-minute play session in a laboratory play room equipped with developmentally appropriate toys. The mother was asked to play with her child as she would at home. All play sessions were video recorded. Videotapes of the play sessions were coded using selected scales from the NICHD Early Child Care Research Network Study of Early Child Care. Coders were two doctoral students trained to reliability of $80 \%$ agreement within one point on the overall composite. The training process took approximately two weeks. Prior to viewing play session videotapes, the doctoral students reviewed the scoring criteria for each scale that would be included in the study and discussed and agreed upon behaviors and actions that would meet those criteria. To practice using the scoring criteria, ten play session videotapes of participants included in the study were chosen at random. Careful attention was paid to ensure that the play sessions were from dates prior to the beginning of the dissertation study. Coders watched and coded the videotapes independently. Once this was completed, the coders compared their scores for each of the videotapes and discussed each rating. Once the coders felt comfortable with the coding procedure, coding for the study began. All videotapes were independently coded by both raters. Additionally, both raters were blind to participants’ DAS-II Nonverbal Reasoning Cluster 
and EVT-2 SSs. For each of the three scales, scores for the two raters were within one point for $100 \%$ of the play sessions. Composite scores for the two raters were within one point for $86.7 \%$ (65 out of 75 ) of the play sessions. For the remaining play sessions, composite scores differed by two points. As the measure of maternal interaction style, the average of the two coders' composite scores was used.

\section{Results}

\section{Descriptive Statistics}

Prior to conducting the primary correlational analyses, histograms of the distributions of the variables [expressive vocabulary (EVT-2 SS), maternal interaction style composite score, nonverbal reasoning (DAS-II Nonverbal Reasoning cluster SS), and estimated annual family income] were examined visually and their distributions compared to the normal curve. Tests of skewness and kurtosis were also conducted. Prior to conducting the multiple regression analyses, standardized residuals were examined and a test of normality of the residuals (Kolmogorov-Smirnov) was conducted. Though the test of normality was not significant, the histogram and boxplot of the standardized residuals indicated that there was one outlier whose value was more than $3 S D$ s below the mean.. This participant was removed. The test of normality was conducted again, and it was not statistically significant. The histogram and boxplot of the standardized residuals did not indicate the presence of outliers.

Multicollinearity of each model was evaluated by examining the variance inflation factor (VIF) (values greater than 10 are problematic) and tolerance (values below .1 are problematic). All VIFS and tolerance values were within acceptable limits. 
Descriptive statistics are reported in Table 6. As indicated in the table, the mean DAS-II Nonverbal Reasoning SS was at the borderline to low average level with a range from moderate intellectual disability to high average ability. The mean EVT-2 SS was at the low average level with a range from severe intellectual disability to high average ability. Maternal interaction style composite scores ranged from low (indicating that the mother's interaction style with her child was not very sensitive) to the highest score possible (indicating that the mother's interaction style with her child was highly sensitive).The mean maternal interaction style composite score was slightly above the midpoint of the interaction style scale.

Table 6

Descriptive Statistics for Independent and Dependent Variables

\begin{tabular}{lcccc}
\hline Variable & Mean & Median & SD & Range \\
\hline Child CA (in years) & 5.66 & 5.17 & 1.52 & $4.01-8.39$ \\
$\begin{array}{l}\text { Estimated Family Income } \\
\text { (in thousands) }\end{array}$ & $\$ 168.2$ & $\$ 120.0$ & $\$ 159.4$ & $\$ 25.0-\$ 1000.0$ \\
$\begin{array}{l}\text { DAS-II Nonverbal } \\
\text { Reasoning Cluster SS }\end{array}$ & 79.37 & 80.00 & 14.80 & $41-113$ \\
$\begin{array}{l}\text { Maternal Interaction Style } \\
\text { Composite }\end{array}$ & 15.77 & 16.00 & 1.92 & $10.5-21.0$ \\
EVT-2 SS & 81.64 & 83.00 & 16.50 & $30-117$
\end{tabular}

Abbreviations: DAS-II = Differential Ability Scales-II Early Years; EVT-2 = Expressive Vocabulary Test-2

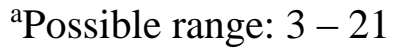

\section{Correlations}

Bivariate Pearson correlations were conducted to examine the potential relations between child CA, estimated annual family income, maternal education, DAS-II Nonverbal Reasoning SS, maternal interaction style composite, and EVT-2 SS (see Table 7). Scatterplots of these correlations are shown in Figures $1-4$. 
Table 7

Parametric Correlations Between Independent and Dependent Variables

\begin{tabular}{|l|c|c|c|c|c|}
\hline & \multicolumn{5}{|c|}{ Correlations } \\
\hline \multicolumn{1}{|c|}{ Variables } & 2 & 3 & 4 & 5 & 6 \\
\hline 1.Child CA & .21 & -.02 & .18 & .06 & .10 \\
\hline $\begin{array}{l}\text { 2. Estimated } \\
\text { Annual Family } \\
\text { Income }\end{array}$ & --- & $.24 *$ & .15 & .06 & .04 \\
\hline $\begin{array}{l}\text { 3. Maternal } \\
\text { Education }\end{array}$ & --- & --- & .18 & -.03 & .06 \\
\hline $\begin{array}{l}\text { 4. DAS-II } \\
\text { Nonverbal } \\
\text { Reasoning } \\
\text { Cluster SS }\end{array}$ & --- & --- & --- & $.37^{* *}$ & $.64^{* * *}$ \\
\hline $\begin{array}{l}\text { 5. Maternal } \\
\text { Interaction } \\
\text { Style } \\
\text { Composite }\end{array}$ & --- & --- & --- & --- & $.44^{* *}$ \\
\hline 6. EVT-2 SS & --- & --- & --- & -- & \\
\hline
\end{tabular}

$* p<.05, * * p<.001$ (2-tailed)

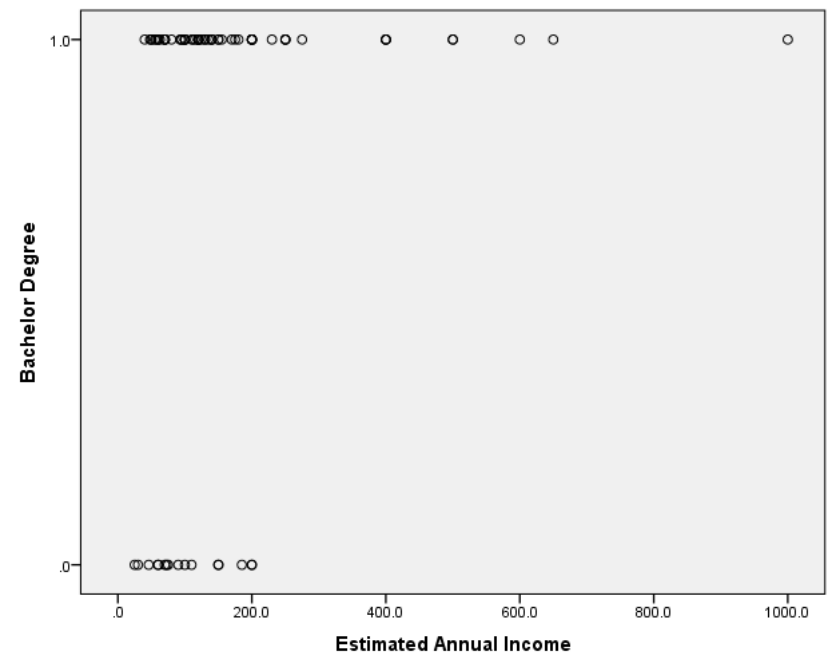

Figure 1. Scatterplot of correlations between Estimated Annual Family Income and Maternal Education. 


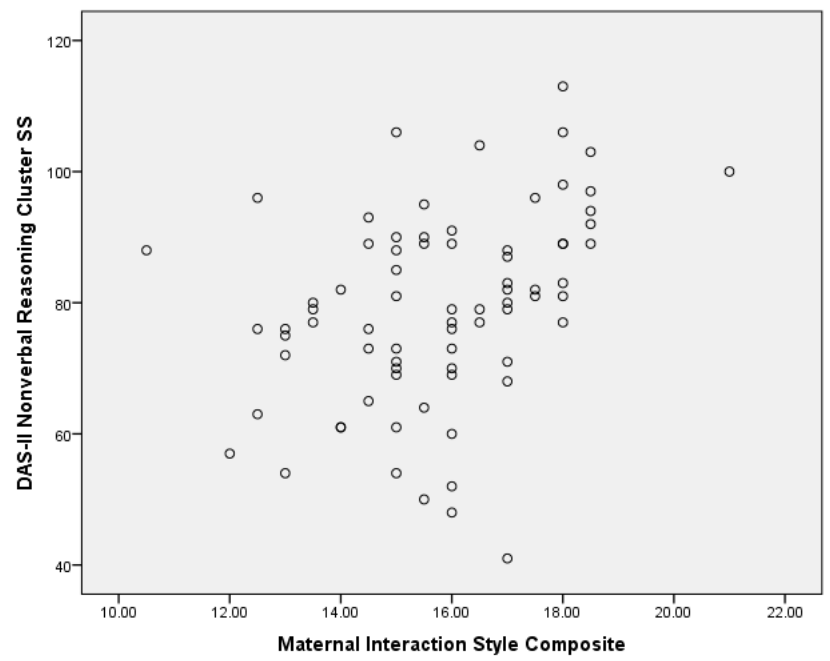

Figure 2. Scatterplot of correlations between Maternal Interaction Style Composite and DAS-II Nonverbal Reasoning Cluster SS.

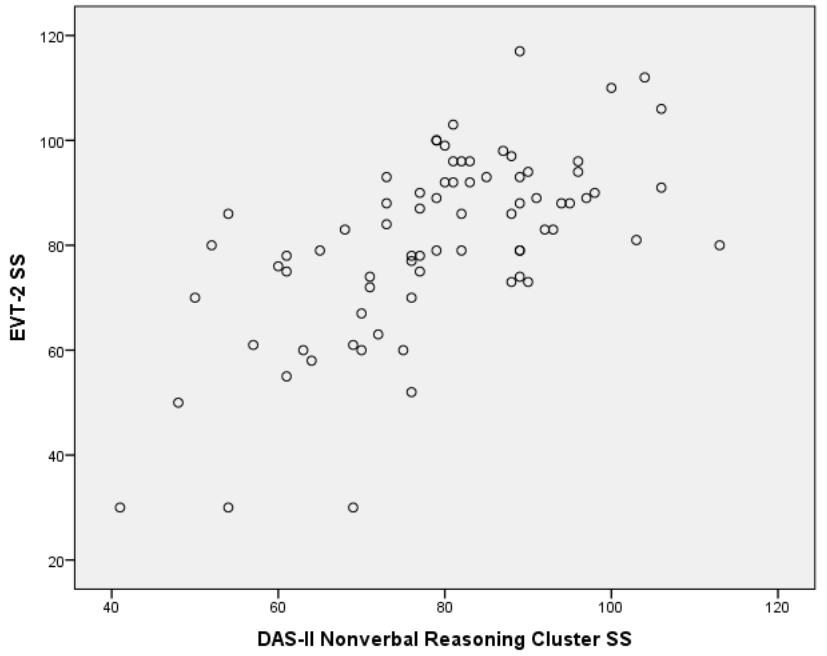

Figures 3. Scatterplot of correlations between DAS-II Nonverbal Reasoning Cluster SS and EVT-2 SS. 


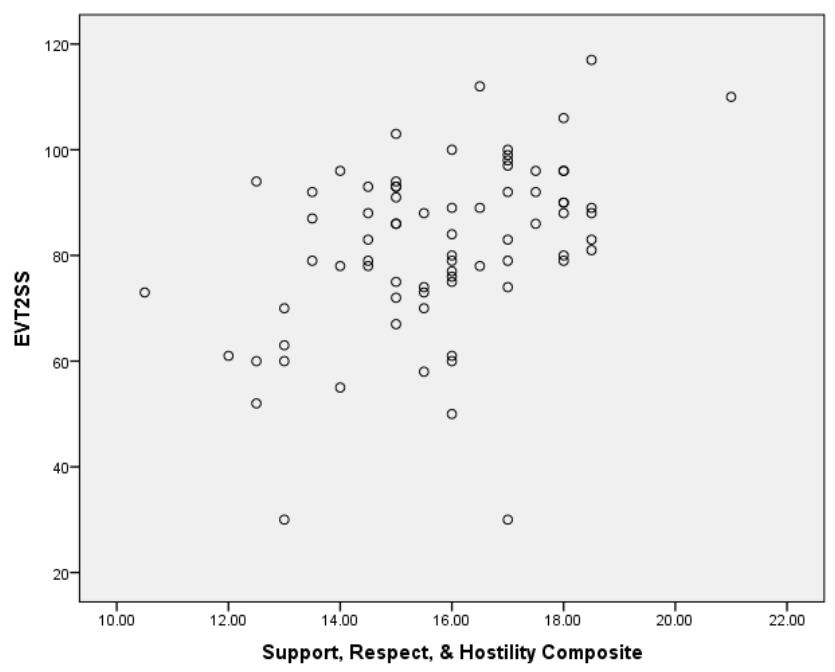

Figure 4. Scatterplot of correlations between Maternal Interaction Style Composite and EVT-2 SS.

Preliminary analyses revealed significant relations between the maternal interaction style composite, nonverbal reasoning ability, and expressive vocabulary ability, and between nonverbal reasoning ability with expressive vocabulary ability. There were also significant relations between annual family income and maternal education.

Following the preliminary analyses, the primary study hypothesis was tested: Mother's interaction style will predict child expressive vocabulary ability in children with WS relative to TD peers, even after taking into account child nonverbal reasoning ability relative to TD peers, child CA, annual family income, and maternal education.

Regressions. To test the hypothesis that maternal interaction style composite significantly predicted child EVT-2 SS even after controlling for child CA, estimated annual family income, maternal education, and child nonverbal reasoning ability, sequential model multiple regression analysis was performed. Model 1 was comprised of child CA, estimated annual family income, maternal education, and DAS-II Nonverbal 
Reasoning Cluster SS. Maternal interaction style was added to form Model 2 (see Table 8). The change in $R^{2}$ and the beta weights are shown in Table 8 .

Model 1 provided a significant fit to the data, $F(4,70)=12.67, p<.001$, yielding a large effect size $\left(f^{2}=.72\right)$ and explaining $38.7 \%$ of the variance in child EVT-2 SS.

DAS-II Nonverbal Reasoning Cluster SS was the only significant predictor of child expressive vocabulary SS $(p<.001)$.

Model 2 also provided a significant fit to the data, $F(1,69)=12.00$, $p<.001$, and the fit provided by Model 2 was significantly better than that provided by Model 1 with an $\mathrm{R}^{2}$ change of $.045(p=.02)$. The effect size was large $\left(f^{2}=.75\right)$ and the model explained $42.6 \%$ of the variance in child EVT-2 SS. Maternal interaction style composite and DAS-II Nonverbal Reasoning Cluster SS were the only significant predictors of child EVT-2 SS ( $p=.02$ and $p<.001$, respectively). These results support the hypothesis that mother-child interaction style significantly predicts child expressive vocabulary in children with WS aged 4- 8 years even after taking into account the effects of nonverbal reasoning ability, family income, maternal education, and child CA. 
Table 8

Sequential Multiple Regression Analysis Predicting EVT-2 SS

\begin{tabular}{|c|c|c|c|c|}
\hline & \multicolumn{4}{|c|}{ EVT-2 SS } \\
\hline Predictor & Adj. $R^{2}$ & $\Delta \mathrm{R}^{2}$ & $\beta$ & $p$ \\
\hline Model 1 & .39 & $.42 * *$ & & \\
\hline Child CA & & & -.01 & .88 \\
\hline Estimated Annual & & & -.04 & .67 \\
\hline Family Income & & & & \\
\hline Maternal Education & & & -.05 & .60 \\
\hline DAS-II Nonverbal & & & .66 & $<.0001$ \\
\hline Reasoning Cluster SS & & & & \\
\hline Model 2 & .43 & $.04 *$ & & \\
\hline Child CA & & & -.01 & .92 \\
\hline Estimated Annual & & & -.05 & .60 \\
\hline Family Income & & & & \\
\hline Maternal Education & & & -.03 & .79 \\
\hline DAS-II Nonverbal & & & .57 & $<.0001$ \\
\hline Reasoning Cluster SS & & & & \\
\hline Maternal Interaction & & & .23 & .02 \\
\hline Style Composite & & & & \\
\hline
\end{tabular}

\section{Additional Analyses}

Generally, there was variability in the scores mothers received on each of the three scales included in the maternal interaction composite. Analyses were conducted in order to examine the effects of each of the three scales. The average of the two coders' scores was used as the measure for each scale. Cohen's $\mathrm{K}$ was run to determine if there 
was agreement between the two raters. There was moderate agreement for Supportive Presence and Respect for child Autonomy, $\mathrm{K}=.59$ (95\% CI, .51 to $.67, p<.0001$ and $\mathrm{K}$ $=.50(95 \% \mathrm{CI}, .42$ to .58$), p<.0001$, respectively and substantial agreement for Hostility $\mathrm{K}=.66(95 \% \mathrm{CI}, .58$ to .74$), p<.0001$. Descriptive statistics for each of the scales are reported in Table 9.

Table 9

Descriptive Statistics for Supportive Presence, Respect for Child Autonomy, and Hostility (reversed)

\begin{tabular}{|c|c|c|c|c|}
\hline Variable & Mean & Median & SD & Range \\
\hline Supportive Presence ${ }^{a}$ & 5.11 & 5.00 & 0.82 & $3-7$ \\
\hline Respect for Child & 4.83 & 5.00 & 0.86 & $2.5-7$ \\
\hline \multicolumn{5}{|l|}{ Autonomy ${ }^{a}$} \\
\hline Hostility $^{\mathrm{a}}$ (reversed) & 5.83 & 6.00 & 0.71 & $4-7$ \\
\hline
\end{tabular}

Possible range: $1-7$

\section{Correlations}

Bivariate parametric correlations were conducted to examine the potential relations between child CA, estimated annual family income, maternal education, DAS-II Nonverbal Reasoning SS, Supportive Presence, Respect for Child Autonomy, Hostility (reversed), and EVT-2 SS (see Table 10). Scatterplots of these correlations are shown in Figures $5-13$. 
Table 10

Parametric Correlations Between Independent and Dependent Variables

\begin{tabular}{|l|c|c|c|}
\hline \multicolumn{1}{|c|}{ Variables } & $\begin{array}{c}|c| \\
\text { Supportive } \\
\text { Presence }\end{array}$ & $\begin{array}{c}\text { Respect for } \\
\text { Child } \\
\text { Autonomy }\end{array}$ & Hostility \\
\hline Child CA & -.02 & .08 & .09 \\
\hline $\begin{array}{l}\text { Estimated Annual } \\
\text { Family Income }\end{array}$ & .02 & .01 & .14 \\
\hline Maternal Education & .15 & -.14 & -.08 \\
\hline $\begin{array}{l}\text { DAS-II Nonverbal } \\
\text { Reasoning Cluster SS }\end{array}$ & .23 & $.34^{*}$ & $.32^{*}$ \\
\hline EVT-2 SS & .19 & $.45^{* *}$ & $.42^{* *}$ \\
\hline Supportive Presence & --- & $.39^{* *}$ & $.41^{* *}$ \\
\hline $\begin{array}{l}\text { Respect for Child } \\
\text { Autonomy }\end{array}$ & --- & --- & $.60^{* *}$ \\
\hline Hostility & --- & --- & --- \\
\hline
\end{tabular}

$* p<.05, * * p \leq .001$ (2-tailed)

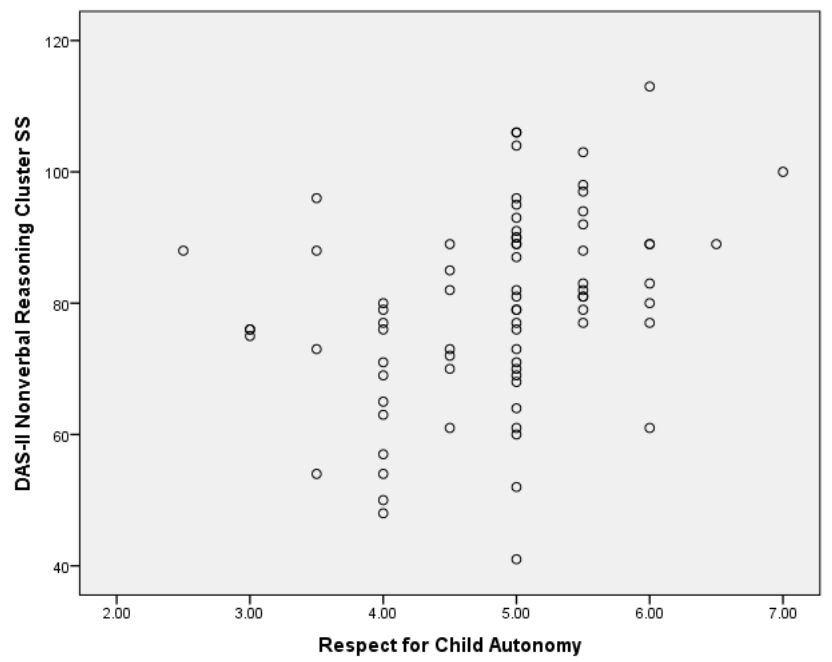

Figure 5. Scatterplot of correlations between Respect for Child Autonomy and DAS-II Nonverbal Reasoning Cluster SS. 


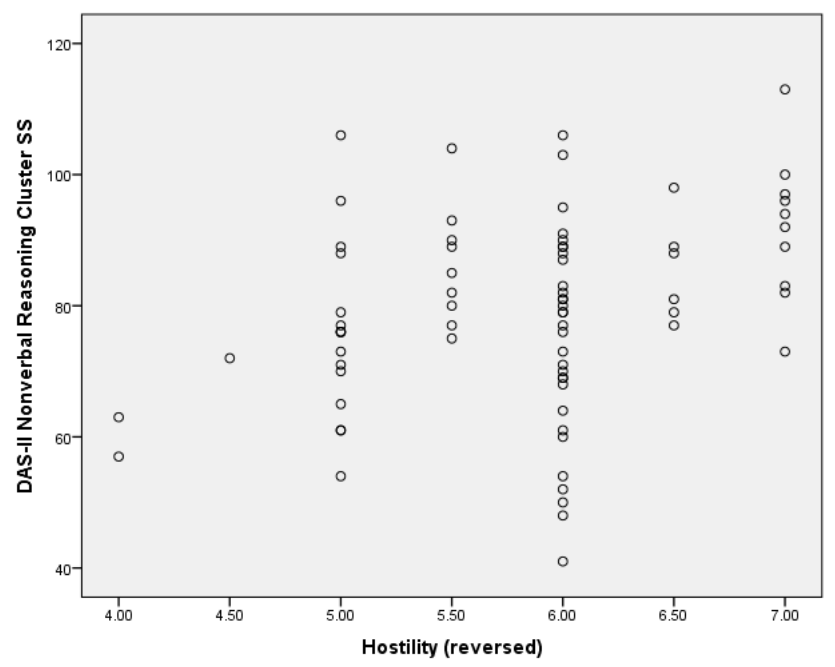

Figures 6. Scatterplot of correlations between Hostility (reversed) and DAS-II Nonverbal Reasoning Cluster SS.

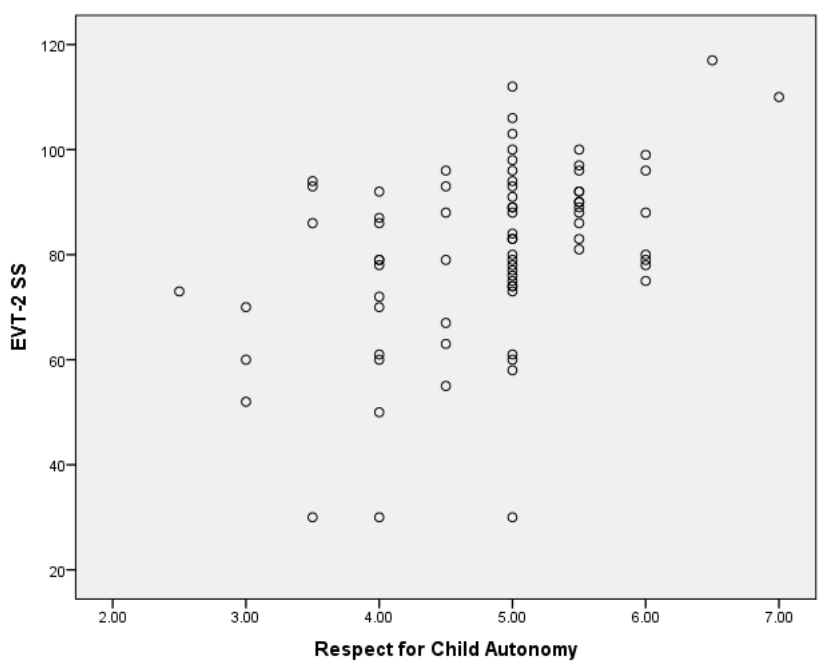

Figures 7. Scatterplot of correlations between Respect for Child Autonomy and EVT-2 SS. 


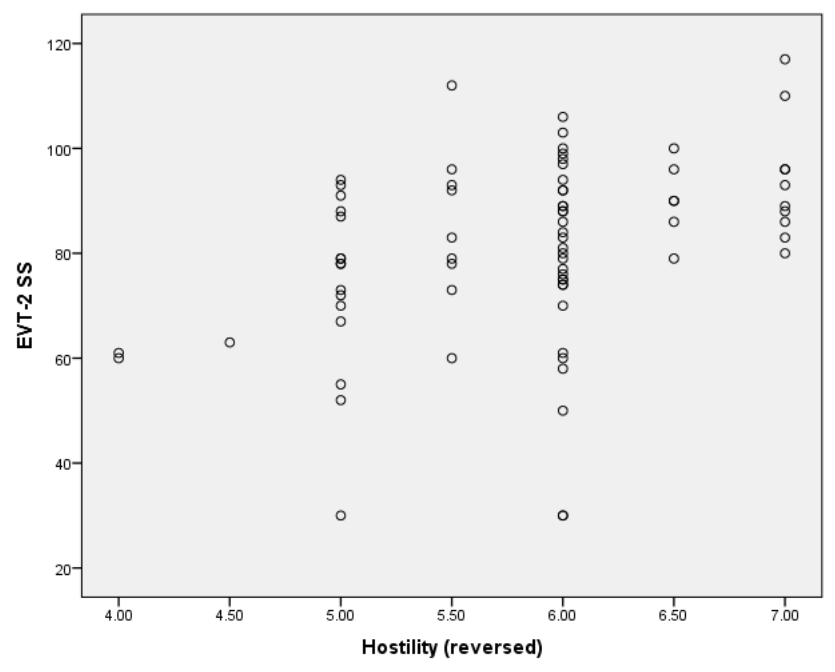

Figure 8. Scatterplot of correlations between Hostility (reversed) and EVT-2 SS.

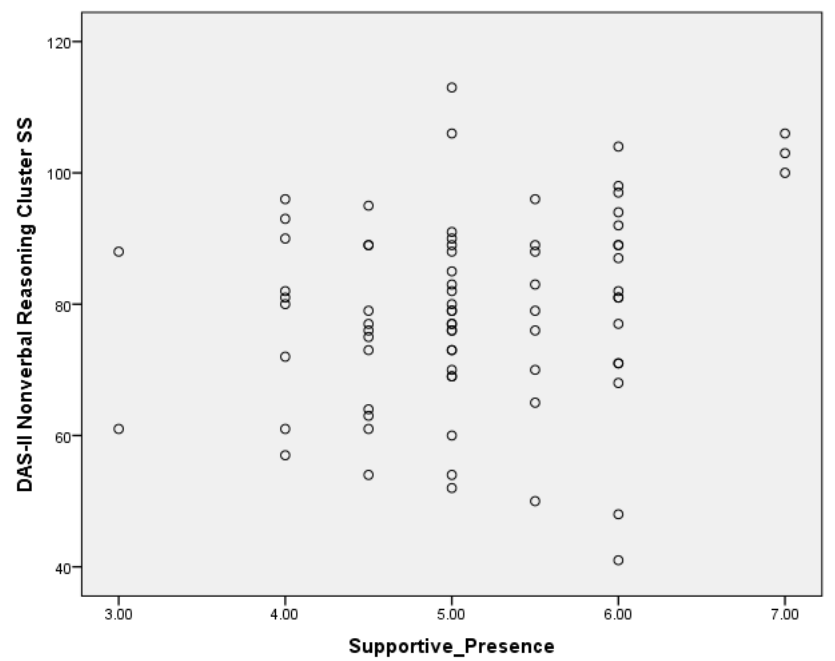

Figure 9. Scatterplot of correlations between Supportive Presence and DAS-II Nonverbal Reasoning Cluster SS. 


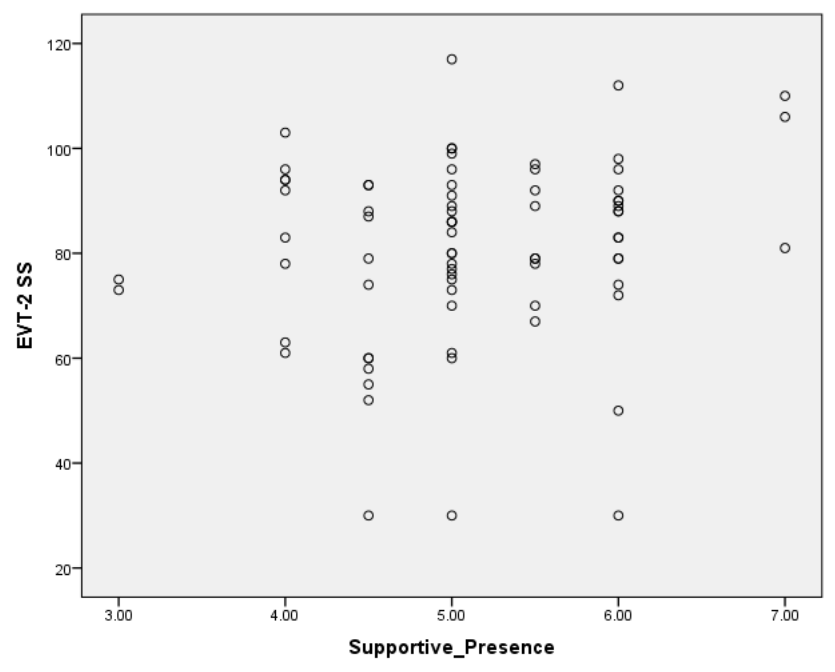

Figure 10. Scatterplot of correlations between Supportive Presence and EVT-2 SS.

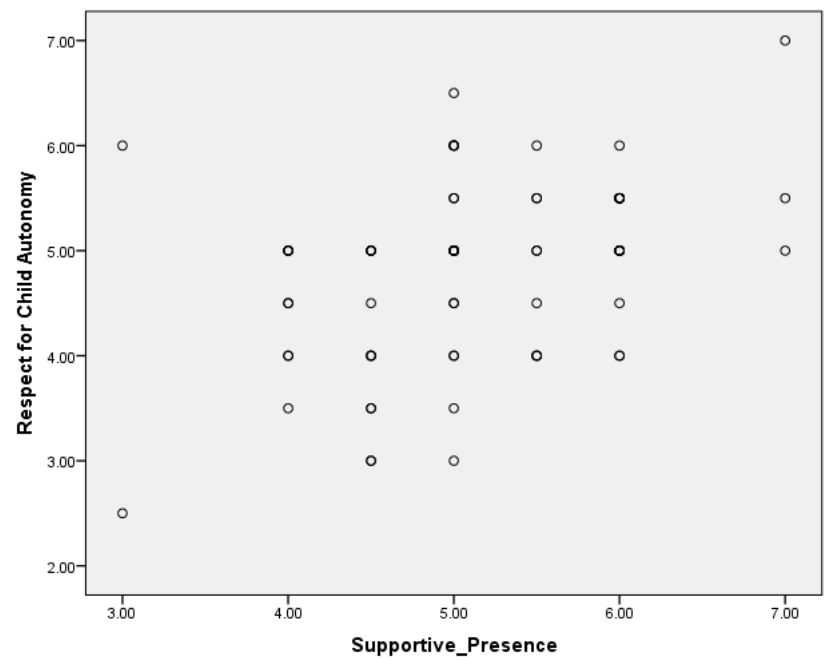

Figure 11. Scatterplot of correlations between Supportive Presence and Respect for Child Autonomy. 


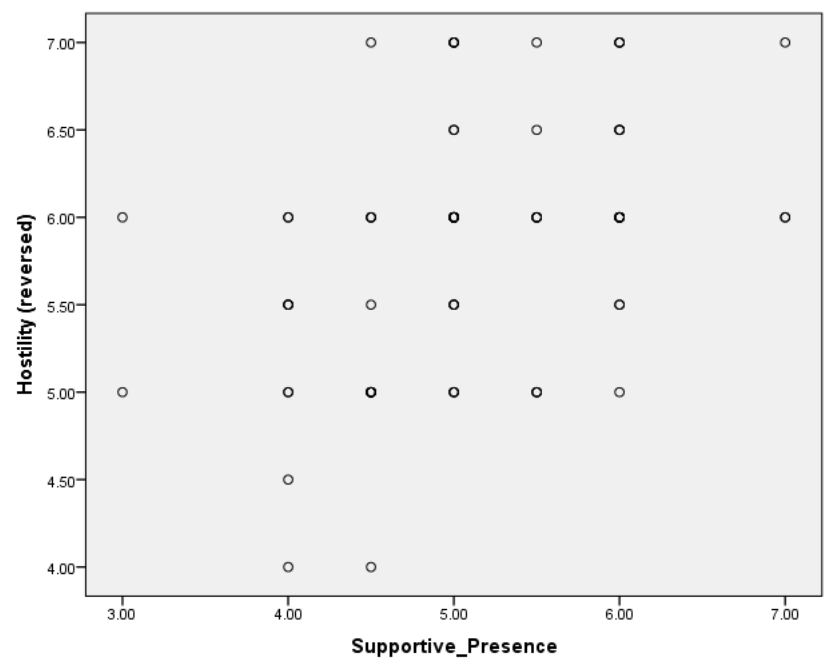

Figure 12. Scatterplot of correlation between Supportive Presence and Hostility (reversed).

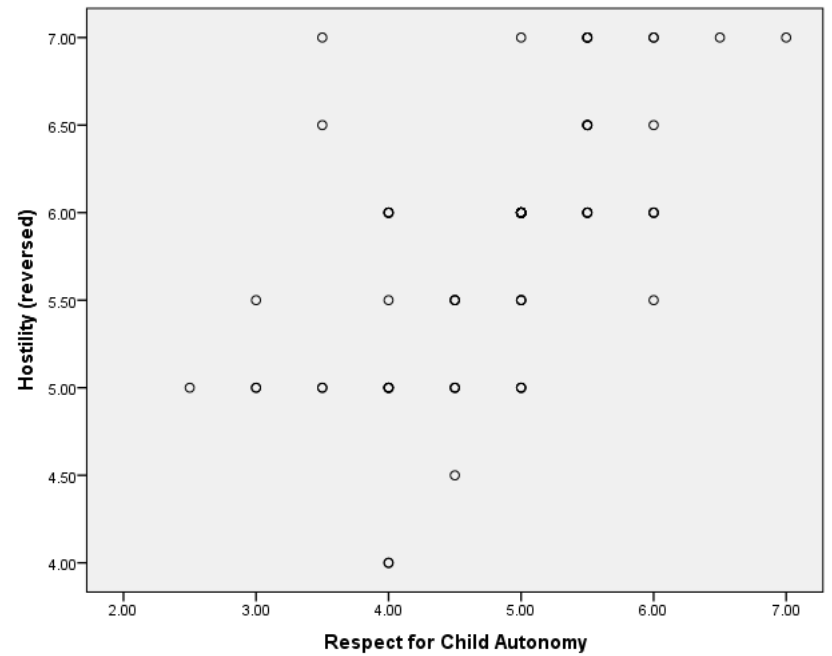

Figure 13. Scatterplot of correlations between Respect for Child Autonomy and Hostility (reversed).

Ratings for Respect for Child Autonomy and for Hostility (reversed) were significantly correlated with child EVT-2 SS. Supportive Presence was not correlated with EVT-2 SS. A new composite comprised of only Respect for Child Autonomy and Hostility (reversed) was created (Respect-Hostility Composite) and the potential relations 
between child CA, estimated annual family income, maternal education, DAS-II

Nonverbal Reasoning SS, and EVT-2 SS were examined (see Table 12). Scatterplots of these correlations are shown in Figures $14-16$.

Table 11

Descriptive Statistics for the Respect-Hostility Composite

\begin{tabular}{ccccc}
\hline Variable & Mean & Median & SD & Range \\
\hline $\begin{array}{c}\text { Respect-Hostility } \\
\text { Composite }\end{array}$ & 10.66 & 11.00 & 1.41 & $7.5-14.0$ \\
\hline
\end{tabular}

Possible range: 2 - 14

Table 12

Parametric Correlations between Independent Variables and the Respect-Hostility Composite

\begin{tabular}{|l|c|}
\hline \multicolumn{1}{|c|}{ Variables } & Correlations \\
\hline Child CA & Respect-Hostility Composite \\
\hline $\begin{array}{l}\text { Estimated Annual Family } \\
\text { Income }\end{array}$ & .09 \\
\hline Maternal Education & -.13 \\
\hline $\begin{array}{l}\text { DAS-II Nonverbal } \\
\text { Reasoning Cluster SS }\end{array}$ & $.37^{* *}$ \\
\hline EVT-2 SS & $.49^{* *}$ \\
\hline Supportive Presence & $.45^{* *}$ \\
\hline Respect for Child Autonomy & --- \\
\hline Hostility & --- \\
\hline
\end{tabular}

$* p<.05, * * p \leq .001$ (2-tailed) 


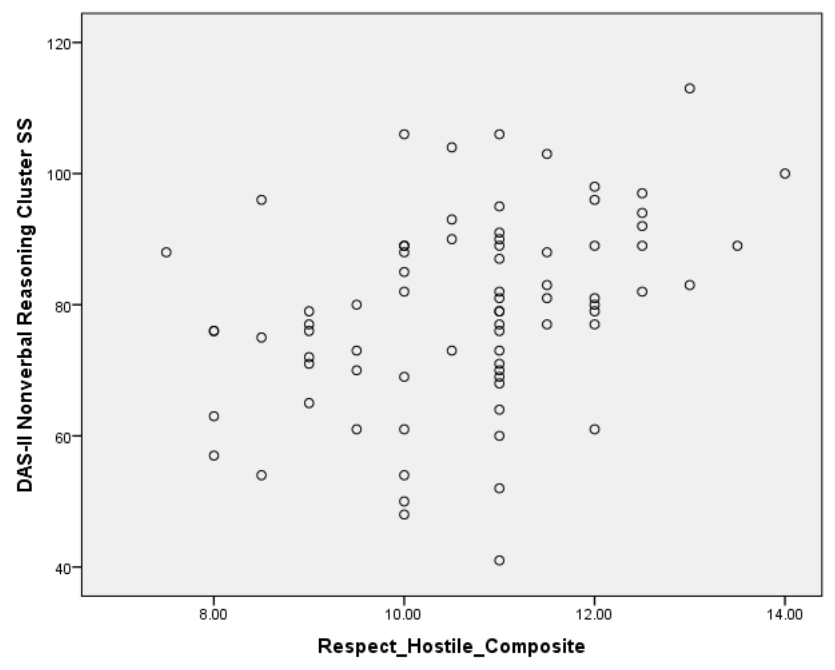

Figure 14. Scatterplot of correlations between Respect-Hostility Composite and DAS-II Nonverbal Reasoning Cluster SS.

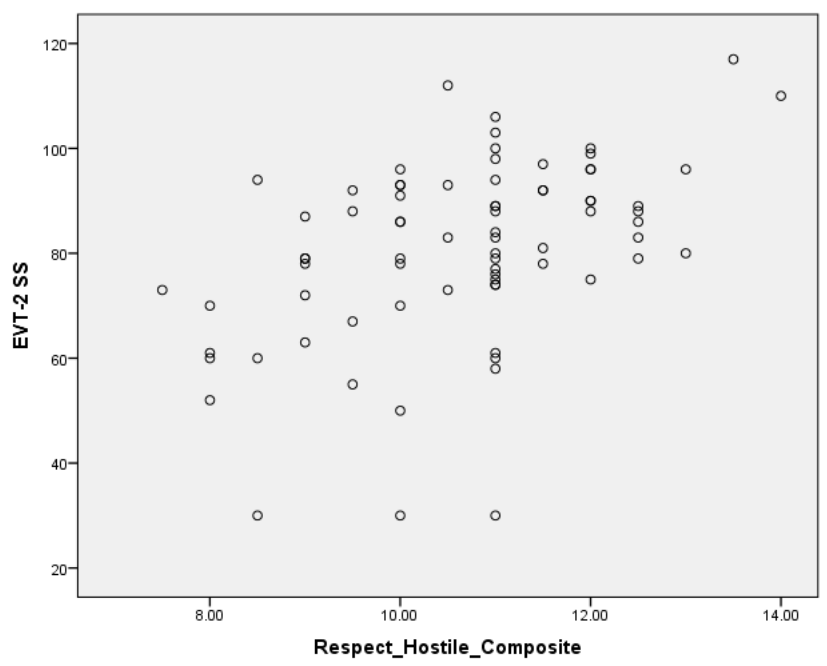

Figures 15. Scatterplot of correlations between Respect-Hostility Composite and EVT-2 SS. 


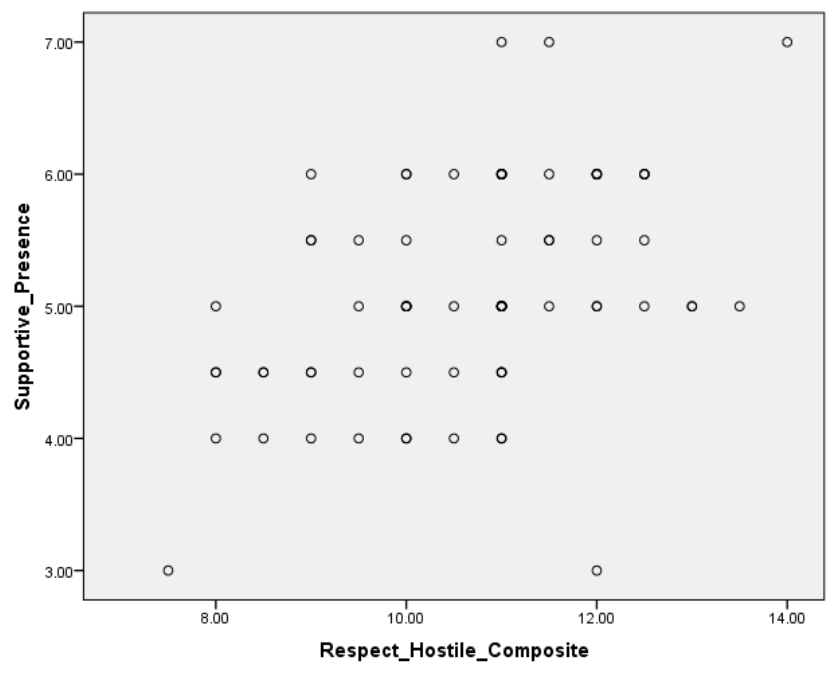

Figure 16. Scatterplot of correlations between Respect-Hostility Composite and Supportive Presence.

Regressions. To determine whether components of the maternal interaction style composite significantly predicted child EVT-II SS even after controlling for child CA, estimated annual family income, maternal education, and child nonverbal reasoning ability, a series of two-step regression models was performed. Model 1 was comprised of child CA, estimated annual family income, maternal education, and DAS-II Nonverbal Reasoning Cluster SS (Table 13). Model 1 provided a significant fit to the data, $F(4,70)$ $=12.67, p<.001$, yielding a large effect size $\left(f^{2}=.72\right)$ and explaining $38.7 \%$ of the variance in child EVT-2 SS. DAS-II Nonverbal Reasoning Cluster SS was the only significant predictor of child expressive vocabulary SS $(p<.001)$.

Four additional regressions (Models 2a, 2b, 2c, and 2d) were conducted with components of the maternal interaction style composite and Model 1 as the first step in each of the regressions (Table 13). 
Table 13

Sequential Multiple Regression Analysis Predicting EVT-2 SS

\begin{tabular}{|c|c|c|c|c|}
\hline & & & & \\
\hline Predictor & Adj. $\mathrm{R}^{2}$ & $\Delta \mathrm{R}^{2}$ & $\beta$ & $p$ \\
\hline Model 1 & .39 & $.42 * *$ & & \\
\hline Child CA & & & -.01 & .88 \\
\hline Estimated Annual & & & -.04 & .67 \\
\hline Family Income & & & & \\
\hline Maternal Education & & & -.05 & .60 \\
\hline DAS-II Nonverbal & & & .66 & $<.0001$ \\
\hline Reasoning Cluster SS & & & & \\
\hline Model 2a & .38 & .003 & & \\
\hline Child CA & & & -.01 & .90 \\
\hline Estimated Annual & & & -.04 & .68 \\
\hline Family Income & & & & \\
\hline Maternal Education & & & -.06 & .56 \\
\hline DAS-II Nonverbal & & & .65 & $<.0001$ \\
\hline Reasoning Cluster SS & & & & \\
\hline Supportive Presence & & & .05 & .58 \\
\hline Model 2b & .43 & $.06^{*}$ & & \\
\hline Child CA & & & -.01 & .87 \\
\hline Estimated Annual & & & -.04 & .65 \\
\hline Family Income & & & & \\
\hline Maternal Education & & & .004 & .96 \\
\hline DAS-II Nonverbal & & & .56 & $<.0001$ \\
\hline Reasoning Cluster SS & & & & \\
\hline
\end{tabular}




\begin{tabular}{|c|c|c|c|c|}
\hline $\begin{array}{l}\text { Respect for Child } \\
\text { Autonomy }\end{array}$ & & & .26 & .01 \\
\hline Model 2c & .43 & $.05^{*}$ & & \\
\hline Child CA & & & -.01 & .88 \\
\hline $\begin{array}{l}\text { Estimated Annual } \\
\text { Family Income }\end{array}$ & & & -.07 & .44 \\
\hline Maternal Education & & & -.01 & .93 \\
\hline $\begin{array}{l}\text { DAS-II Nonverbal } \\
\text { Reasoning Cluster SS }\end{array}$ & & & .58 & $<.0001$ \\
\hline Hostility (reversed) & & & .24 & .003 \\
\hline Model 2d & .45 & $.07 *$ & & \\
\hline Child CA & & & -.01 & .88 \\
\hline $\begin{array}{l}\text { Estimated Annual } \\
\text { Family Income }\end{array}$ & & & -.06 & .51 \\
\hline Maternal Education & & & -.01 & .89 \\
\hline $\begin{array}{l}\text { DAS-II Nonverbal } \\
\text { Reasoning Cluster SS }\end{array}$ & & & .55 & $<.0001$ \\
\hline $\begin{array}{l}\text { Respect-Hostility } \\
\text { Composite }\end{array}$ & & & .29 & .003 \\
\hline
\end{tabular}

Supportive Presence (Model 2a) does not significantly increase the amount of variance accounted for in EVT-2 beyond that which is accounted for in Model 1.

Respect for Child Autonomy (Model 2b) significantly increased the amount of variance accounted for in Model 1 with an $\mathrm{R}^{2}$ change of $.06(p=.008)$. The effect size was large $\left(f^{2}=.79\right)$ and the model explained $43.8 \%$ of the variance in child EVT-2 SS. Child CA, estimated family income, and maternal education were not significant 
predictors of child EVT-2 SS ( $p$ s > .5). Respect for Child Autonomy and DAS-II Nonverbal Reasoning Cluster SS were significant predictors of child EVT-2 SS ( $p=.008$ and $p<.001$, respectively).

Hostility (reversed) (Model 2c) significantly increased the amount of variance accounted for in Model 1 with an $\mathrm{R}^{2}$ change of $.05(p=.01)$. The effect size was large $\left(f^{2}\right.$ $=.75$ ) and the model explained $43.2 \%$ of the variance in child EVT-2 SS. Child CAs, estimated family income, and maternal education were not significant predictors of child EVT-2 SS ( $p$ s > .5). Hostility (reversed) and DAS-II Nonverbal Reasoning Cluster SS were significant predictors of child EVT-2 SS ( $p=.01$ and $p<.001$, respectively).

The Respect for Child Autonomy-Hostility Composite (Model 2d) significantly increased the amount of variance accounted for in Model 1 with an $\mathrm{R}^{2}$ change of .07 ( $p=$ $.01)$. The effect size was large $\left(f^{2}=.82\right)$ and the model explained $45 \%$ of the variance in child EVT-2 SS. Child CAs, estimated family income, and maternal education were not significant predictors of child EVT-2 SS ( $p$ s $>.5$ ). The Composite and DAS-II Nonverbal Reasoning Cluster SS were significant predictors of child EVT-2 SS $(p=.003$ and $p<$ .001 , respectively). 


\section{CHAPTER III}

\section{GENERAL DISCUSSION}

The purpose of this dissertation was to examine the relations between child CA, estimated annual family income, maternal education, child nonverbal reasoning ability, child expressive vocabulary, and maternal interaction style for young children with WS. The hypothesis of the study was that mothers' interaction style would predict child expressive vocabulary ability in children with WS relative to TD peers, even after taking into account child nonverbal reasoning ability relative to TD peers, child CA, and annual family income. This is the first study to examine interaction style in mothers of young children with WS and its relation to child expressive vocabulary. This chapter is divided into seven sections. In the first five sections,, the results are discussed in the context of prior research. In the sixth section, the clinical implications of these findings are considered,, and in the seventh, directions for future research are addressed.

\section{Relations between Maternal Interaction Style and Child Expressive Vocabulary}

Maternal interaction style is one aspect of a mother's parenting style that refers to how she engages with her child. Broadly, a positive maternal interaction style is warm, nurturing, stable, and predictable (Warren \& Brady, 2007). In the present study, maternal interaction style was rated using a composite comprised of three scales from the NICHD Study of Early Child Care Research Network- Supportive Presence (demonstration of positive regard and emotional support), Respect for Child Autonomy (recognition and respect for the validity of the child's individuality, motives, and perspectives), and 
Hostility (adult expression of anger, discounting, or rejecting the child). The score on the Hostility scale was reversed, so that higher scores corresponded to lower hostility. Together, these three scales have been used to measure maternal sensitivity in studies examining relations between maternal sensitivity and child outcomes (e.g., Belsky et al., 2007; Downer \& Pianta, 2006; NICHD Early Child Care Research Network, 2003). In the present study, a significant correlation with a moderate effect size was found between the maternal interaction style composite and children expressive vocabulary ability relative to TD peers. This finding is consistent with those from prior studies both of TD children and children with ID. Using the same maternal interaction style composite as in the present study, Belsky et al. (2007) found correlations with medium-to-large effect sizes between the maternal interaction style composite and concurrent expressive vocabulary abilities when the children were 54 months old, and when they were in first, third, and fifth grades. Also based on the same maternal interaction style composite, the authors of the NICHD Early Child Care Research Network (2003) study found a correlation with a medium effect size between maternal interaction style when the child was 54 months and the child's concurrent performance on a composite including receptive and expressive language for a large sample of children from the general population.

Similar findings using different measures of maternal interaction style that also focused on maternal sensitivity/responsivity have been reported in studies of children with ID/DD. Baker et al. (2010) reported a large effect size for the relation between maternal sensitivity at 18 months and child expressive vocabulary change between ages 2 and 3 years for a sample of 33 children with an autism spectrum disorder (ASD). Brady 
et al. (2014) found medium to large effect sizes for the relation between maternal responsivity (averaged over four observations at different ages) and child expressive vocabulary as measured by EVT-2 raw scores for children with fragile X syndrome (FXS).

Importantly, in the present study maternal interaction style composite accounted for a significant amount of the variance $(5 \%)$ in child expressive vocabulary ability relative to TD peers even after accounting for the effects of child age, family annual income, and child nonverbal reasoning ability relative to TD peers. Multiple regression analyses determined that maternal interaction style was a significant predictor of child expressive vocabulary even after child nonverbal reasoning abilities were taken into account.

The finding that maternal interaction style was a significant predictor of child expressive vocabulary is consistent with previous literature. Belsky et al. (2007) reported that higher levels of parenting quality at 54 months, first grade, and third grade predicted greater vocabulary achievement in fifth grade even after child ethnicity, child gender, maternal education, maternal depression, and mean income-to-needs ratio were taken into account. Maternal sensitivity at age 3 years significantly predicted expressive language scores at age 54 months (Hirsh-Pasek \& Burchinal, 2006) even after controlling for quality of parenting and teaching. Maternal sensitivity at age 54 months significantly predicted concurrent expressive language scores (NICHD Early Child Care Research Network, 2003) even after controlling for child gender, child temperament at 1 month of age, child attention at 15 months of age, family income, and maternal vocabulary. 
Similar results have been reported in studies of children with ID/DD. Maternal sensitivity at age 18 months predicted expressive language growth in children with ASD (Baker et al., 2010). No variables were controlled for in the study. Maternal sensitivity (averaged over four observations at different ages) predicted expressive vocabulary scores at age 8 years in children with FXS (Brady et al., 2014) even after controlling for responsivity at the first time period, autism symptoms, and cognitive development. In a study of toddlers and preschoolers with FXS, using hierarchical linear modeling, Warren et al (2010) found a significant effect of maternal sensitivity (over three observations at different ages) on child expressive vocabulary as measured by Mullen Scales of Learning Expressive Language raw scores for children with FXS even after controlling for child developmental level and autism symptoms.

\section{Relations with Nonverbal Reasoning Ability}

In the present study, a significant correlation with a large effect size was found between child nonverbal reasoning SS and child expressive vocabulary SS. This finding is consistent with prior studies of individuals with WS. Controlling for participant CA, Mervis (1999) found a large effect size for the relation between expressive vocabulary as measured by K-BIT Verbal (measuring primarily expressive vocabulary) SS and Nonverbal (measuring nonverbal reasoning) SS. Pitts and Mervis (2016) found large effect sizes for the relation between KBIT-2 Verbal SS and Nonverbal SS for children aged 4 -6 years and 7-12 years. Don et al. (1999) found a large effect size for the relation between receptive vocabulary as measured by the PPVT-R and Performance IQ on the WISC-III and a large effect size for the relation between Verbal IQ and Performance IQ on the WISC-III for children aged $8-13$ years. 
In the present study, a significant correlation with a medium effect size was also found between maternal interaction style composite and child nonverbal reasoning. One related finding has been reported. Belsky et al. (2007) found correlations with mediumto-large effect sizes between maternal interaction style composite at 54 months and child first, third, and fifth grade and concurrent math abilities, for children in the general population.

\section{Relations between Maternal Interaction Style Subscales and Expressive Vocabulary and Nonverbal Reasoning}

The current study is the first to examine the relations between maternal interaction style subscales and expressive vocabulary and nonverbal reasoning. Significant correlations with medium effect sizes were found between child expressive vocabulary and Respect for Child Autonomy, Hostility (reversed) and a composite of those two subscales. Significant correlations with medium effect sizes were also found between child nonverbal reasoning and Respect for Child Autonomy, Hostility (reversed) and a composite of those two subscales. Supportive Presence was significantly correlated with Respect for Child Autonomy and Hostility (reversed), but it was not significantly correlated with child expressive vocabulary or nonverbal reasoning.

Respect for Child Autonomy, Hostility (reversed), and the composite of these two subscales were significant predictors of child expressive vocabulary. These findings indicate that a behavioral style that included validation of the child's individuality, perspectives, and motives (Respect for Child Autonomy) and a lack of expression of anger, discounting, or rejection directed toward the child (Hostility (reversed)) positively predicted expressive vocabulary SS for children with WS even after controlling for 
nonverbal reasoning ability and demographic variables. Maternal expression of positive regard and support toward the child (Supportive Presence) was not significantly related to child expressive vocabulary SS and appears to play less of a role in development of child expressive vocabulary.

These results indicate that interventions for parent-child interactions that target child language development in children with disabilities should target instructing the parent to validate the child as an individual and his/her perspectives and motives and working to minimize expressions of anger, discounting, or rejection directed toward the child. One such intervention that has examined the role of maternal responsivity on child expressive language development in children with developmental disabilities is milieu teaching. The intervention has been shown to significantly increase both prelinguistic communication skills (Warren et al., 1993; Yoder \& Warren, 2001; Yoder \& Warren, 2002) and intentional communication (Yoder \& Warren, 1998). Prelinguistic mileu teaching (PMT) focuses on helping children with language delays build foundations for verbal communication (Fey et al., 2006; Fey et al., 2013). In PMT, caregivers are taught specific gestures, vocalizations, and coordinated eye gaze behavior (Fey et al., 2006). Teaching opportunities occur within developmentally appropriate activities, which helps children generalize skills (Warren et al., 1993). In milieu teaching, the teacher attends to the child's attentional lead and instruction is given based on the child's interests and communicative intentions (Warren et al., 1993). PMT also includes a responsivity education component, which focuses on parents' recoding of children's verbal and nonverbal acts as well as compliance to these acts (Fey et al., 2006). The responsivity component of PMT is comparable to Respect for Child Autonomy and Hostility 
(reversed), the two-scale composite used in this study, which was a significant predictor of child expressive vocabulary.

\section{Relations with Estimated Family Income and Age}

In the current study, estimated annual family income was not significantly correlated with any of the other study variables. Almost all of the families were middleclass, with $94 \%$ reporting an annual income over $\$ 50,000$. The income distribution of the families who participated in the Baker et al. (2010) study was relatively similar, with $82 \%$ of the families reporting an annual income over $\$ 50,000$. Baker et al. also did not find significant relations between annual family income and any of the other variables included in their study. Relations between estimated family income and study variables were not examined by Brady et al. (2014). In contrast, the participants in the studies conducted by the NICHD Early Child Care Research Network (e.g., NICHD Early Child Care Research Network, 2001; Hirsh-Pasek \& Burchinal, 2006) included a much larger proportion of low-income families. For this sample, annual family income was significantly positively correlated with maternal interaction style composite, and both family income-to-needs ratio and maternal interaction style composite significantly predicted child language scores. The results of several other studies that included a large proportion of low income families also indicated that annual family income predicts child language and/or cognitive development (e.g., Duncan \& Brooks-Gunn, 2000; Hart \& Risley, 1995; Klebanov, Brooks-Gunn, McCarton, \& McCormic, 1998). Thus, the absence of significant relations involving annual family income in the present study is most likely due to the very small proportion of families who had very low annual incomes. 
Child CA also was not significantly correlated with any of the study variables. Child nonverbal reasoning and child expressive vocabulary were measured by SSs so a significant correlation between child CA and these variables would not be expected. This finding is consistent with prior studies of expressive vocabulary in children with WS. Pitts and Mervis (2016) did not find a significant correlation between child CA and KBIT-2 Verbal SS or KBIT-2 Nonverbal SS in individuals aged $4-17$ years. KleinTasman et al. (2011) reported finding few consistent correlations between child CA and intellectual functioning as measured by the KBIT-2 in a study of children with WS aged $4-16$ years.

The maternal interaction style composite, subscales of the composite, and the Respect-Hostility composite were not significantly correlated with child CA. Only one study (Brady et al. (2014) examined changes in maternal responsivity longitudinally. A subset of mothers had somewhat low responsivity over all observations; another subset had somewhat high responsivity over all observations; and yet another subset fluctuated between high and low responsivity over time. For most mothers, the rate of responsivity increased over time. The effects of these pattern differences were unable to be identified due to insufficient numbers of participants, which could be addressed in future research.

\section{Clinical Implications}

In the current study, considerable variability was found in maternal interaction style for mothers of children with WS. This variability was significantly related to child expressive language. Therefore, it would be reasonable to consider interventions that might facilitate strengthening maternal-child interaction. Parent-child interaction therapy 
(PCIT) and mindful parenting are two evidence-based interventions that are currently used to improve parent-child interactions.

Parent-Child Interaction Therapy. PCI therapy is a manualized therapy created for families with children aged 2 to 6 years who are experiencing behavioral, emotional, and family problems (Herschell, Calzada, Eyberg, \& McNeil, 2002). Though most families of children with WS would not be described as experiencing significant family problems, aspects of PCIT would be helpful for parents of children with WS. Childdirected interaction (CDI) and parent-directed interaction (PDI) are the two discrete phases of the training.

The foundations of PCIT are rooted in attachment theory and social learning theory. The goal of the CDI phase is to provide a secure attachment for the child and restructure the parent-child relationship (Herschell et al., 2002). Parents learn skills that will help foster positive and nurturing interaction patterns. PCIT teaches parents the PRIDE skills (Praise, Reflection, Imitation, Description, and Enthusiasm) and encourages them to use the skills frequently. Parents are also taught to avoid questions, demands, and criticism when playing with their child and are instructed to praise their child's appropriate behavior as a way to add warmth to interactions (Herschell et al., 2002). They are instructed to listen to the child and reflect what he/she is saying as a way to improve language skills; to allow the child to lead interactions in order to increase child autonomy; and to exhibit excitement and warmth during interactions (Eyberg, 1999). Parents are also given instruction in how to appropriately make requests of the child and communicate consequences when parental requests have not been respected (Eyberg, 1999). Studies have reported clinically and statistically significant improvements in 
parent-child interactions and in child problem behaviors at home and at school after families have engaged in the therapy (Herschell et al., 2002). PCIT has been an effective therapy for families of children with autism spectrum disorder and families of children with DD. In a study of boys aged $5-12$ years with autism spectrum disorder and clinically significant problem behaviors, PCIT reduced the parent's perceptions of child problem behaviors and helped increase child adaptability. Additionally, positive affect between parent and child increased during the course of therapy (Solomon, Ono, Timmer, \& Goodlin-Jones, 2008). In a clinical case study, a young child with DD and oppositional defiant disorder (ODD) was successfully treated using PCIT. After the course of therapy, his behaviors were rated within the normal range (McDiarmid \& Bagner, 2005).

The PRIDE skills fit well with the interaction qualities measured by Respect for Child Autonomy and Hostility (reversed), as well as PMT. Reflection corresponds to allowing the child to exert autonomy by leading interactions and conversations. Exhibiting enthusiasm will decrease the presence of hostility in interactions.

Mindful parenting. The disciplined practice of mindfulness meditation brings moment-to-moment awareness to daily experiences (Duncan, Coatsworth, \& Greenberg, 2009). Mindfulness seeks to increase awareness and decrease avoidance of thoughts, feelings, and sensations. Mindfulness allows for flexibility and accuracy in perception of what is occurring in the moment, greater acceptance, and decreased reactivity to physical sensations, thoughts, feelings, and behaviors (Duncan et al., 2009). Mindfulness-based interventions have been effective in reducing psychological and physiological reactivity to stressful life experiences and chronic illnesses and has been used to treat anxiety and depression (Duncan et al., 2009). 
Mindfulness parenting applies five principles to parent-child interaction: (1) attentive listening; (2) nonjudgment and acceptance of self and child; (3) awareness of emotions of self and child; (4) regulation of self within the parent-child relationship; and (5) self-compassion and compassion for child (Duncan et al., 2009). Applying these principles allows the parent to appreciate the child's qualities and traits, notice and respond to the child's emotional needs, exhibit positive affection when interacting with his/her child, and be less emotionally reactive (Duncan et al, 2009). Mindfulness-based parenting interventions may also focus on helping parents to understand the impact of their present-moment interactions with their child on their long-term relationships with him or her.

Findings from one study of parents of children with DD indicated that mindfulness-based interventions are helpful for this group. In particular, parents of children with DD aged 2.5 - 5 years reported a significant decrease in child problematic behavior and a significant increase in their ratings of their relationship with their child after completing mindfulness-based intervention (Neece, 2013).

The five mindfulness principles also relate well to the qualities measured by the three NICHD Early Child Care Research Network scales used in the present study. Awareness of the emotions of oneself and one's child allows the parent to provide a supportive presence during the interaction. Listening with full attention allows the parent to respect the child's autonomy and allow him/her to express emotions and feelings freely. Nonjudgmental acceptance of self and child, self-regulation, and compassion serve to decrease parental hostility. 


\section{Future Directions}

Maternal interaction style is most likely bidirectional - the mother contributes behaviors to the interactions and the child contributes behaviors as well. This study only evaluated the interaction style from one direction - mother to child for a cross-sectional sample of children with WS. Evaluating the relations between child behaviors and maternal interaction style and the unique contributions of child behaviors to maternal interaction style would be important to better understand how a mother interacts with her child. To accomplish this, the study would need to be repeated with the same children at a later time point to allow for longitudinal analyses.

In this study, during observation of mother-child interactions, only maternal behaviors were coded. The NICHD Early Child Care Research Network Child Rating scales could be used to code the qualities of the child's interaction with the mother. The evaluation of child behaviors would allow for a better understanding and qualitative analysis of the contribution of the child to his/her mother's interaction style.

Each of the rating scales was coded globally, meaning a score was given for each scale that was based on its quality throughout the 30-minute play session. Repeating the study and coding each scale in smaller time increments, five minutes for example, would allow possible changes in the presence and quality of the behaviors measured by each scale to be examined over the period of the interaction.

Almost all of families in the current study were middle class. Future studies should include an expanded range of estimated annual family incomes, including a substantial proportion of families with low or very low annual incomes. This would provide an opportunity to examine the relations between study variables with a sample 
that provides a more complete representation of families of children with WS. This could also provide an opportunity to give support and encouragement to families in need of interventions.

Conclusion. This is the first study to examine interaction style in mothers of young children with WS and its relation to child expressive vocabulary. The results demonstrated that mother-child interaction style significantly predicted child expressive vocabulary, as measured by EVT-2 SS, in children with WS aged $4-8$ years even after taking into account the effects of nonverbal reasoning abilities, family income, and child CA. These findings help to explain some of the variance in child expressive vocabulary by highlighting the relation with maternal interaction style. Using these findings to tailor interventions for parent-child interactions may help strengthen the parent-child relationship and facilitate the child's expressive vocabulary development. 


\section{REFERENCES}

American Academy of Pediatrics Committee on Genetics (2001). Health care supervision for children with Williams syndrome. Pediatrics, 107, 1192-1204.

Arnold, R., Yule, W., \& Martin, N. (1985). The psychological characteristics of infantile hypercalcemia: A preliminary investigation. Developmental Medicine and Child Neurology, 27, 49-59.

Baker, J. K., Messinger, D. S., Lyons, K. K., \& Grantz, C. J. (2010).A pilot study of maternal sensitivity in the context of emergent autism. Journal of Autism and Developmental Disorders, 40, 988-999. doi: 10.1007/s10803-010-0948-4

Bates, E., Beechly, M., Bretherton, I., McNew, S., Oakes, L., O’Connell, B.,...Whitesell, K. (1985). Language and Gesture Inventory. Unpublished test materials, University of California, San Diego

Bayley, N. (1969). Manual for the Bayley Scales of Infant Development. San Antonio, TX: The Psychological Corporation.

Bellugi, U., Marks, S., Bihrle, A., \& Sabo, H. (1988). Dissociation between language and cognitive functions in Williams syndrome. In D. Bishop \& K. Mogford (Eds.), Language development in exceptional circumstances (pp 177-189). London: Churchill-Livingston.

Belsky, J., Vandell, D. L., Burchinal, M., Clarke-Stewart, K. A., McCartney, K., .. . NICHD Early Child Care Research Network (2007). Are there long-term effects of early child care? Child Development, 78, 681-701. 
Bennett, F. C., LaVeck, B., \& Sells, C. J. (1978). The Williams elfin facies syndrome: The psychological profile as an aid in syndrome identification. Pediatrics, 61, 303-306.

Boddaert, N., Mochel, F., Meresse, I., Seidenwurm, D., Cachia, A., Brunelle, F.,...Zilbovicius, M. (2006). Parieto-occipital grey matter abnormalities in children with Williams syndrome. Neuroimage, 30, 721-725. doi:

10.1016/j.neuroimage.2005.10.051

Bondy, C., Cohen, R., Eggert, D., \& Luer, G. (1969). Testbatterie für Geistig Behinderte Kinder TBGB. Beltz-Verlag; Weinhem, Germany.

Bornstein M. H. (1989). Maternal responsiveness: Characteristics and consequences. San Francisco, CA: Jossey-Bass.

Bornstein, M. H. ,\& Tamis-LeMonda, C. S. (1997). Maternal responsiveness and infant mental abilities: specific predictive relations. Infant Behavior and Development 20, 283-296.

Bracken, B. A. (1984). Bracken Basic Concepts Scale. San Antonio, TX: Psychological Corporation.

Brady, N., Warren, S. F., Fleming, K., Keller, J., \& Sterling, A. (2014). The effect of maternal responsivity on later vocabulary development in children with Fragile x syndrome. Journal of Speech Language and Hearing Research, 57, 212-226. doi: 10.1044/1092-4388(2013/12-0341)

Caldwell, B. M., \& Bradley, R. H. (1984). Home observation for measurement of the environment. Little Rock, AR: University of Arkansas at Little Rock. 
Carlier, M., Stefanini, S., Deruelle, C., Volterra, V., Doyen, A., Lamard, C.,...Fisch, G. (2006). Laterality in persons with intellectual disability: Do patients with Trisomy 21 and Williams-Beuren syndrome differ from typically developing persons? Behavior Genetics, 36, 365-376. doi: 10.1007/s10519-006-9048-9

Crisco, J. J., Dobbs, J. M., \& Mulhern, R. K. (1988).Cognitive processing of children with Williams syndrome. Developmental Medicine and Child Neurology, 30, 650656.

Davies, M., Udwin, O., \& Howlin, P. (1998). Adults with Williams syndrome. Preliminary study of social, emotional and behavioural difficulties. The British Journal of Psychiatry, 172, 273-276.doi: 10.1192/bjp.172.3.273

Deruelle, C., Mancini, J., Livet, M.O., Casse-Perrot, C., \& de Schonen, S. (1999). Configural and local processing of faces in children with Williams syndrome. Brain and Cognition, 41, 276-298.

Dilts, C. V., Morris, C. A., \& Leonard, C. O. (1990). Hypothesis for development of a behavioral phenotype in Williams syndrome. American Journal of Medical Genetics Supplement, 6, 126-131.doi: 10.1002/ajmg.1320370622

Don, A. J., Schellenberg, E. G., \& Rourke, B. P. (1999). Music and language skills of children with Williams syndrome. Child Neuropsychology, 5, 154-170.

Downer, J. T., \& Pianta, R. C. (2006). Academic and cognitive functioning in first grade: Associations with earlier home and child care predictors and with concurrent home and classroom experiences. School Psychology Review, 35, 11-30.

Duncan, G. J., \& Brooks-Gunn, J. (2000). Family poverty, welfare reform, and child development. Child Development, 71, 188-196. 
Duncan, L. G., Coatsworth, J. D., \& Greenberg, M. T. (2009). A model of mindful parenting: Implications for parent-child relationships and prevention research. Clinical Child and Family Psychology Review, 12, 255-270. doi: 10.1007/s10567009-0046-3

Dunn, L., \& Dunn, D. (2007). The Peabody Picture Vocabulary Test, fourth edition. San Antonio, TX: The Psychological Corporation.

Dyches, T.T., Smith, T.B., Korth, B.B., Roper, S.O., \& Mandleco, B. (2012). Positive parenting of children with developmental disabilities: A meta-analysis. Research in Developmental Disabilities, 33, 2213-2220. doi: 10.1016/j.ridd.2012.06.015

Dykens, E. M., \& Rosner, B. A. (1999).Refining behavioral phenotypes: Personalitymotivation in Williams and Prader-Willi syndromes. American Journal on Mental Retardation, 104, 158-169.

Elliott, C. D. (1990). Differential Ability Scales. San Antonio, TX: The Psychological Corporation.

Elliott, C.D. (2007). Differential Ability Scales, second edition. San Antonio, TX: The Psychological Corporation.

Ewart, A. K., Morris, C. A., Atkinson, D., Jin, W., Sternes, K., Spallone, P., . . Keating, M. T. (1993). Hemizygosity at the elastin locus in a developmental disorder, Williams syndrome. Nature Genetics, 5, 11-16. doi: 10.1038/ng0993-11

Eyberg, S. (1999). Parent-child interaction therapy: Integrity checklists and session materials. Retrieved from University of Florida website: pcit.phhp.ufl.edu/Presentations/PCITIntegrityChecklistsandMaterials4-13-06.pdf 
Faul, F., Erdfelder, E., Lang, A., \& Buchner, A. (2007). G*Power 3: A flexible statistical power analysis program for the social, behavioral, and biomedical sciences. Behavior Research Methods, 39, 175-191.

Feagans, L. V., \& Farran, D. C. (1983). The Adaptive Language Inventory. Chapel Hill, NC: The Frank Porter Graham Child Development Center.

Fenson, L., Dale, P., Reznick, S., Thal, D., Bates, E., Hartung, J.,...Reilly, J. (1993). MacArthur Communicative Development Inventories: Technical manual. San Diego, CA: Singular Publishing Group.

Fenson, L., Thal, D., Marchman, V., Dale, P., \& Bates, E. (2007). MacArthur-Bates Communicative Development Inventories User's guide and Technical manual, second edition. Baltimore, MD: Brookes Publishing Company.

Fey, M.E., Warren, S.F., Brady, N., Finestock, L.H., Bredin-Oja, S.L., Fairchild, M., Sokol, S., \& Yoder, P.J. (2006). Early effects of responsivity education/prelinguisting milieu teaching for children with developmental delays and their parents. Journal of Speech, Language, and Hearing Research, 49, 526547. doi: 10.1044/1092-4388(2006/039)

Fey, M.E., Yoder, P.J., Warren, S.F., \& Bredin-Oja, S.L. (2013). Is more better? Milieu communication teaching in toddlers with intellectual disabilities. Journal of Speech, Language, and Hearing Research, 56, 679-693. doi: 10.1044/10924388(2012/12-0061)

Finestack, L. H., Sterling, A. M., \& Abbeduto, L. (2013). Discriminating Down syndrome and fragile $\mathrm{X}$ syndrome based on language ability. Journal of Child Language, 40, 244-265. doi: 10.1017/S0305000912000207 
Fisch, G. S., Carpenter, N., Howard-Peebles, P. N., Holden, J. J. A., Tarleton, J., \& Simensen, R. (2010). The course of cognitive-behavioral development in children with FMR1 mutation, Williams-Beuren syndrome, and neurofibromatosis type 1: The effect of gender. American Journal of Medical Genetics, Part A, 152A, 14981509. doi: 10.1002/ajmg.a.33412

Fryns, J., Borghgraef, M., Volcke, P., \& van den Berge, H. (1991). Adults with Williams syndrome. American Journal of Medical Genetics, 40, 253-260.doi: 10.1002/ajmg.1320400228

Gosch, A., \& Pankau, R. (1997). Personality characteristics and behaviour problems in individuals of different ages with Williams syndrome. Developmental Medicine \& Child Neurology, 39, 527-533.doi: 10.1111/j.1469-8749.1997.tb07481.x

Greer, M. K., Brown, F. R. III, Pai, G., Choudry, S. H., \& Klein, A. J. (1997). Cognitive, adaptive, and behavioral characteristics of Williams syndrome. American Journal of Medical Genetics, 74, 521-525.

Hart, B. \& Risley, T. R. (1995).Meaningful differences in the everyday experience of young American children. Baltimore, MD: Brookes.

Hedrick, D., Prather, E., \& Tobin, A. (1975). Sequenced Inventory of Communication Development. Seattle, WA: University of Washington Press.

Herschell, A. D., Calzada, E. J., Eyberg, S. M., \& McNeil, C. B. (2002). Parent-child interaction therapy: New directions in research. Cognitive and Behavioral Practice, 9, 9-16. 
Hirsh-Pasek, K. \& Burchinal, M. (2006). Mother and caregiver sensitivity over time: Predicting language and academic outcome with variable-and person-center approaches. Merrill-Palmer Quarterly, 52, 449-485.

Hoffmann, A., Martens, M. A., Fox, R., Rabidoux, P., \& Andridge, R. (2013). Pragmatic language assessment in Williams syndrome: A comparison of the Test of Pragmatic Language-2 and the Children's Communication Checklist-2. American Journal of Speech-Language Pathology, 22, 198-204.

Hungerford, A. \& Cox, M. J. (2006). Family factors in child care research. Evaluation Review, 30, 631-655. doi: 10.1177/0193841X06291532

Inter-University Consortium For Political and Social Research, National Institute of Child Health and Human Development. (2007). NICHD Study of Early Child Care and Youth Development: Phase II, 1996-1999 [United States] (ICPSR 21941). Retrieved from http://www.icpsr.umich.edu/icpsrweb/ICPSR/studies/21940

Jones, K. L.,\& Smith, D. W. (1975). The Williams elfin facies syndrome. The Journal of Pediatrics, 86, 718-723.

Jones, W., Bellugi, U., Lai, Z., Chiles, M., Reilly, J., Lincoln, A., \& Adolphs, R. (2000). II. Hypersociability in Williams syndrome. Journal of Cognitive Neuroscience, $12,30-46$.

Karmiloff-Smith, A., Grant, J., Berthoud, I., Davies, M., Howlin, P., \& Udwin, O. (1997). Language and Williams syndrome: How intact is 'intact'? Child Development, 68, 246-262. 
Kataria, S., Goldstein, D. J., \& Kushnick, T. (1984). Developmental delays in Williams ('Elfin Facies') syndrome. Applied Research in Mental Retardation, 5, 419-423.

Kaufman, A. S. \& Kaufman, N. L. (1983). Kaufman Assessment Battery for Children administration and scoring manual. Circle Pine, MN: American Guidance Service.

Kaufman, A. S., \& Kaufman, N. L. (1990). Kaufman Brief Intelligence Test. Circle Pines, MN: American Guidance Services.

Kaufman, A. S., \& Kaufman, N. L. (2004). Kaufman Brief Intelligence Test, second edition. Circle Pines, MN: American Guidance Services.

Kermani, H. \& Brenner, M.E. (2000). Maternal scaffolding in the child's zone of proximal development across tasks: Cross-cultural perspectives. Journal of Research in Childhood Education, 15, 30-52.

Klebanov, P. K., Brooks-Gunn, J., McCarton, C., \& McCormick, M. (1998).The contribution of neighborhood and family income to developmental test scores over the first three years of life. Child Development, 69, 1420-1436.

Klein-Tasman, B. P., \& Mervis, C. B. (2003). Distinctive personality characteristics of 8, 9-, and 10-year-olds with Williams syndrome. Developmental Neuropsychology, 23, 269-290. doi: 10.1080/87565641.2003.9651895

Klein-Tasman, B. P., Li-Barber, K. T., \& Magargee, E. T. (2011). Honing in on the social phenotype in Williams syndrome using multiple measures and multiple raters. Journal of Autism and Developmental Disorders, 41, 341-351. doi: $10.1007 / \mathrm{s} 10803-01-1060-5$ 
Laing, E., Butterworth, G., Ansari, D., Gsödl, M., Longhi, E., Panagiotaki, G.,...Karmiloff-Smith, A. (2002). Atypical development of language and social communication in toddlers with Williams syndrome. Developmental Science, 5, 233-246. doi: 10.1111/1467-7687.00225

Landry, S. H., Garner, P. W., Swank, P. R., \& Baldwin, C. D. (1996). Effects of maternal scaffolding during joint toy play with preterm and full-term infants. MerrillPalmer Quarterly, 42, 177-199.

Landry, S. H., Smith, K. E., Miller-Loncar, C. L., \& Swank, P. R. (1997). Predicting cognitive-language and social growth curves from early maternal behaviors in children at varying degrees of biological risk. Developmental Psychology, 33, 1040-1053.

Landry, S. H., \& Smith, K. E. (2000). Early maternal and child influences on children's later independent cognitive and social functioning. Child Development, 71, 358375.

Leigh, P., Nievar, M. A., \& Nathans, L. (2011). Maternal sensitivity and language in early childhood: A test of the transactional model. Perceptual \& Motor Skills, 113, 281-299.doi: 10.2466/10.17.21.28.PMS.113.4.281-299

Lense, M., \& Dykens, E. (2013). Musical learning in children and adults with Williams syndrome. Journal of Intellectual Disability Research, 57, 850-860. doi: 10.1111/j.1365-2788.2012.01611.x

Levy, Y., \& Bechar, T. (2003). Cognitive, lexical, and morpho-syntactic profiles of Israeli children with Williams syndrome. Cortex, 39, 255-271. 
Levy, Y., \& Eilam, A. (2013). Pathways to language: A naturalistic study of children with Williams syndrome and children with Down syndrome. Journal of Child Language, 40, 106-138. doi: 10.1017/S0305000912000475

Leyfer, O., John, A. E., Woodruff-Borden, J., \& Mervis, C.B. (2012). Factor structure of the Children's Behavior Questionnaire in Williams syndrome. Journal of Autism and Developmental Disorders, 42, 2346-2353. doi: 10.1007/s10803-012-1482-3

Martens, M. A., Hasinski, A. E., Andridge, R. R., \& Cunningham, W. A. (2012). Continuous cognitive dynamics of the evaluation of trustworthiness in Williams syndrome. Frontiers in Psychology, 3. doi:10.3389/fpsyg.2012.00160

Martens, M. A., Jungers, M. K., \& Steele, A. L. (2011). Effect of musical experience on verbal memory in Williams syndrome: Evidence from a novel word learning task. Neuropsychologia, 49, 3093-3102.

doi:10.1016/j.neuropsychologia.2011.07.016

McCarthy, D. (1972). The McCarthy Scales of Children's Abilities. New York: The Psychological Corporation.

McDiarmid, M. D., \& Bagner, D. M. (2005). Parent child interaction therapy for children with disruptive behavior and developmental disabilities. Education and Treatment of Children, 28, 130-141.

McDuffie, A., \& Yoder, P. (2010). Types of parent verbal responsiveness that predict language in young children with autism spectrum disorder. Journal of Speech, Language, and Hearing Research, 53, 1026-1039. doi: 10.1044/1092$4388(2009 / 09 / 0023)$ 
Mervis, C. B. (1999). The Williams syndrome cognitive profile: Strengths, weaknesses, interrelations, among auditory short term memory, language, and visuospatial constructive cognition. In E. Winograd, R. Fivush, \& W. Hirst (Eds.), Ecological approaches to cognition: Essays in honor of Ulric Neisser (pp. 193-227).

Mahwah, NJ: Erlbaum.

Mervis, C. B. \& Becerra, A. M. (2007).Language and communicative development in Williams syndrome. Mental Retardation and Developmental Disabilities Research Reviews, 13, 3-15. doi: 10.1002/mrdd.20140

Mervis, C. B., \& John, A. E. (2010). Cognitive and behavioral characteristics of children with Williams syndrome: Implications for intervention approaches. American Journal of Medical Genetics Part C, 154C, 229-248. doi:10.1002/ajmg.c.30263

Mervis, C. B., \& John, A. E. (2012). Precursors to language and early language development in Williams syndrome. In E. K. Farran \& A. Karmiloff-Smith (Eds.), Neurodevelopmental disorders across the lifespan: A neuroconstructive approach, (pp.187-204). Oxford, UK: Oxford University Press.

Mervis, C. B., \& Morris, C. A. (2007).Williams syndrome. In M. M. M. Mazzocco \& J. L. Ross (Eds.), Neurogenetic developmental disorders: Variation of manifestation in childhood (pp.199-262). Cambridge, MA: MIT Press.

Mervis, C. B., \& Pitts, C. H. (2015).Children with Williams syndrome: Developmental trajectories for intellectual abilities, vocabulary abilities, and adaptive behavior. American Journal of Medical Genetics Part C, 169C,158-171. doi: 10.1002/ajmg.c.31436 
Mervis, C. B., \& Robinson, B. F. (2000). Expressive vocabulary ability of toddlers with Williams syndrome or Down syndrome: A comparison. Developmental Neuropsychology, 17, 111-126. doi: 10.1207/S15326942DN1701_07

Mervis, C. B., \& Velleman, S. L. (2011). Children with Williams syndrome: Language, cognitive, and behavioral characteristics and their implications for intervention. Perspectives on Language, Learning, and Education, 18, 98-107. doi: $10.1044 / 1$ e18.3.98

Mervis, C. B., Kistler, D. J., John, A. E., \& Morris, C. A. (2012). Longitudinal assessment of intellectual abilities of children with Williams syndrome: Multilevel modeling of performance on the Kaufman Brief Intelligence Test second edition. American Journal on Intellectual and Developmental Disabilities, 117, 134-155. doi:10.1352/1944-7558-117.2.134

Mervis, C. B., Klein-Tasman, B. P., \& Mastin, M. E. (2001). Adaptive behavior of 4 through 8-year-old children with Williams syndrome. American Journal on Mental Retardation, 106, 82-93.

Mervis, C. B., Robinson, B. F., Bertrand, J., Morris, C. A., Klein-Tasman, B. P., \& Armstrong, S. C. (2000). The Williams syndrome cognitive profile. Brain and Cognition, 44, 604-628. doi: 10.1006/brcg.2000.1232

Mervis, C. B., Robinson, B. F., Rowe, M. L., Becerra, A. M., \& Klein-Tasman, B. P. (2003). Language abilities of individuals with Williams syndrome. International Review of Research in Mental Retardation, 27, 35-81. 
Meyerson, M. D., \& Frank, R. A. (1987). Language, speech, and hearing in Williams syndrome: Intervention approaches and research needs. Developmental Medicine and Child Neurology, 29, 258-270.

Morris, C. A. (2006). The dysmorphology, genetics, and natural history of WilliamsBeuren syndrome. In C. A. Morris, H. M. Lenhoff, \& P. P. Wang (Eds.), Williams-Beuren syndrome: Research, evaluation and treatment (pp. 3-17). Baltimore, MD: The Johns Hopkins University Press.

Mullen, E. M. (1995). Mullen Scales of Early Learning. Circle Pines, MN: American Guidance Service.

Neece, C. L. (2013). Mindfulness-based stress reduction for parents of young children with developmental delays: Implications for parental mental health and child behavior problems. Journal of Applied Research in Intellectual Abilities, 27, 174186.

NICHD Early Child Care Research Network. (2001). Nonmaternal care and family factors in early development: An overview of the NICHD study of early child care. Applied Developmental Psychology, 22, 457-492.

NICHD Early Child Care Research Network. (2003). Do children's attention processes mediate the link between family predictors and school readiness? Developmental Psychology, 39, 581-593. doi: 10.1037/0012-1649.39.3.581

NICHD Early Child Care Research Network.(2006). Child-care effect sizes for the NICHD study of early child care and youth development. American Psychologist, 61, 99-116. doi: 10.1037/0003-066X.61.2.99 
Opfer, J. E., \& Martens, M. A. (2012). Learning without representational change:

Development of numerical estimation in individuals with Williams syndrome. Developmental Science, 15, 863-875. doi:10.1111/j.14677687.2012.01187.x

Palomares, M., \& Shannon, M. T. (2013). Global dot integration in typically developing children and in Williams syndrome. Brain and Cognition, 83, 262-270. doi:10.1016/j.bandc.2013.09.003

Papaeliou, C. F., Fryssira, H., Kodakos, A., Kaila, M., Benaveli, E., Michaelides, K.,...Polemikos, N. (2011). Nonverbal communication, play, and language in Greek young children with Williams syndrome. Child Neuropsychology, 17, 225241. doi:10.1080/09297049.2010.524151

Plesa Skwerer, D., Ammerman, E., \& Tager-Flusberg, H. (2013). Do you have a question for me? How children with Williams syndrome respond to ambiguous referential communication during a joint activity. Journal of Child Language, 40, 266-289. doi:10.1017/S0305000912000360

Pitts, C. H., \& Mervis, C. B. (2016). Performance on the Kaufman Brief Intelligence Test-2 by children with Williams syndrome. American Journal on Intellectual and Developmental Disabilities, 121, 33-47. doi:10.1352/1944-7588-121.1.33

Porter, M. A., \& Coltheart, M. (2005). Cognitive heterogeneity in Williams syndrome. Developmental Neuropsychology, 27, 275-306. doi: 10.1207/s15326942dn2702_5

Porter, M. A., \& Dodd, H. (2011). A longitudinal study of cognitive abilities in Williams syndrome. Developmental Neuropsychology, 36, 255-272. doi:

$10.1080 / 87565641.2010 .549872$ 
Rae, C., Karmiloff-Smith, A., Lee, M. A., Dixon, R. M., Grant, J., Blamire, A.

M.,...Radda, G. K. (1998). Brain biochemistry in Williams syndrome: Evidence for a role of the cerebellum in cognition? Neurology, 51, 33-40.

Rescorla, L. (1989). The Language Development Survey: A screening tool for delayed language in toddlers. Journal of Speech and Hearing Disorders, 54, 587-599.

Reynell, J. K. (1977). Manual for the Reynell Development Language Scales. Windsor: NFER.

Roid, G. H., \& Miller, L. J. (1997). Leiter International Performance Scale-Revised. Wood Dale, IL: Stoelting.

Singer Harris, N. G., Bellugi, U., Bates, E., Jones, W., \& Rossen, M. (1997). Contrasting profiles of language development in children with Williams and Down syndromes. Developmental Neuropsychology, 13, 345-370. doi:

$10.1080 / 87565649709540683$

Solomon, M., Ono, M., Timmer, S., \& Goodlin-Jones, B. (2008). The effectiveness of parent-child interaction therapy for families of children on the autism spectrum. Journal of Autism and Developmental Disorders, 38, 1767-1776. doi: $10.1007 / \mathrm{s} 10803-008-0567-5$

Steelman, L. M., Assel, M. A., Swank, P. R., Smith, K. E., \& Landry, S. H. (2002). Early maternal warm responsiveness as a predictor of child social skills: Direct and indirect paths of influence over time. Journal of Applied Developmental Psychology, 23, 135-156.

Sterling, A. M., Warren, S. F., Brady, N., \& Fleming, K. (2013).Influences on maternal responsivity in mothers of children with fragile X syndrome. American Journal 
on Intellectual and Developmental Disabilities, 118, 310-326. doi: 10.1352/1944$7558-188.4 .310$

Stevens, T., \& Karmiloff-Smith, A. (1997). Word learning in a special population: Do individuals with Williams syndrome obey lexical constraints? Journal of Child Language, 24, 737-765.

Strømme, P., Bjørnstad, P. G., \& Ramstad, K. (2002). Prevalence estimation of Williams syndrome. Journal of Child Neuropsychology, 17, 269-271.doi: $10.1177 / 088307380201700406$

Sullivan, K., Winner, E., \& Tager-Flusberg, H. (2003). Can adolescents with Williams syndrome tell the difference between lies and jokes? Developmental Neuropsychology, 23, 85-104. doi: 10.1080/87565641.2003.9651888

Tamis-LeMonda, C.S., \& Baumwell, L. (2011). Parental sensitivity in early development: Definition, methods, measurement, and generalizability. In D. W. Davis \& M. C. Logsdon (Eds.), Maternal sensitivity: A scientific foundation for practice (pp. 115). New York, NY: Nova Science Publishers, Inc.

Tamis-LeMonda, C. S., Bornstein, M. H., \& Baumwell, L. (2001). Maternal responsiveness and children's achievement of language milestones. Child Development, 72, 748 - 767. doi: 10.1111/1467-8624.00313

Teixeira, M. C. T. V., Monteiro, C. R. C., Velloso, R. L., Kim, C. A., \& Carreiro, L. R. R. (2010). Behavioral and cognitive phenotype of children and adolescents with Williams-Beuren syndrome (original title: Fenótipocomportamental e cognitivo de crianças e adolescentes com Síndrome de Williams-Beuren). Pró-Fono Revista de Atualização Científica, 22, 215-220. 
Terman, L.M., \& Merrill, M.A. (1973). Stanford-Binet Intelligence Scale, $3^{\text {rd }}$ edition. Boston: Houghton Mifflin.

Thal, D., Bates, E., \& Bellugi, U. (1989). Language and cognition in two children with Williams syndrome. Journal of Speech and Hearing Research, 32, 489-500.

Udwin, O., \& Yule, W. (1991). A cognitive and behavioural phenotype in Williams syndrome. Journal of Clinical and Experimental Neuropsychology, 13, 232-244.

Udwin, O., Yule, W., \& Martin, N. (1987). Cognitive abilities and behavioral characteristics of children with idiopathic infantile hypercalcemia. Journal of Child Psychology and Psychiatry, 28, 297-309.

Unterstein, A. P. (2000). Examining the differences in expressive and receptive lexical language skills in preschool children with cochlear implants and children with typical hearing (Doctoral dissertation). Retrieved from https://aura.alfred.edu/handle/10829/2675

van der Fluit, F., Gaffrey, M. S., \& Klein-Tasman, B. P. (2012). Social cognition in Williams syndrome: Relations between performance on the social attribution task and cognitive and behavioral characteristics. Frontiers in Psychology, 3. doi:10.3389/fpsyg.2012.00197

Vicari, S., Bates, E., Caselli, M.C., Pasqualetti, P., Gagliardi, C., Tonucci, F., \& Volterra, V. (2004). Neuropsychological profile of Italians with Williams syndrome: An example of a dissociation between language and cognition? Journal of the International Neuropsychological Society, 10, 862-876. doi:10.1017/S1355617704106073 
Vicari, S., Caselli, M. C., Gagliardi, C., Tonucci, F., \& Volterra, V. (2002). Language acquisition in special populations: A comparison between Down and Williams syndromes. Neuropsychologia, 40, 2461-2470.

Volterra, V., Caselli, M. C., Capirci, O., Tonucci, F., \& Vicari, S. (2003). Early linguistic abilities of Italian children with Williams syndrome. Developmental Neuropsychology, 23, 33-58. doi: 10.1080/87565641.2003.9651886

Warren, S. F., Yoder, P.J., Gazdag, G.E., Kim, K., \& Jones, H.A. (1993). Facilitating prelinguistic communication skills in young children with developmental delay. Journal of Speech and Hearing Research, 36, 83-97.

Warren, S. F. \& Brady, N. (2007). The role of maternal responsivity in the development of children with intellectual disabilities. Mental Retardation and Developmental Disabilities Research Reviews, 13, 330-338. doi: 10.1002/mrdd.20177

Warren, S. F., Brady, N., Sterling, A., Fleming, K., \& Marquis, J. (2010). Maternal responsivity predicts language development in young children with fragile $\mathrm{X}$ syndrome. American Journal on Intellectual and Developmental Disabilities, 115, 54-75. doi: 10.1111/j.1365-2788.2006.00896.x

Wechsler, D. (1976). Wechsler Intelligence Scale for Children-Revised. New York: The Psychological Corporation.

Wechsler, D. (1981). Wechsler Adult Intelligence Scale - Revised. San Antonio, TX: The Psychological Corporation.

Wechsler, D. (1989). Wechsler Preschool and Primary Scale of Intelligence-Revised. San Antonio, TX: The Psychological Corporation. 
Wechsler, D. (1991). Wechsler Intelligence Scale for Children, third edition. San Antonio, TX: The Psychological Corporation

Wertsch, J.V. (2008). From social interaction to high psychological processes: A clarification and application of Vygotsky's theory. Human Development, 51, 6679.

Wiig, E., Secord, W., \& Semel, E. (1992). Clinical Evaluation of Language Fundamentals - Preschool. New York: The Psychological Corporation.

Williams, K. T.(2007). EVT-2: Expressive Vocabulary Test, second edition. San Antonio, TX: Pearson.

Woodcock, R. W., \& Johnson, M. B. (Eds.).(1989, 1990). Woodcock-Johnson PsychoEducational Battery-Revised: Itasca, IL: Riverside Publishing.

Yoder, P.J., \& Warren, S.F. (1998). Maternal responsivity predicts the prelinguistic communication intervention that facilitates generalized intentional communication. Journal of Speech, Language, and Hearing Research, 41, $1207-$ 1219.

Yoder, P. J., \& Warren, S. F. (1999). Maternal responsivity mediates the relationship between prelinguistic intentional communication and later language. Journal of Early Intervention, 22, 126-136. doi: 10.1177/105381519902200205

Yoder, P. J., \& Warren, S. F. (2001). Relative treatment effects of two prelinguistic communication interventions on language development in toddlers with developmental delays vary by maternal characteristics. Journal of Speech, Language, and Hearing Research, 44, 224-237. doi: 10.1044/10924388(2001/019) 
Yoder, P. J., \& Warren, S. F. (2002). Effects of prelinguistic milieu teaching and parent responsivity education on dyads involving children with intellectual disabilities. Journal of Speech, Language, and Hearing Research, 45, 1158-1174. doi: $10.1044 / 1092-4388(2002 / 094)$

Yoshioka, T., Dillon, M. R., Beck, G. C., Rapp, B., \& Landau, B. (2013). Tactile localization on digits and hand: Structure and development. Psychological Science, 24, 1653-1663. doi:10.1177/0956797613478617

Zimmerman, I. L., Steiner, V. G., \&Pond, R. E. (1979). Preschool Language Scale. San Antonio, TX: The Psychological Corporation. 
CURRICULUM VITAE

Danielle R. Henderson

\section{PERSONAL INFORMATION}

Office Address:

317 Life Sciences Building

University of Louisville

Louisville, KY 40292

Phone: 502-852-6775

E-Mail Address: drhend03@ louisville.edu

\section{HIGHER EDUCATION}

APA-Accredited Doctoral Internship, 2016-present, Indiana University School of Medicine, Indianapolis, IN

Ph.D., Clinical Psychology (APA-Accredited), 2009-present, University of Louisville,

Louisville, KY

Dissertation (defended October 2015): Interaction Style of Mothers of Young Children with Williams Syndrome. Expected August 2017.

Advisor: Carolyn B. Mervis, Ph.D.

M.A., Clinical Psychology, 2011, University of Louisville, Louisville, KY

B.S., Psychology, 2007, University of Louisville, Louisville, KY

Major: Psychology

B.A., Chemistry, 2004, Indiana State University, Terre Haute, IN

Major: Chemistry, Minors: German and Music

\section{HONORS AND AWARDS}

July 2014 Travel Award, Williams Syndrome Association Professional Conference

March 2013 Travel Award, Gatlinburg Conference on Research and Theory in Intellectual and Developmental Disabilities

July 2012 Travel Award, Williams Syndrome Association Professional Conference

June 2010 Travel Award, Symposium on Research in Child Language Disorders

2009-2011 University Fellow, University of Louisville

\section{CLINICAL EXPERIENCE}

July 2016 - present

Clinical Psychology Intern, Indiana University School of Medicine

Indianapolis, IN

Complete 4-month rotations in each of the following areas :

- Adult Health Psychology (July 2016 - October 2016) 
- Advanced Heart and Lung Care Clinic, Indiana University Methodist Hospital

- Behavioral Sleep Medicine Clinic and Adult Outpatient Psychiatry Clinic, Indiana University Health Neuroscience Center

- Multidisciplinary Clinic, Indiana University Melvin and Bren Simon Cancer Center

Clinical Supervisor : Yelena Chernyak, Ph.D., HSPP

- Child Outpatient Clinic, Riley Hospital for Children (November 2016 - February 2017)

- Tics, Anxiety, and Compulsions Clinic

- Mood \& Anxiety Disorders Clinic

Clinical Supervisor : Ann Lagges, Ph.D., HSPP

- Pediatric Pain Clinic

Clinical Supervisor : Amy E. Williams, Ph.D., HSPP

○ Psychology Testing Clinic

Clinical Supervisor : William Kronenberger, Ph.D., HSPP

- Pediatric Consultation \& Liaison, Riley Hospital for Children (March 2017 - June 2017)

Clinical Supervisor : Amy E. Williams, Ph.D., HSPP

- Pediatric Sleep Medicine, Riley Hospital for Children (March 2017 - June 2017)

Clinical Supervisor : Sarah Honaker, Ph.D., HSPP

- Integrated Care, Riley Physicians Pediatrics, Georgetown Clinic (March 2017 - June 2017)

Clinical Supervisor : Lezlie Blackford, Ph.D., HSPP

July 2015 - May 2016

\section{St. Matthews Group and Associates in Pediatric Therapy}

Louisville, KY

Clinical Practicum in Private Practice

Supervisor: Rochelle C. Mehl, Ph.D.

- Conducting interviews with parents of typically-developing children and children with developmental disabilities from diverse ethnic, economic, and education backgrounds

- Individual therapy with clients from the surrounding community with diverse ethnic, economic, and educational backgrounds

- Utilize play therapy, exposure therapy, and cognitive-behavioral techniques to treat a broad range of psychopathology, including mood and anxiety disorders

- Development of clinical case conceptualizations for complex client presentations using a biopsychosocial approach and drawing heavily on cognitive behavioral theory

- Administer various neuropsychological and cognitive assessment instruments

- Complete integrated reports detailing conclusions drawn from assessment measures.

- Provide feedback pertaining to psychodiagnostic testing results.

September 2011 - August 2013

Psychological Services Center (PSC), University of Louisville, Louisville, KY

Graduate Student Therapist

Mindfulness and Acceptance Based Behavior Therapy

2009-20

Supervisor: Paul Salmon, Ph.D.

- Individual therapy with clients from the surrounding community with diverse ethnic, economic, and educational backgrounds 
- Utilization of mindfulness and acceptance based treatments to treat anxiety and depressive symptoms.

- Development of clinical case conceptualizations for complex client presentations and drawing heavily on mindfulness and acceptance theory

- Attending weekly group and individual supervision in which mindfulness practices were included

September 2012 - July 2013

\section{Division of Developmental and Behavioral Pediatrics}

Cincinnati Children's Hospital Cincinnati, $\mathrm{OH}$

Assessment Practicum

Supervisors: Holly D. Barnard, Ph.D. and Jannel Phillips, Ph.D.

- Conducted interviews with parents of children with developmental disabilities from diverse ethnic, economic, and education backgrounds

- Administered various neuropsychological and cognitive assessment instruments

- Completed integrated reports detailing conclusions drawn from assessment measures.

- Provision of feedback pertaining to psychodiagnostic testing results.

September 2011 - May 2012

\section{Outpatient Psychiatry}

University of Louisville Louisville, KY

Assessment Practicum

Supervisor: Tracy D. Eells, Ph.D.

- Administered neuropsychological assessments

- Completed integrated reports detailing conclusions drawn from assessment measures.

- Provision of feedback pertaining to psychodiagnostic testing results.

September 2009 - August 2011

Psychological Services Center (PSC), University of Louisville, Louisville, KY

Graduate Student Therapist

Cognitive-Behavior Therapy for Anxiety and Related Disorders

Supervisor: Janet Woodruff-Borden, Ph.D.

- Individual therapy with clients from surrounding community with diverse ethnic, economic, and educational backgrounds

- Utilization of cognitive-behavioral techniques to treat a broad range of psychopathology, including mood and anxiety disorders

- Development of clinical case conceptualizations for complex client presentations using a biopsychosocial approach and drawing heavily on cognitive behavioral theory

- Attending weekly group supervision in which assessment and cognitive-behavioral practices were discussed

August 2010 - June 2016

Psychological Services Center (PSC), University of Louisville Louisville, KY

Assessment Practica

Supervisor: Bernadette Walter, Ph.D. and David Winsch, Ph.D.

- Conduct comprehensive psychological assessments with clients from the surrounding community with diverse ethnic, economic, and educational backgrounds 
- Administration of assessment intake interviews and intellectual, achievement, and personality assessments

- Completion of integrated reports detailing conclusions draw from scores received during assessments

- Provision of feedback to clients pertaining to the results of testing and diagnostic impressions

\section{EDUCATIONAL ACTIVITIES}

October 2016

IU School of Medicine, Indianapolis, IN

Invited Lecturer, Psychiatric Resident Training in CBT

July 2016 - October 2016

IU School of Medicine, Indianapolis, IN

Psychology Intern

Behavioral Sleep Medicine

Supervisor: Yelena Chernyak, Ph.D., HSPP

- Provision of peer supervision to two practicum students

September 2011 - August 2013

Psychological Services Center (PSC), University of Louisville, Louisville, KY

Graduate Student Therapist

Mindfulness and Acceptance Based Behavior Therapy

Supervisor: Paul Salmon, Ph.D.

- Provision of peer supervision to novice graduate students

\section{RESEARCH AND PRIOR EXPERIENCE}

July 2009 - June 2015 Neurodevelopmental Sciences Lab: Doctoral Student,

Advisor: Carolyn B. Mervis, Ph.D.

- Research and data analysis for longitudinal projects examining the following in individuals with 7q11.23 deletions or duplications (funded by NICHD and NINDS):

○ Psychopathology

- Personality, Problem Behavior, and Executive Function

$\circ$ Communication and Language Skills in Children

- Intellectual Functioning

- Supervision of graduate and undergraduate students involved in research and training

July 2008 - June 2009 Neurodevelopmental Sciences Lab: Lab Coordinator/Project Coordinator, Supervisor, Carolyn B. Mervis, Ph.D.

- Research and data analysis for longitudinal projects examining the following in individuals with 7q11.23 deletions or duplications (funded by NICHD and NINDS):

○ Psychopathology

- Personality, Problem Behavior, and Executive Function

- Communication and Language Skills in Children 
- Intellectual Functioning

- Supervision of graduate and undergraduate students involved in research and training

June 2007 - June 2008 Developmental Neuroscience Lab: Research Analyst,

Supervisor, Dennis L. Molfese, Ph.D.

- Impact of sleep loss and simulated micro-gravity on neuropsychological functioning (funded by NASA)

○ Record, analyze, and interpret event-related potential brain imaging data

- Neuropsychological impact of sleep loss in children (funded by NIH)

$\circ$ Record, analyze, and interpret event-related potential brain imaging data

\section{PEER-REVIEWED PUBLICATIONS}

Mervis, C.B., Klein-Tasman, B.P., Huffman, M.J., Velleman, S.L., Pitts, C.H., Henderson, D.R., Woodruff-Borden, J., Morris, C.A., Osborne, L.R. (2015). Children with 7q11.23 duplication syndrome: Psychological characteristics. American Journal of Medical Genetics Part A. DOI: 10.1002/ajmg.a.37071

Mervis, C. B., Dida, J., Lam, E., Crawford-Zelli, N. A., Young, E. J., Henderson, D. R., Onay, T., Morris, C. A., Woodruff-Borden, J., Yeomans, J., Osborne, L. R. (2014). Duplication of GTF2I results in separation anxiety in mice and humans.

Woodruff-Borden, J., Kistler, D. J. , Henderson, D. R., Crawford, N. A., \& Mervis, C. B. (2010). Longitudinal course of anxiety in children and adolescents with Williams syndrome.

American Journal of Medical Genetics Part C, 154C, 277-290.

\section{PROFESSIONAL PRESENTATIONS}

Henderson, D.R., Pérez-Garcia, D., \& Mervis, C.B. (2016, March). Interaction Style of Mothers of Young Children with Williams Syndrome and Relations with Child Expressive Vocabulary. Gatlinburg Conference on Research and Theory in Intellectual and Developmental Disabilities, San Diego, CA.

Henderson, D.R. \& Mervis, C.B. (2014, July). Stress in Parents of Young Children with Williams Syndrome and Child Outcome. Williams Syndrome Association Professional Conference, Anaheim, CA.

Henderson, D.R., Crawford-Zelli, N.A., Woodruff-Borden, J., \& Mervis, C.B. (2014, March). Genetic factors in psychiatric diagnoses: A comparison of children with 7q11.23 deletions (Williams syndrome) and duplications (7q11.23 duplication syndrome). Gatlinburg Conference on Research and Theory in Intellectual and Developmental Disabilities, Chicago, IL.

Henderson, D.R. \& Mervis, C.B. (2013, March). Emotional and problem behaviors in children with Williams syndrome: A longitudinal study. Gatlinburg Conference on Research and Theory in Intellectual and Developmental Disabilities, San Antonio, TX.

Henderson, D.R., Crawford-Zelli, N.A., \& Mervis, C.B. (2012, July). Parental stress in mothers of 4- and 5-year-olds with Williams syndrome. Williams Syndrome Association Professional Conference, Boston, MA. 
Henderson, D.R., Crawford-Zelli, N.A., Woodruff-Borden, J., \& Mervis, C.B. (2012, March). Genetic factors in temperament: A comparison of children with $7 q 11.23$ deletions (Williams syndrome) and duplications (7q11.23 duplication syndrome). Gatlinburg Conference on Research and Theory in Intellectual and Developmental Disabilities, Annapolis, MD.

Henderson, D.R., Crawford, N.A., Woodruff-Borden, J.W., \& Mervis, C.B. (2011, March). Peer relationships and extracurricular activities of children with Williams syndrome: A preliminary study. Gatlinburg Conference on Research and Theory in Intellectual and Developmental Disabilities, San Antonio, TX.

Henderson, D. R., Becerra, A. M., John, A. E., \& Mervis, C. B. (2010, June). Language abilities of toddlers with Williams syndrome: Performance on the CDI-III. Symposium on Research in Child Language Disorders, Madison, WI.

Becerra, A. M., Henderson, D. R., John, A. E., \& Mervis, C. B. (2010, June). Relations between early language milestones and intellectual abilities at age 4 years. Symposium on Research in Child Language Disorders, Madison, WI.

Henderson, D. R., John, A. E., \& Mervis, C. B. (2010, March). Problem behaviors in Preschoolers with Down syndrome or Williams syndrome. Kentucky Psychological Association Foundation Spring Academic Conference, Louisville, KY.

Molfese, D. L., Garrod, K. Henderson, D., Molfese, V. J. \& Molfese, P. J. (2007, October). Dynamic links between emerging brain and reading processes. Conference on The Development and Analysis of Neural Systems Supporting Language (DANSSL). New York, NY.

\section{PROFESSIONAL DEVELOPMENT}
July 2015 - June 2016
University of Louisville School of Interdisciplinary and Graduate Studies Supervisor, Latonia Craig, Ed.D.
- Assisting with recruitment of prospective, and retention of, current minority graduate students
- Assisting with individual meetings with students
- Representing the Graduate School at educational fairs
- Giving presentations of interest to minority graduate students
August 2014 - April $2015 \quad$ University of Louisville School of Interdisciplinary and
Graduate Studies
Facilitator, Michelle Rodems, Ph.D.
- Attendance at professional development presentations with topics such as, diversity in the classroom, professional networking, and graduate-level writing

\section{ADDITIONAL TRAINING/CONTINUING EDUCATION \\ February $2015 \quad$ Fundamentals of HIV Prevention Counseling \\ Facilitator, Karen Kriegger, M.D. and Kentucky Health Department \\ - Attendance at an intensive, all-day training in the virology, transmission, and prevalence of HIV and AIDS \\ - Training in counseling individuals who request the rapid HIV Test; administering the test; and giving test results}


January 2015 - April 2015 Cognitive-Behavioral Therapy Training, University of Louisville Depression Center

Facilitator, Jesse Wright, M.D., Ph.D.

- Attendance at training workshops in which cognitive-behavioral therapy and its efficacy and applicability were discussed

September 2014 - April 2015 Certification in LGBT Health and Wellness

Facilitator, University of Louisville LGBT Center

- Attendance at presentations about health and wellness issues unique to LGBT patients and clients

August 2009 - June $2016 \quad$ University of Louisville Psychological Services Center

- Attendance at presentations with topics such as, therapeutic interventions for veterans, substance abuse, and tic disorders

\section{PROFESSIONAL SERVICE}

$2016-2017$

$2016-2017$

November 2012

November 2011

August 2011 - August 2013

January 2010 - January 2012
Chief Psychology Intern

Facilitator for Riley Teen Leadership Group

Discussion Facilitator at the Louisville Chapter's Multiple Sclerosis Family Weekend

Discussion Facilitator at the Louisville Chapter's Multiple

Sclerosis Family Weekend

Peer Mentor to Novice Graduate Students

Student Interviewer and Assistant for the Clinical Psychology

Program's Interview Days 